Check for updates

Cite this: RSC Adv., 2019, 9, 313

\title{
Middle-down approach: a choice to sequence and characterize proteins/proteomes by mass spectrometry $\dagger$
}

\author{
P. Boomathi Pandeswari and Varatharajan Sabareesh (D)*
}

Owing to rapid growth in the elucidation of genome sequences of various organisms, deducing proteome sequences has become imperative, in order to have an improved understanding of biological processes. Since the traditional Edman method was unsuitable for high-throughput sequencing and also for $\mathrm{N}$ terminus modified proteins, mass spectrometry (MS) based methods, mainly based on soft ionization modes: electrospray ionization and matrix-assisted laser desorption/ionization, began to gain significance. MS based methods were adaptable for high-throughput studies and applicable for sequencing $\mathrm{N}$-terminus blocked proteins/peptides too. Consequently, over the last decade a new discipline called 'proteomics' has emerged, which encompasses the attributes necessary for highthroughput identification of proteins. 'Proteomics' may also be regarded as an offshoot of the classic field, 'biochemistry'. Many protein sequencing and proteomic investigations were successfully accomplished through MS dependent sequence elucidation of 'short proteolytic peptides (typically: 7-20 amino acid residues), which is called the 'shotgun' or 'bottom-up (BU)' approach. While the BU approach continues as a workhorse for proteomics/protein sequencing, attempts to sequence intact proteins without proteolysis, called the 'top-down (TD)' approach started, due to ambiguities in the BU approach, e.g., protein inference problem, identification of proteoforms and the discovery of posttranslational modifications (PTMs). The high-throughput TD approach (TD proteomics) is yet in its infancy. Nevertheless, TD characterization of purified intact proteins has been useful for detecting PTMs. With the hope to overcome the pitfalls of BU and TD strategies, another concept called the 'middle-down (MD)' approach was put forward. Similar to BU, the MD approach also involves proteolysis, but in a restricted manner, to produce 'longer' proteolytic peptides than the ones usually obtained in BU studies, thereby providing better sequence coverage. In this regard, special proteases (OmpT, Sap9, IdeS) have been used, which can cleave proteins to produce longer proteolytic peptides. By reviewing ample evidences currently existing in the literature that is predominantly on PTM characterization of histones and antibodies, herein we highlight salient features of the MD approach. Consequently, we are inclined to claim that the MD concept might have widespread applications in future for various research areas, such as clinical, biopharmaceuticals (including PTM analysis) and even for general/routine characterization of proteins including therapeutic proteins, but not just limited to analysis of histones or antibodies.

Received 29th August 2018 Accepted 11th December 2018

DOI: $10.1039 / \mathrm{c} 8 \mathrm{ra0} 200 \mathrm{k}$

rsc.li/rsc-advances instances of sequence strongly impacting the biological function, a very popularly known case is 'sickle cell anemia', wherein a mutation of 'valine' to 'glutamic acid' significantly alters the structure of hemoglobin, thereby severely hampering its ability to transport oxygen $\left(\mathrm{O}_{2}\right)$.

\subsection{Protein/peptide sequencing}

For many years, proteins had been traditionally sequenced by Edman's method, popularly known as N-terminal sequencing, which is accomplished using phenylisothiocyanate (PITC). ${ }^{1-4}$ While Edman sequencing method has been successful in numerous cases, it cannot be useful to sequence proteins having blocked N-terminus, e.g., N-terminus formylated or
Advanced Centre for Bio Separation Technology (CBST), Vellore Institute of Technology (VIT), Vellore, Tamil Nadu, 632014, India. E-mail: v.sabareesh@vit.ac.in; sabareesh6@gmail.com

$\dagger$ Electronic supplementary information available. See DOI: 10.1039/c8ra07200k 
acetylated proteins and several eukaryotic proteins are known to have modified N-terminus. ${ }^{3,4}$ Further, Edman's method can be applicable on an isolated and purified protein/peptide only, which means purity of the isolated protein/peptide is essential. Moreover, considerable time and quantity of sample would be consumed to sequence even a single protein by Edman's method. ${ }^{4}$ As a result, Edman method is not suitable for highthroughput sequencing of proteins. Nevertheless, N-terminal sequencing method indeed finds application for conventional biochemical or biophysical studies, ${ }^{\mathbf{4 , 5}}$ whenever highthroughput is not necessary.

However, for more than a decade or so from now, sequencing of proteins has increasingly becoming rapid and highthroughput. Such a transition can be mainly attributed to the '-omics' approach to study proteins, known as 'proteomics' and the prime impetus for this transformation came from 'genomics'. Rapid growth in elucidation of genome sequences from various organisms, ${ }^{6-8}$ in particular, the Human Genome Sequencing project, ${ }^{9,10}$ provided motivation to identify proteome sequences, with the main objective to identify and understand the relationship between genome and proteome. In other words, knowledge of sequences of proteome could be helpful in discerning, which genes code for proteins and which are not. ${ }^{11,12}$ Further, by comparing protein sequences with transcriptome (messenger ribonucleic acid (mRNA)), it may be possible to know the translation efficiency. ${ }^{\mathbf{1 1 , 1 3 - 1 5}}$ Moreover, processes such as alternative splicing ${ }^{\mathbf{1 6 , 1 7}}$ and posttranslational modifications (PTMs) ${ }^{18-21}$ expand the diversity of proteome (Scheme 1), which can be known from the deduced protein sequences, but are otherwise ambiguous to predict at the level of genome and transcriptome sequences. All these exercises enable to understand not only the normal biological processes, but also aids in knowing those factors that are responsible for abnormal or diseased conditions. ${ }^{19,22,23}$ Thus, the foremost objective of any proteomic investigation is to elucidate sequences of as many proteins as possible. As a result, there has been a radical shift from the typically followed approaches and/ or methods and/or strategy to characterize and study proteins.

Mass spectrometry (MS), particularly, subsequent to the advent of electrospray ionization (ESI) and matrix-assisted laser desorption/ionization (MALDI), enabled highthroughput determination of protein sequences at a faster rate. The key highlight of these two ionization modes is their 'soft nature', which enables transferring large protein molecular ions from solid or liquid phase to gas phase or vacuum, in their 'intact' form with little molecular fragmentations. ${ }^{24,25}$ Consequently, it became possible to determine 'intact molecular mass' of large proteins and peptides. Prior to the arrival of ESI and MALDI, the ionization modes such as fast atom bombardment (FAB), chemical ionization (CI), field ionization (FI) and electron impact/ionization (EI) were not capable of ionizing polar macromolecules (viz. proteins); though FAB was somewhat successful for about a decade or so, to determine intact molecular mass of certain large-sized polar compounds, for instance, polypeptides up to a mass of about 8 or 10 kilodaltons $(\mathrm{kDa}){ }^{26-29}$
Simultaneous innovations in the development of mass analyzers, especially 'hybrid configuration', wherein two or more mass analyzers are used in combination, enabled rapid sequencing of peptides and proteins. ${ }^{30}$ The basic aspect that facilitated sequencing of peptides and proteins was 'tandem mass spectrometry', referred as MS/MS. Through MS/MS experiments, the peptide or protein molecular ions are dissociated and the mass-to-charge $(\mathrm{m} / \mathrm{z})$ values of the resulting fragment ions are used to deduce the sequence of the peptide or protein. ${ }^{3,30-32}$ A variety of MS/MS fragmentation methods have been devised with the aim to achieve good sequence coverage. ${ }^{32-39}$ Additionally, improvements in resolution and sensitivity offered by different kinds of mass analyzers ${ }^{\mathbf{4 0 - 4 2}}$ proved valuable not only for better identification of peptides/ proteins, with the concomitant decrease in the false discovery rate, but also for detecting low abundant peptides/proteins with a good signal-to-noise ratio.

Not only mass spectrometry, but advancements in the field of 'chromatography' too contributed significantly for highthroughput identification of proteins, whereby development of various pre-fractionation and other separation methods helped in reducing the complexity of the samples, which in turn facilitated increase in the number of identifications. ${ }^{43}$ The feasibility of linking chromatography, in particular reverse phase liquid chromatography (LC) to MS (viz. LC-MS) in an online fashion, viz., analytical mode, without offline collection of eluents, proved a major step forward for realization of highthroughput identification and characterization of peptides and proteins. ${ }^{44}$ Also, there have been efforts on using two or three different chromatographic methods in tandem prior to mass spectrometric analysis, so as to reduce the complexity of the sample for better and enhanced identifications; a well known example being, MudPIT. ${ }^{45-48}$

\subsection{Approaches to sequence and characterize proteins or proteomes}

Sequencing of proteins and proteomes can be carried out either directly on their intact form or by truncating them. With regard to truncation, the proteins are subjected to enzymatic proteolysis (e.g. trypsin) or chemically degraded (e.g. cyanogen bromide) and the resulting peptides or polypeptides are then sequenced. Subsequently, the derived sequences of peptides/ polypeptides are joined in an appropriate manner; thereby the sequence of the entire protein is elucidated. Depending on the nature of the protease and its specificity, peptide/polypeptide fragments of various sizes could be obtained from the intact protein. According to the 'number' and respective 'positions' of enzyme cleavable sites on the intact protein's sequence, the size/length of the resulting peptide or polypeptide fragments would vary. Consequently, engineering of the proteolysis step is critical, which needs to be optimized depending on the nature of proteins that are being investigated.

Edman's N-terminal sequencing method is applicable to deduce the primary structure of intact proteins. Edman's method has also been shown to be useful to derive sequences of internal peptides, in the case of blocked/modified N-terminus 


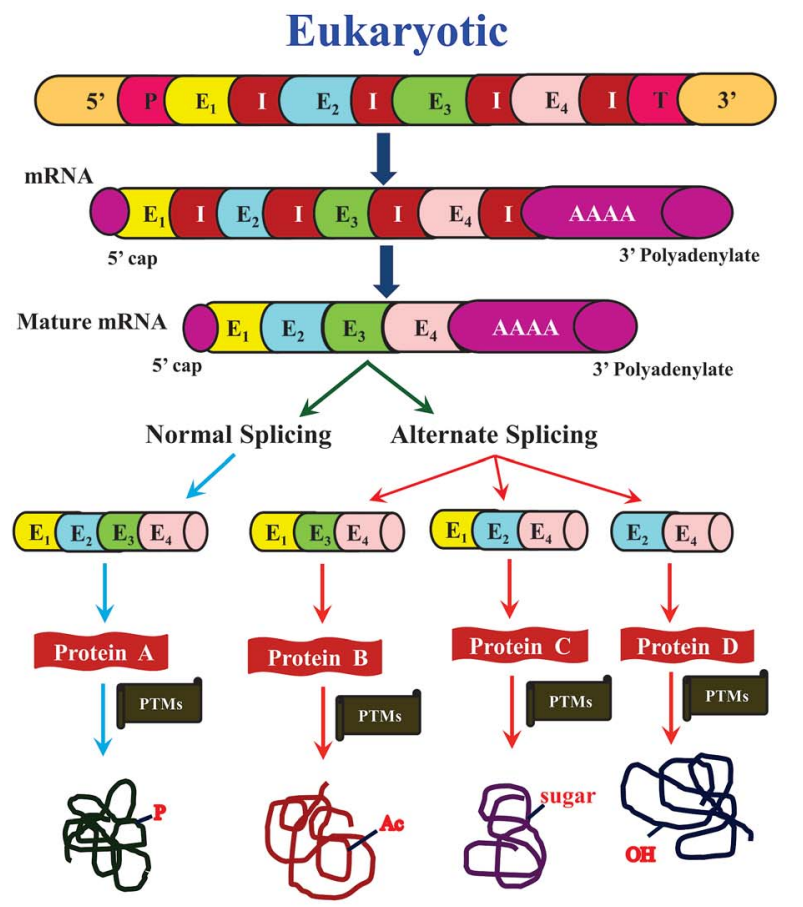

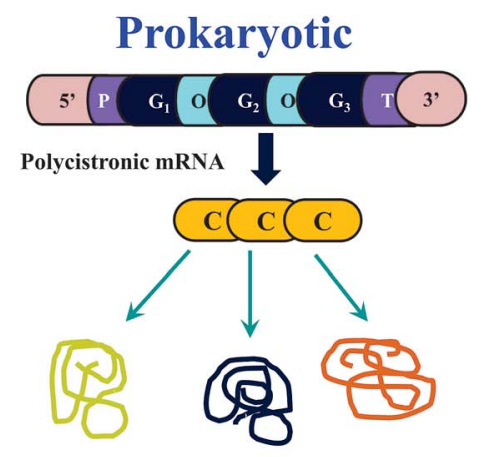

Many Proteins

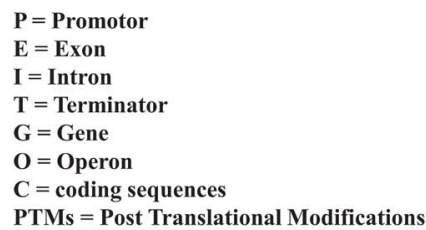

Scheme 1 Overview of central dogma of molecular biology in (a) eukaryotic and (b) prokaryotic biological systems. This scheme highlights the importance of and the need for proteomics research, in order to correlate protein sequence information with the RNA and DNA sequence. In the case of eukaryotic system, proteomics is essential for elucidation of posttranslational modifications (PTMs), e.g., P: phosphorylation; Ac: acetylation; sugar: glycosylation; OH: hydroxylation.

of the protein; for which the intact protein would need to be proteolysed or chemically degraded to yield shorter peptides/ polypeptides. ${ }^{4}$ In contrast, applications of mass spectrometry (MS) to elucidate sequence using only the intact form of the protein is limited, when compared to the utility of MS to derive sequences of shorter polypeptides or peptides. Although ESI and MALDI based MS has proven to be very successful to derive molecular mass of intact proteins, only few attempts of 'directly sequencing intact protein without truncation' by MS have yielded good results.

1.3.1 Bottom-up approach. Protein investigation by characterizing or sequencing its truncated form obtained by proteolysis or chemical degradation, viz., peptides or polypeptides can be referred as 'bottom-up (BU) approach'. Several Nterminal sequencing assignments and majority of proteomic investigations are accomplished by $\mathrm{BU}$ approach, which involves peptides-based identification of proteins, typically by means of tryptic peptides..$^{\mathbf{4 , 5}, 30,49-51}$ By this strategy, a protein's identity is inferred by unequivocal detection of one or two tryptic peptides that have unique sequence(s). In other words, in the case of MS based proteomics, the presence of a protein in a sample is adjudged from the mass spectrometric detection and sequencing of one or more tryptic peptides of that particular protein. A typical protocol of this approach would involve the conditions necessary to carry out 'complete' trypsin digestion of proteins/proteome; which would result in production of peptides of length, $\sim 7-20$ amino acids, viz., molecular mass $(M)$ of the peptides would be in the range: $0.8 \mathrm{kDa}<M<2 \mathrm{kDa}$.
Thus, such a procedure would give rise to numerous peptides and of course, the number of tryptic peptides formed would depend on the complexity of the sample that is under study, viz., whether the sample of interest contains one or several proteins. Consequently, suitable separation i.e., chromatographic methods are essential prior to mass spectrometric analysis of such a mixture. ${ }^{45,48,49,52}$ Many tryptic peptides are quite often not detected, subject to the complexity of the sample under study and however good be the chromatographic methods employed. As a consequence, inadequate sequence coverage of proteins is commonly encountered in bottom-up proteomics, which in turn hampers detecting important PTMs and proteoforms. Nevertheless, this approach is useful to sequence or characterize 'a purified protein', since not many peptides would be generated upon complete trypsin digestion of a protein, when compared to the complete digestion of a mixture of several proteins.

Altogether, the extent of usefulness and applicability of BU approach, be it to study a single purified protein or proteome, is dependent on the number of trypsin cleavable sites (viz. no. of arginines and lysines) and the sequence of the protein(s) itself, viz., average number of amino acid residues between two trypsin cleavable sites.

1.3.2 Top-down approach. Sequencing or characterizing intact protein without resorting to any kind of truncation is referred as 'top-down (TD) approach'. Edman's N-terminal sequencing method aptly fits into this approach, which has been widely successful to sequence several 'intact proteins' 


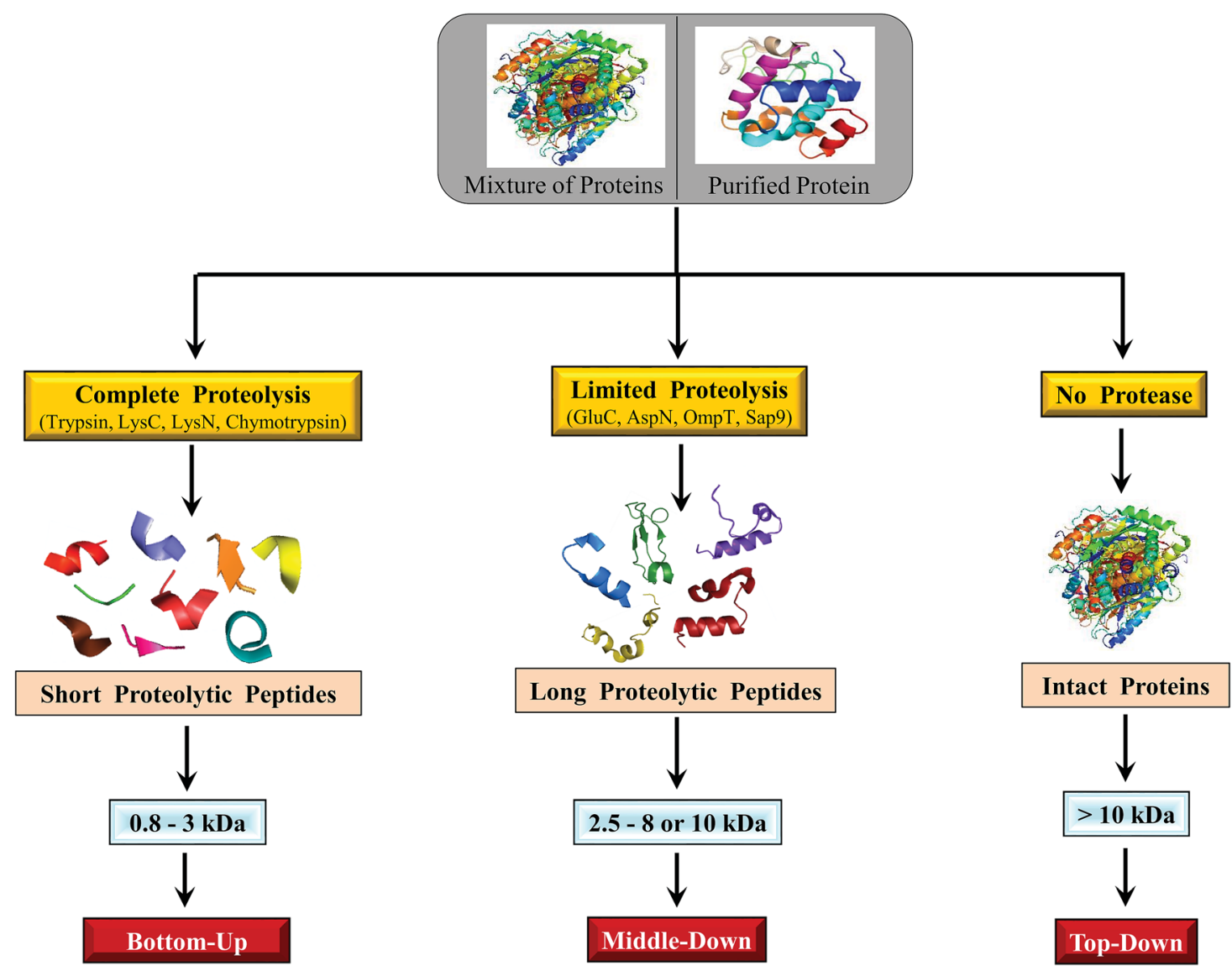

Scheme 2 Illustration of the fundamental criteria of three different approaches for analysis of proteins or proteomes.

without truncation, whereas TD approach has found only limited applications thus far, in the case of MS based methods to study proteins or proteomes, although applying MS for this approach has been found to be relatively more useful for the sake of detecting PTMs and isoforms. ${ }^{53-55}$ Nevertheless, there have been attempts to fructify the application of MS based TD investigation for sequencing of proteins and proteome. ${ }^{55-62}$

1.3.3 Middle-down approach. This approach is an emerging one, which has the potential for successful applications in future, for the study of isolated/purified proteins as well as for proteomics. It has been devised and introduced recently, based on the merits and demerits experienced in the BU and TD studies. Thus, the features of BU and TD approaches have been combined in an appropriate manner, with the objective to arrive at optimum condition(s) that constitute the middle-down approach. ${ }^{\mathbf{5 4 6 3 , 6 4}}$ This implies that this approach also would involve study of truncated peptides (instead of 'intact proteins') obtained by proteolysis or chemical degradation steps (which is characteristic of $\mathrm{BU}$ approach), but the size of the resulting peptides would be greater than the ones that are usually encountered in BU approach. As already mentioned above, proteolytic peptides of length $\sim 7-20$ amino acid residues $(M$ : $0.8-2 \mathrm{kDa}$ ) are characterized in BU approach and thus, the middle-down approach would entail generation of proteolytic peptides of length greater than about 20-25 amino acid residues and up to about 100 amino acid residues, viz., molecular mass $(M)$ of polypeptides: $2.5 \mathrm{kDa}<M<10 \mathrm{kDa} .{ }^{64}$ As a consequence, the number of (proteolytic) peptides in a sample produced by middle-down approach would be relatively lesser than the number of peptides produced by typical protocols of BU approach. This means that the complexity of a sample resulting by adopting middle-down approach would be lesser than that would be obtained from BU approach. And therefore, there is enhanced probability of detecting more unique peptides through middle-down approach. Detecting more unique peptides particularly of greater lengths would indeed help to achieve enhancement in the sequence coverage of the protein(s)/proteome under study. And enhancement in the sequence coverage would mean, more PTMs and proteoforms could be detected, when compared to the BU approach.

The major steps involved in the three approaches, as described above are summarized in Scheme 2. In this review, various strategies reported thus far by different research groups for accomplishing middle-down approach are discussed. Diverse workflows of BU and TD approaches are also briefed and compared with middle-down approach. Fundamental aspects of steps involved in the workflow such as proteolytic methods, chromatography (separation techniques), mass spectrometry and data analysis strategies are described. 
Table 1 List of proteases and chemicals along with their respective specificity towards cleaving the peptide bonds ${ }^{a}$

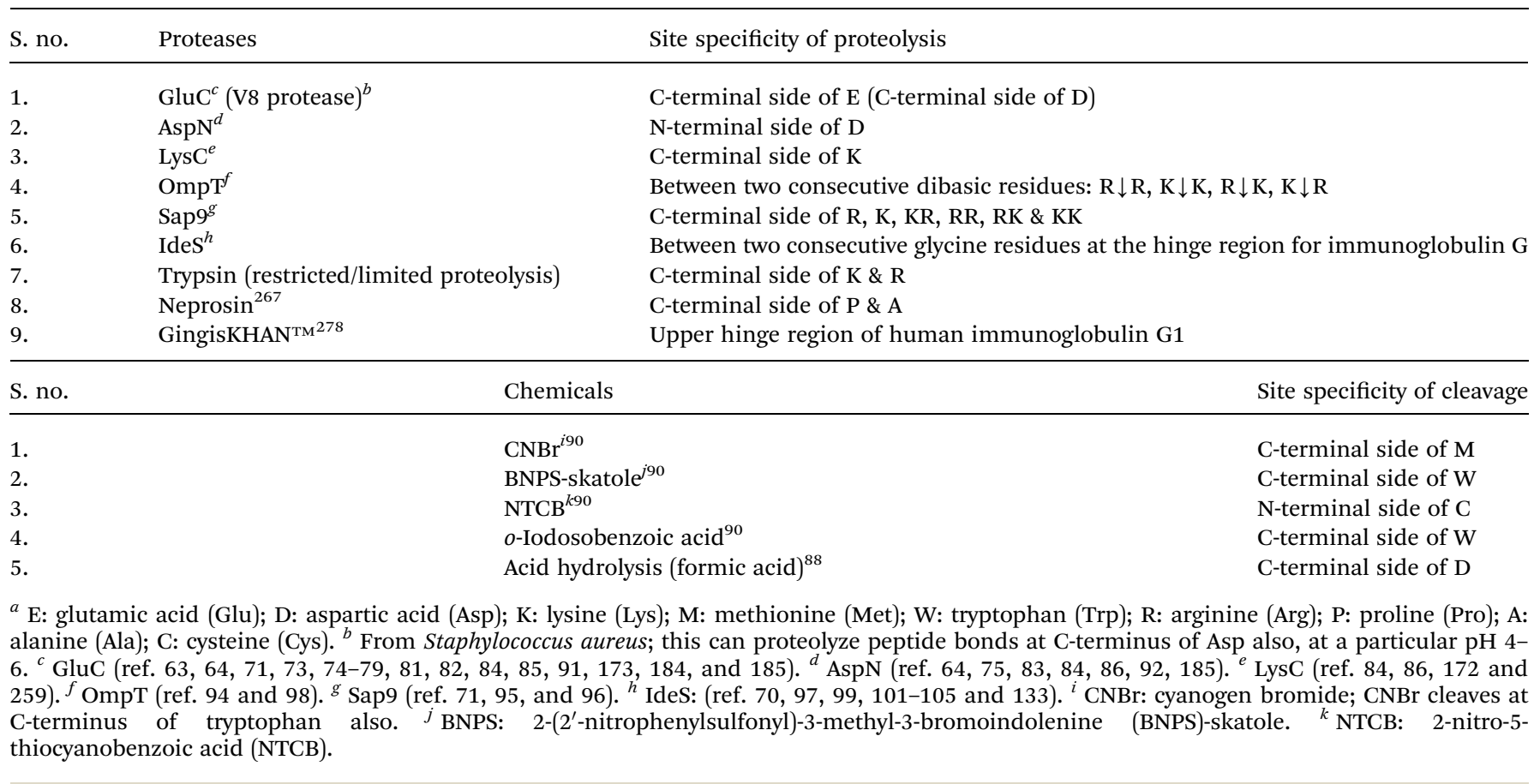

\section{Workflow of middle-down sequencing or proteomic approach}

\subsection{Proteolysis}

As explained in the previous section, the major step that distinguishes one approach from the other is 'proteolysis'. In the case of TD approach, proteolysis is not carried out at all, whereas the 'extent of proteolysis' is the key criterion or perhaps the subtlety that demarcates bottom-up and middle-down approaches. While in BU approach the proteolysis is allowed to proceed completely, the process of proteolysis in middledown (MD) approach could be challenging, which necessitates careful optimization so as to get proteolytic peptides, whose lengths should be greater than $\sim 25$ amino acid residues and of maximum length up to about 100 amino acid residues. Thus, MD approach entails 'restricted digestion', depending on the choice of protease that is employed. Certain special proteases have also been identified that could be useful to yield longer peptides specifically suited for MD approach to study proteins and proteomes.

2.1.1 Limited proteolysis/restricted digestion. Restricted digestion has been carried out for MD studies on proteins, with the widely available and relatively inexpensive proteases such as trypsin, chymotrypsin and pepsin, by optimizing the incubation time of proteolysis or by suitably manipulating the relative concentrations of the enzyme \& substrate. For example, MD approach was followed to investigate ubiquitin by performing minimal digestion using trypsin. ${ }^{65-67}$ In another study, restricted pepsin digestion was performed before reduction and alkylation of disulfide bonds, on a recombinant antibody, Herceptin, with the objective to get larger peptide fragments that were required for structural analysis by following hydrogen/ deuterium exchange. ${ }^{68}$ Controlled digestion have also been performed for very short time periods (viz., millisecond to second timescales) over nylon membranes that are coated with proteases such as trypsin, $\alpha$-chymotrypsin and pepsin, whereby longer peptides containing more protonation states have been observed. ${ }^{69}$ For instance, a polypeptide of $8 \mathrm{kDa}$, possessing 10 charges was obtained, when apomyoglobin was subjected to controlled pepsin digestion for a period of seconds to minutes on the nylon membrane; likewise, restricted peptic digestion of bovine serum albumin (BSA) in about 2 seconds on the nylon membrane resulted in the formation of longer peptides, which corresponded to sequence coverage of about $53-82 \% .{ }^{69}$ An advantage in carrying out restricted proteolysis is, it helps in minimizing the extent of oxidation and deamidation of the samples, which are usually expected to take place during long periods of digestion, as followed in typical BU proteomics (BUP). ${ }^{70,71}$

Proteases such as GluC, AspN and LysC have also been widely used for MD Proteomics (MDP). ${ }^{72}$ Of note, most of the MDP studies have been carried out particularly to characterize histones by utilizing GluC enzyme for getting longer peptides. ${ }^{63,73-82}$ AspN also has been used to study histones and their PTMs by MD approach. ${ }^{75,83}$ Additionally, MD approach has been applied to characterize phosphorylation (in cardiac myosin binding protein C) and glycosylation (in human erythropoietin, human plasma properdin, human transferrin and human $\alpha 1$-acid glycoprotein) by employing AspN.$^{84-86}$ Further, in a study by Forbes et al., restricted digestion using LysC was shown to be useful to achieve higher sequence coverage of a mixture of proteins, whose molecular masses were greater 
Table 2 Peptide sequences obtained by in silico proteolysis of carbamidomethylated RNase A (Bovine, Uniprot KB ID: P61823) using three different proteases.

1 - KETAAAKFERQHMDSSTSAASSSNYCNQMMKSRNLTKDRCKPVNTFVHES - 50

51 - LADVQAVCSQKNVACKNGQTNCYQSYSTMSITDCRETGSSKYPNCAYKTT - 100

101 - QANKHIIVACEGNPYVPVHFDASV - 124

LysC \& Trypsin

Lys-C digest $^{a}$

Trypsin digest ${ }^{a}$

1. [2-7]: ETAAAK

2. [8-31]: FERQHMDSSTSAASSSNYC*NQMMK ${ }^{b}$

1. [2-7]: ETAAAK

3. [32-37]: SRNLTK

2. [11-31]: QHMDSSTSAASSSNYC*NQMMK

4. [38-61]: DRC*KPVNTFVHESLADVQAVC*SQK

5. [67-91]: NGQTNC*YQSYSTMSITDC ${ }^{*}$ RETGSSK

3. [40-61]: C*KPVNTFVHESLADVQAVC ${ }^{*}$ SQK

6. [92-98]: YPNC*AYK

7. [99-104]: TTQANK

8. [105-124]: HIIVAC*EGNPYVPVHFDASV

4. [67-85]: NGQTNC*YQSYSTMSITDC* $R$

5. [86-91]: ETGSSK

6. [92-98]: YPNC*AYK

7. [99-104]: TTQANK

8. [105-124]: HIIVAC* EGNPYVPVHFDASV

GluC

Glu-C digest

1. [1-9]: KETAAAKFE

2. [10-49]: RQHMDSSTSAASSSNYC*NQMMKSRNLTKDRC*KPVNTFVE

3. [50-86]: SLADVQAVC ${ }^{*}$ SQKNVAC $^{*}$ KNGQTNC $^{*}$ YQSYSTMSITDC $^{*} \mathrm{RE}$

4. [87-111]: TGSSKYPNC ${ }^{*}$ AYKTTQANKHIIVAC ${ }^{*} \mathrm{E}$

5. [112-124]: GNPYVPVHFDASV

${ }^{a}$ Peptides of length $\leq 5$ are not shown.

${ }^{b} \mathrm{C}^{*}$ refers to carbamidomethyl cysteine

than $70 \mathrm{kDa}$, though they have not claimed such a strategy as a MD approach. ${ }^{87}$ Microwave accelerated acid digestion experiments have been attempted on ribosomal proteins and RPMI 8226 multiple myeloma cells, which gave rise to polypeptides rich in basic amino acid residues, whose sizes varied in the range: $3-9 \mathrm{kDa}$ (maximum of 12 charges). ${ }^{88,89}$

In a very recent study, Tsybin and co-workers report chemical-mediated proteolysis as an alternative to the conventional enzyme-assisted digestion, wherein they use the already well-known chemical reagents (see Table 1) to specifically effect cleavages of the peptide bonds at $\mathrm{C}$-terminus to methionine, tryptophan and cysteine, on some model proteins, in order to assess the suitability of this strategy for MD proteomic applications. ${ }^{90}$ Table 1 shows list of various proteases and chemicals along with their respective specificity towards cleaving the peptide bonds.

2.1.2 Distribution of the lengths of proteolytic peptides obtained by action of four different proteases on some proteins: an in silico comparative analysis. The likelihood of obtaining longer proteolytic peptides can be enhanced, by performing 'restricted digestion/limited proteolysis', which is a condition of not permitting the protease to carry out its catalytic activity for the hydrolysis of one or two or more peptide bond(s) of the proteins. Proteolytic peptides derived in this manner are referred as 'peptides due to 1-missed cleavage' or 'peptides due to 2-missed cleavages', so on and so forth. Achieving the condition of restricted digestion/limited proteolysis indeed requires careful optimization of several parameters, such as time period of proteolytic action; $\mathrm{pH}$ of the medium, in which proteolysis takes place; temperature of the proteolytic condition and the relative concentrations of the enzyme:proteins. Furthermore, it is important to understand that the extent of proteolysis also depends on the protein sequence, particularly depending on the 'positions' of those amino acid residues, which are the targets of a particular protease. For instance, complete LysC digestion or complete trypsinolysis of carbamidomethylated bovine pancreatic ribonuclease A (RNase A) would result in short length peptides, whereas upon digestion with GluC (V8 protease from Staphylococcus aureus), two longer peptides are obtained: residue [10-49] and residue [50-86] (see Table 2). Not only the 'length' of these two GluC peptides, but also their respective ESI charge state distribution (see Fig. 1 and 2; also refer Section 2.3.3, vide infra) indicate that complete GluC digestion is a better choice over complete trypsinolysis or LysC to characterize RNase A by MD approach. Thus, the workflow for the sample preparation, i.e., preparing suitable proteolytic digest for MD approach mainly depends on the sequence (viz. primary structure) of the proteins under investigation.

In order to have a better understanding and obtain a clearer picture about the role of primary structure of the proteins in influencing the extent of proteolysis, in silico proteolysis was performed herein on 15 representative proteins from each of five different organisms: Homo sapiens (human), Saccharomyces cerevisiae (yeast), Escherichia coli (E. coli, bacteria), Arabidopsis thaliana (plant) and Methanococcus jannaschii (archaea). The sequences of all the representative proteins were taken from UniProt KB database and most of these are enzymes involved in 
(a) C*KPVNTFVHESLADVQAVC*SQK: [40-61] Bovine Pancreatic RNase A

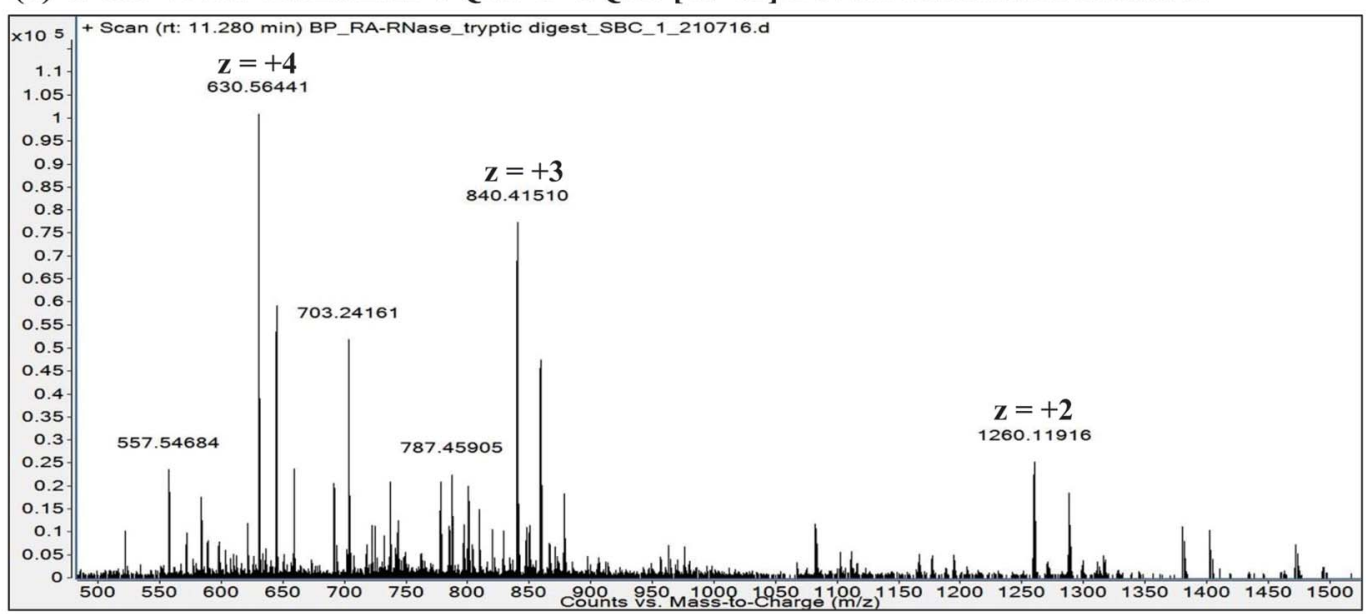

(b) NGQTNC*YQSYSTMSITDC*R: [67-85] Bovine Pancreatic RNase A

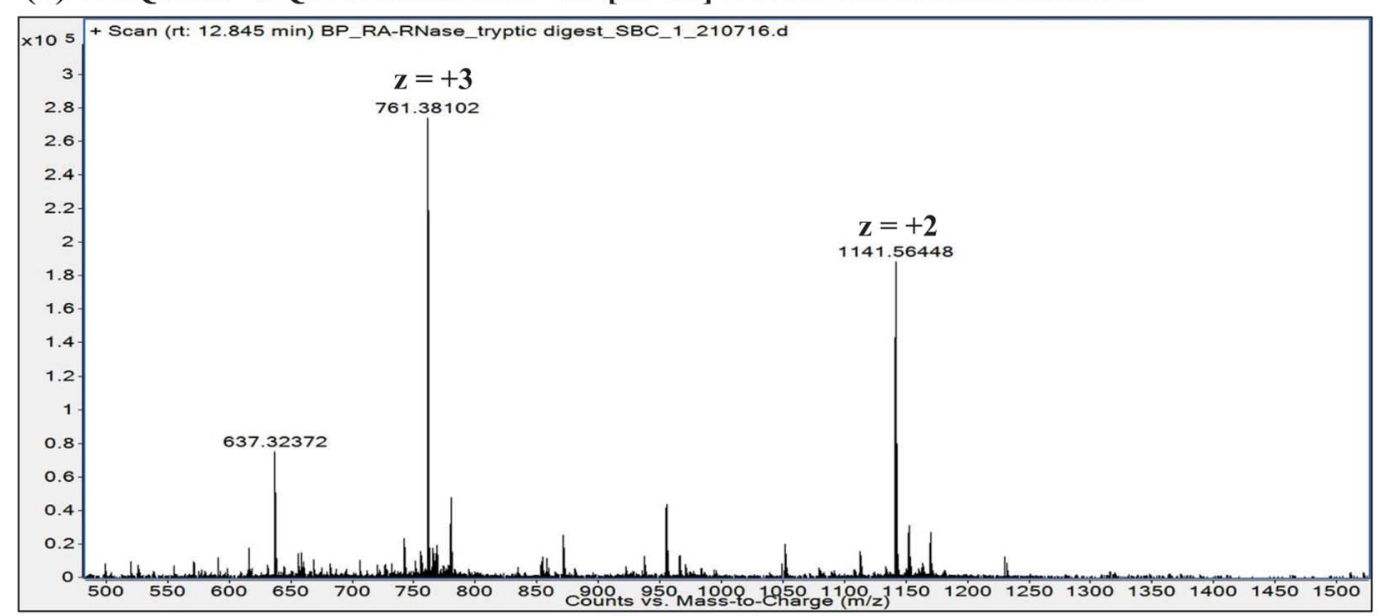

(c) HIIVAC*EGNPYVPVHFDASV: [105-124] Bovine Pancreatic RNase A

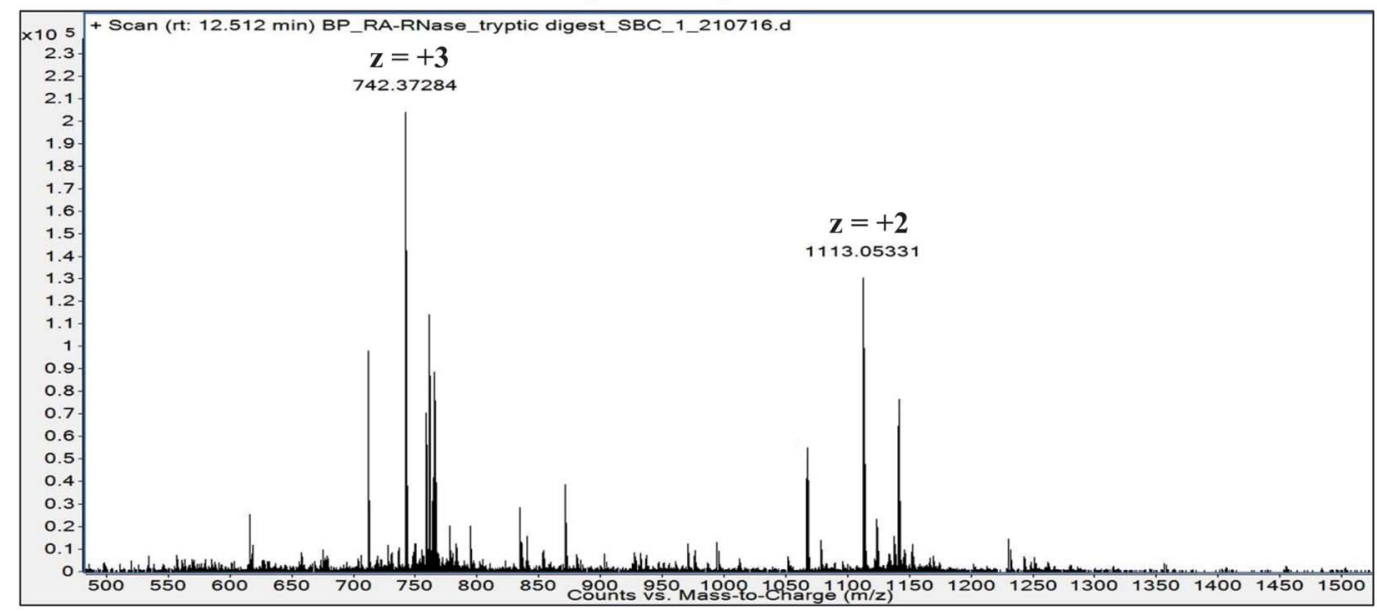

Fig. 1 LC-ESI mass spectra of tryptic peptides: (a) Residue No. [40-61] (22 a.a. residues long); (b) Residue No. [67-85] (19 a.a. residues long) and (c) Residue No. [105-124] (20 a.a. residues long) from carbamidomethylated RNase A (Bovine pancreas). These data were acquired on an ESI-Q/ TOF mass spectrometer (6540 Ultra High Definition Accurate-Mass Q-TOF LC/MS attached to 1290 Infinity LC; Agilent Technologies). Note: C* refers to carbamidomethyl cysteine.

glycolytic pathway and in tri-carboxylic acid cycle (see Table S1, supplementary information $\dagger$ ). The intact molecular masses of the 15 proteins from each of these organisms are in the range:
20-100 kDa. We compared the results obtained from complete proteolysis with that of 1-missed cleavage (1-MC) proteolysis corresponding to each of the four proteases: trypsin, GluC, LysC 
RQHMDSSTSAASSSNYC*NQMMKSRNLTKDRC*KPVNTFVHE: [10-49] of Bovine Pancreatic RNase A

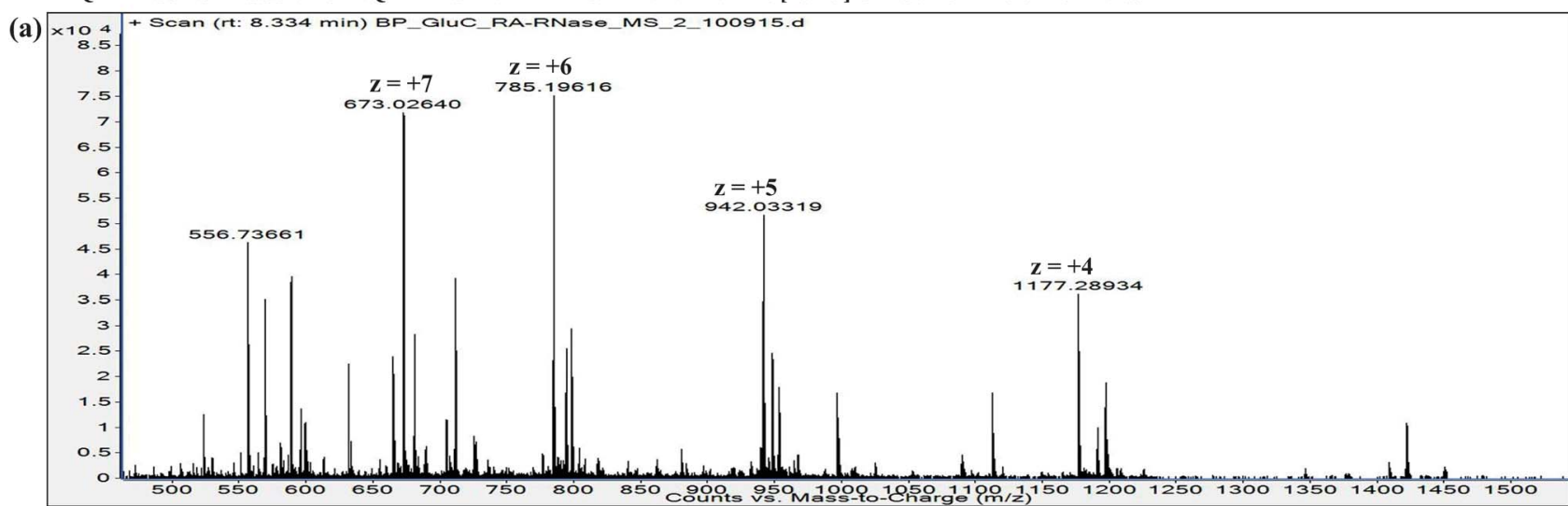

SLADVQAVC*SQKNVAC*KNGQTNC*YQSYSTMSITDC*RE: [50-86] of Bovine Pancreatic RNase A

(b) $\times 105$ + Scan (rt: $9.884 \mathrm{~min})$ BP_GluC_RA-RNase_MS_2_100915.d

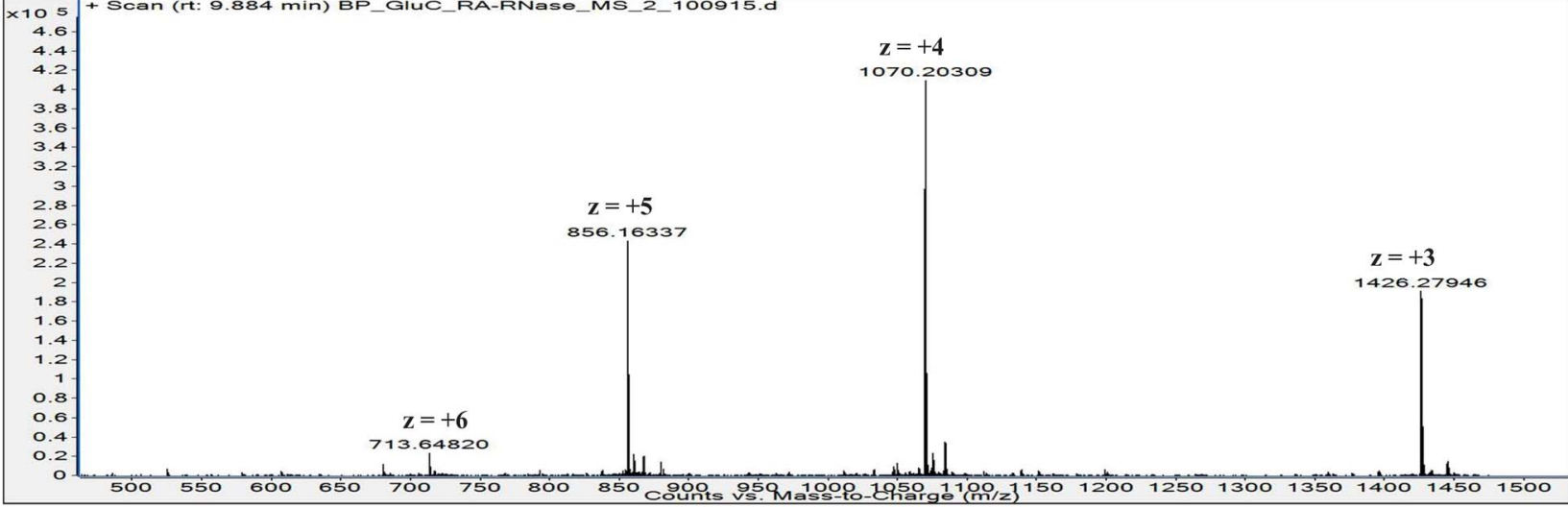

Fig. 2 LC-ESI mass spectra of GluC digested peptides: (a) Residue No. [10-49] (40 a.a. residues long) and (b) Residue No. [50-86] (37 a.a. residues long) from carbamidomethylated RNase A (Bovine pancreas). These data were acquired on an ESI-Q/TOF mass spectrometer (6540 Ultra High Definition Accurate-Mass Q-TOF LC/MS attached to 1290 Infinity LC; Agilent Technologies). Note: C* refers to carbamidomethyl cysteine.

and AspN, with the objective to find, which protease can be suitable to execute the strategy of limited proteolysis for the sake of MDP.

To simplify this analysis, the proteolytic peptides resulting from every in silico digestion were classified into five categories, based on the number of amino acid residues (a.a.r) in peptide, i.e., length of the peptide: (1) 5-15 a.a.r, (2) 16-25 a.a.r, (3) 26-35 a.a.r, (4) 36-45 a.a.r and (5) 46-55 a.a.r. The results of these in silico exercises depicting population distribution of different lengths of proteolytic peptides plotted for four different proteases can be seen in Fig. 3. An interesting aspect emerging from this in silico comparative analysis is that there is not only increase in the number of AspN peptides of lengths in the range 16-55 a.a.r due to 1-MC, when compared with the results of complete AspN digestion, but there is also a significant decrease in the number of AspN peptides of length 5-15 a.a.r because of 1-MC AspN proteolysis compared to complete AspN digestion. Likewise, reduction in the number of GluC peptides of length 515 a.a.r, accompanied by increase in the number of longer GluC peptides (16-55 a.a.r), due to 1-MC can be noticed. In contrast, with regard to digestion by trypsin and LysC, there is no significant decrease in the population of shorter peptides of length 5-15 a.a.r, although there is a good enhancement in the population of tryptic \& LysC peptides of lengths in the range 1655 a.a.r. It is important to note that the main purpose of restricted or limited digestion is in fact, not only to improve the yield of longer proteolytic peptides, but decrease in the population of shorter proteolytic peptides also is desirable, so that the complexity of the proteolytic peptides' concoction could be minimized. This purpose does not seem to be fulfilled by the use of trypsin and LysC over the 15 representative proteins that we have chosen from five different species. Although the population of the peptides of length 16-55 a.a.r increases due to 1MC proteolysis in the cases of all these four proteases, the extent of decrease in the population of shorter peptides of length 5-15 a.a.r, in the cases of 1-MC AspN and 1-MC GluC proteolysis, is noteworthy.

Thus, it is apparent from this in silico analysis that restricted digestion using AspN and GluC could be more apt for performing MD studies on proteins or for proteomics, rather than performing limited trypsin or LysC digestion and to arrive at this inference, "100 proteolytic peptides" was chosen as the threshold value (Fig. 3).

Furthermore, we performed in silico proteolysis for 2-missed cleavage (2-MC) condition using all these four proteases on these seventy five proteins (Table S1, supplementary 

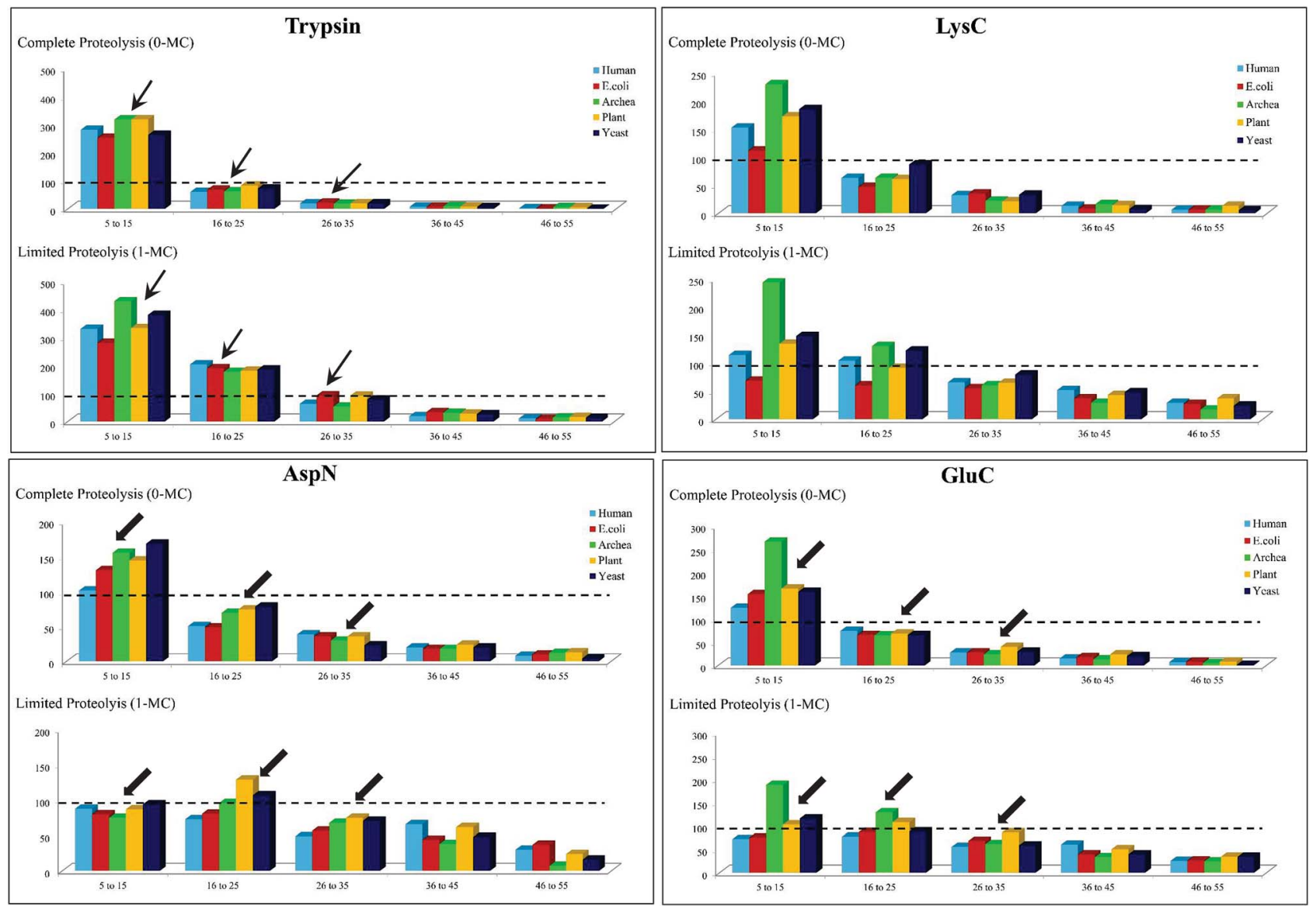

Fig. 3 In silico proteolysis of 15 representative proteins (see Table S1, supplementary information†) using four different proteases: (1) trypsin, (2) LysC, (3) GluC and (4) AspN. Comparison of population of proteolytic peptides of different lengths obtained from 'complete proteolysis (0-MC)' and 'limited proteolysis (1-MC)'. Based on their length (no. of a.a.r), the peptides have been classified into five different categories: (1) 5-15 a.a.r, (2) 16-25 a.a.r, (3) 26-35 a.a.r, (4) 36-45 a.a.r and (5) 46-55 a.a.r.

information; $\uparrow$ also see Fig. 4). To assess the performance of 2MC proteolysis on these seventy five proteins, it was decided to define a ratio, as shown below:

$$
\text { Ratio }=\frac{(\text { No. of proteolytic peptides of length }[26-55])}{(\text { No. of proteolytic peptides of length }[5-25])}
$$

The extent of proteolysis can be understood from this ratio values. Higher the value of this ratio, viz., when the value exceeds 0.5 or 1 , better is that proteolytic condition suited for MD proteomic approach. We calculated this ratio for three different proteolytic conditions: 0 -missed cleavage (0-MC), 1missed cleavage (1-MC) and 2-missed cleavage (2-MC), using each of the four proteases on all of the fifteen model proteins from each of the five organisms (see Table 3). Although it is obvious to conceive that 2-MC would be better than 1-MC and 0MC cleavage conditions for MDP, the values shown in Table 3 clearly indicate that out of these four proteases, AspN and GluC are better than trypsin and LysC, to pursue 2-MC limited proteolysis, for MDP; especially 2-MC by AspN yields better results (i.e., better ratio values) than 2 -MC by GluC. Indeed, quite a number of MD investigations, particularly on histones have been accomplished by the use of AspN and
GluC..$^{63,73-79,81-83,91,92}$ It can also be noted in Table 3 that 2-MC by trypsin does not give favorable ratio values, excepting the case of yeast, suggesting that 2-MC by trypsin is not a useful option for MD approach.

A similar kind of analysis has been carried out by Trevisiol et al., wherein only human proteome was subjected to in silico proteolysis (using the proteases: trypsin, LysC, ArgC, LysN, AspN, GluC (D\&E), GluC(E)) and the lengths of the resulting peptides, in the range 8-25 a.a.r only were analyzed; indicating the suitability of this investigation primarily on BU approach. ${ }^{93}$ Whereas, we are interested in MD approach and therefore, the analyses presented herein are focused on proteolytic peptides longer than 25 a.a.r and moreover, we have paid attention to other biological species, in addition to human.

2.1.3 Proteases specifically prepared for MD approach. Since limited or restricted proteolysis requires very careful optimization of proteolysis conditions such as time and relative concentrations of enzyme : substrate, there have been attempts in search of special proteases, for instance OmpT, Sap9 and IdeS, that have been used to ease the process of 'restricted proteolysis', and to enhance the probability of consistently obtaining longer peptides suited for MD approach than those typically encountered in $\mathrm{BU}$ investigations. ${ }^{\text {0,94-97}} \mathrm{OmpT}$ is 


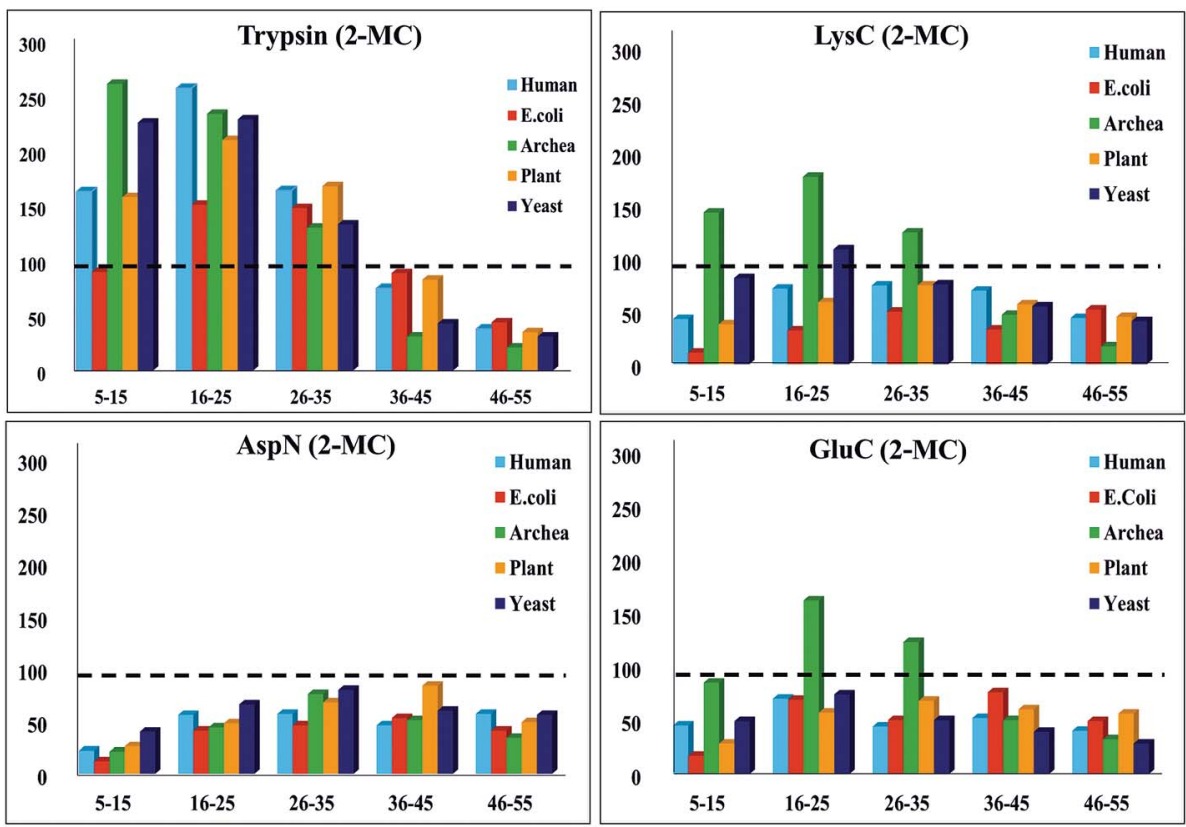

Fig. 4 In silico proteolysis of 15 representative proteins (see Table S1, supplementary information广) using four different proteases: (1) trypsin, (2) LysC, (3) GluC and (4) AspN. Distribution of population of proteolytic peptides of different lengths obtained from '2-missed cleavage (2-MC) limited proteolysis'. Based on their length (no. of a.a.r), the peptides have been classified into five different categories: (1) 5-15 a.a.r, (2) 16-25 a.a.r, (3) 26-35 a.a.r, (4) 36-45 a.a.r and (5) 46-55 a.a.r. (Compare this with Fig. $3 \&$ also see Table 3.)

Table 3 Comparison of $0-M C, 1-M C$ and 2-MC in silico proteolysis, carried out on fifteen different proteins from five different species (see Table S1, supplementary information) using four different proteases

Comparison of results obtained from Trypsin and LysC

\begin{tabular}{|c|c|c|c|c|c|c|}
\hline \multirow[b]{2}{*}{ Species } & \multicolumn{3}{|l|}{ Trypsin } & \multicolumn{3}{|l|}{ LysC } \\
\hline & $0-\mathrm{MC}$ & 1-MC & 2-MC & $0-\mathrm{MC}$ & 1-MC & 2-MC \\
\hline Human & 0.0818 & 0.1681 & 0.6595 & 0.2361 & 0.6697 & 1.6434 \\
\hline E. coli & 0.0931 & 0.2878 & 1.1659 & 0.3081 & 0.9296 & 3.1395 \\
\hline Archaea & 0.0866 & 0.1619 & 0.3676 & 0.1501 & 0.2834 & 0.5869 \\
\hline Plant & 0.0796 & 0.2651 & 0.7771 & 0.2051 & 0.64 & 1.8247 \\
\hline Yeast & 0.0744 & 0.2074 & 0.4549 & 0.1648 & 0.5592 & 0.9005 \\
\hline
\end{tabular}

Comparison of results obtained from GluC and AspN

\begin{tabular}{llllllll}
\hline & GluC & & & & AspN \\
\cline { 2 - 3 } Species & 0-MC & 1-MC & 2-MC & & 0-MC & 1-MC & 2-MC \\
\hline Human & 0.25 & 0.9395 & 1.1826 & 0.4379 & 0.9006 & 2.0512 \\
E. coli & 0.2454 & 0.8209 & 2.0348 & & 0.3555 & 0.8571 & 2.6415 \\
Archaea & 0.1265 & 0.3722 & 0.8299 & & 0.2654 & 0.6608 & 2.4769 \\
Plant & 0.3063 & 0.8056 & 2.1647 & 0.3318 & 0.7453 & 2.7162 \\
Yeast & 0.2266 & 0.6421 & 0.9512 & 0.1895 & 0.6716 & 1.8490
\end{tabular}

a novel protease belonging to the omptin family, which has specificity to catalyze cleavage of peptide bonds between consecutive dibasic sites, $\mathrm{K} \downarrow \mathrm{R}, \mathrm{R} \downarrow \mathrm{R}, \mathrm{R} \downarrow \mathrm{K}$ and $\mathrm{K} \downarrow \mathrm{K} ; \mathbf{9 4}^{\mathbf{9 4} 98}$ whereas Sap9 (Candida albicans) is an aspartic protease derived from yapsin family; both enzymes are capable of yielding peptides of length > 2 kDa. ${ }^{94-96}$ Sap9 has been applied for extended bottomup proteomics ${ }^{96}$ and it is also envisaged to be promiscuous for successfully carrying out MD proteomic studies. ${ }^{95}$ In the case of studies on antibodies by MD approach, immunoglobulin Gdegrading enzyme (IdeS) from Streptococcus pyogenes have been employed, wherein IdeS catalyse hydrolysis of peptide bond between two consecutive glycines present specifically at the hinge region of immunoglobulin (Ig).$^{97,99-101}$ For example, three larger sized proteolytic peptides were obtained by IdeS treatment on the commercially available antibodies, cetuximab, rituximab, etc. ${ }^{\mathbf{7 0 , 1 0 2 - 1 0 5}}$ Proteases that have been used exclusively for MDP studies are shown in Table 1.

Moreover, there is another endopeptidase, Kex2, which is specific in catalyzing the hydrolysis of peptide bonds that are Cterminal to consecutive dibasic residues, viz., C-terminus to KR or RR or PR. ${ }^{106}$ Although currently, there are no published reports about the usage of Kex2 in MD proteomic studies, it might be applicable for MD based proteomic investigations in future.

\subsection{Separation technology}

Proteomic studies are relatively more complicated, when compared to genomic investigations because proteomic studies involve characterization of protein isoforms, PTMs and various kinds of analyses to monitor expression levels at different stages of growth of cells/tissues. Therefore, different types of separation strategies are essential for proteomics, so as to decrease the complexity of proteome. Application of various separation or chromatographic methods can significantly influence the detection and analysis of even the low abundance level of proteins/proteolytic peptides by $\mathrm{MS}^{\mathbf{1 0 7 - 1 1 0}}$ Separation of proteome can be carried out by either of the two approaches: gelbased or gel-free. ${ }^{111-113}$ 
2.2.1 Gel electrophoresis. Gel-based approach primarily involves 1-dimensional or 2-dimensional gel electrophoresis, whereby proteins are separated on the basis of molecular mass (i.e., molecular size) and charge. In 2-dimensional gel electrophoresis, separation in the first dimension is accomplished according to the isoelectric points of the respective proteins, and in the second dimension, separation is achieved based on the molecular mass of the proteins. Gel-based approach has proven to be successful for innumerable proteomic investigations pursued by BU approach, in that difference gel electrophoresis or differential in-gel electrophoresis (DIGE) has been extensively applied for quantitation purposes. ${ }^{\mathbf{1 1 4 - 1 1 9}}$ Gel-based methods have also been applied for MD based mass spectrometric analysis and proteomics; for example, tube gel electrophoresis has been utilized in conjunction with the protease OmpT for a study conducted on HeLa cell lysate. ${ }^{94}$ Conventional sodium dodecyl sulfate (SDS)-polyacrylamide gel electrophoresis (PAGE) was used to study the extent of branching of polymeric ubiquitin chains in $E$. coli and this study was carried out by MD based mass spectrometry, involving limited trypsinolysis. ${ }^{66}$ In another study aimed to isolate, enrich and characterize ubiquitin chains from HEK cell lysate, conventional SDS-PAGE was utilized, followed by limited trypsin digestion. ${ }^{67}$

2.2.2 Capillary electrophoresis. While gel-free approach predominantly encompasses applications of liquid chromatography (LC) based techniques for proteome characterization, capillary electrophoresis $(\mathrm{CE})^{\mathbf{1 2 0}}$ can be considered either as gelfree or as gel-based method. Capillary electrophoresis (CE) consists of various modes of operation, viz., capillary gel electrophoresis (CGE), capillary zone electrophoresis (CZE), capillary isoelectric focusing (CIEF), capillary isotachophoresis (CITP), capillary affinity electrophoresis (CAE) and micellar electrokinetic chromatography (MEKC). ${ }^{\mathbf{1 2 1 , 1 2 2}}$ Among these, CGE is the earlier method used for the separation of proteins/ peptides based on the size. ${ }^{\mathbf{1 2 3}}$ But in coupling with MS, there are drawbacks with CGE, for example, need of high buffer concentrations to effect the separation process, which decreases the sensitivity for MS analysis. ${ }^{\mathbf{1 2 4}}$ Therefore, CGE was not quite compatible for MS and consequently, not many proteomic studies have been reported involving CGE along with MS. Rather, the most widely used CE is CZE, which is most compatible to MS based proteomic studies, in particular with ESI-MS. ${ }^{120,125-128}$ It separates the proteins based on the charge-tosize ratio. There are some studies reporting about utilization of CZE for both BU and TD approaches. ${ }^{\mathbf{1 2 7 - 1 3 2}}$ Additionally, other capillary electrophoresis methods such as CIEF, CITP, CAE and MEKC have also been applied for proteomics. ${ }^{\mathbf{1 0 8 , 1 2 1 , 1 2 2}}$ Thus far, there have not been many investigations about application of CE for MDP, excepting two studies, which report the application of $\mathrm{CE}$ for MD approach based analysis conducted on monoclonal antibodies. ${ }^{101,133}$

2.2.3 Liquid chromatography. In the case of LC, extent of separation of proteolytic peptides or intact proteins depends on the nature of mobile phase (solvents) and stationary phase. The mobile phase enables elution of the analyte molecules that are bound to stationary phase. The order of elution effected by the mobile phase depends on the strength of binding between the analyte molecules and the stationary phase. Therefore, the choice of column (i.e., stationary phase) and solvents (viz., mobile phase) is critical to obtain good separation of complex mixtures of proteolytic peptides or intact proteins. Among several factors that influence selectivity and resolution of separation, one important factor is chemistry of the stationary phase, e.g., C18 in the case of reverse phase chromatography, polysulfoethyl for ion exchange chromatography, $\mathrm{Cu}^{2+}$ immobilized on imino diacetic acid (IDA) in the context of immobilized metal ion affinity chromatography (IMAC), etc. Other key factors that could also significantly impact the resolution of separation are column length, particle size and pore size of the packing material within the column, mobile phase elution conditions such as $\mathrm{pH}$, salt gradient, etc.

2.2.3.1 Reverse phase liquid chromatography (RPLC). Most of the proteomic studies are successfully done by reverse phasehigh performance liquid chromatography (HPLC) or RPLC. ${ }^{107}$ The mobile phase or solvents of RPLC are water, acetonitrile and methanol which are compatible to ESI-MS and consequently, it was possible to successfully couple RP-HPLC with ESI-MS, which is denoted as LC-MS or LC-ESI-MS. ${ }^{\mathbf{1 3 4 , 1 3 5}}$ In general, online separation of peptides by LC-MS can save time, sample and also can be more sensitive, when compared to the offline direct infusion method. Moreover, with the introduction of ultra performance or ultra high performance LC (UPLC/ UHPLC), there was further improvement in the speed, sensitivity and resolution of separation of complex samples containing peptides for LC-MS in proteomics, which can be attributed to the use of sub $2 \mu \mathrm{m}$ particle size containing reverse phase columns. ${ }^{136,137}$

Silica based C18, C8 and C4 are some well known column chemistries that have been more widely used for RP-HPLC of peptides and proteins ${ }^{3}$ and thus, these column chemistries are also extensively applied for several online LC-MS experiments in proteomics. For BUP, C18 columns are predominantly used for LC-MS as it involves characterization of short length peptides. ${ }^{45,46}$ In the case of MD approach, since longer or larger proteolytic peptides are encountered, C4, C5 and C8 columns have been utilized for online LC-MS. ${ }^{65,68,70,71,90,99,104,105,138,139}$ Nevertheless, C18 column (in the form of Nano LC) also has been utilized for efficient separation of proteolytic peptides, in certain MD studies. ${ }^{64,75,85,89,139}$

2.2.3.2 Other liquid chromatographic methods. With regard to application of other LC methods for MD approach based studies, there are perhaps no reports showing the utility of affinity chromatography for MDP. However, for BUP, IMAC has been proven to be of immense utility. ${ }^{\mathbf{1 4 0}}$ A major application of IMAC in BUP is enrichment of phosphorylated peptides by $\mathrm{Ti}^{4+}$ and $\mathrm{Zr}^{4+}$ based IMAC. ${ }^{\mathbf{1 4 1 , 1 4 2}}$ Recently, IMAC using monolithic columns for proteomics is on the rise and in this connection, IMAC has been shown to be a pre-fractionation method with the use of monolith disks. ${ }^{\mathbf{1 4 3 , 1 4 4}}$ Furthermore, lectin affinity chromatography has been well utilized for the study of glycated peptides and glycans in BUP. ${ }^{\mathbf{1 4 5}-\mathbf{1 4 7}}$ Boronate affinity chromatography also has been of utility for enrichment of glycoproteins and glycopeptides, prior to mass spectrometric analysis. ${ }^{\mathbf{1 4 8 , 1 4 9}}$ 
With regard to size exclusion chromatography (SEC), excepting an investigation, no reports are available on its use for MD approach; Hummel et al. have applied SEC to extract $2 \mathrm{~S}$ albumin from the mustard. ${ }^{138}$ Ion exchange chromatography, particularly weak cation exchange (WCX) chromatography in conjunction with hydrophilic interaction chromatography (HILIC) has been successfully applied for MD approach based studies ( $c f$. vide infra).

2.2.3.3 Multi-dimensional $L C$. The introduction of multidimensional protein identification technology (MudPIT) revolutionized the field of proteomics, in particular, for BUP. ${ }^{45-47}$ MudPIT involves combining the use of more than one separation method or technology for achieving better separation of proteins/proteolytic peptides, thereby decreasing the complexity of the sample for further analysis. Coupling strong cation exchange (SCX) chromatography with RPLC, viz., SCXRPLC has been the predominantly followed MudPIT approach, ${ }^{45,47,64}$ which has proven to be successful in several BUP investigations. ${ }^{48}$ Other examples of MudPIT strategies applied for proteomics are: LC with CE, SEC with RPLC, RPRPLC and IMAC coupled to $\mathrm{CE}^{\mathbf{4 7 , 1 5 0 , 1 5 1}}$ In the case of MD approach, WCX in conjunction with HILIC, termed as WCXHILIC has been widely followed, particularly for the investigations focused on histones. ${ }^{76-79,82,92,152}$ Young et al. reported the first use of "saltless-pH gradient" to carry out WCX-HILIC (online coupled to ESI-MS/MS), which became widely applicable to several other $\mathrm{MD}$ based studies on histones. ${ }^{92}$ In contrast, in a recent report by Shabaz Mohammed, Heck and coworkers, traditional MudPIT approach encompassing SCXRPLC has been shown to be useful for MDP to separate longer proteolytic peptides. ${ }^{64}$ Scheme 3 summarizes different types of gel-based and non-gel-based (gel-free) separation techniques that have been applied for different kinds of proteomic analyses including that of MD approach based investigations. In addition to gel-based and gel-free approaches, separation has been attempted in gas phase also, accomplished by means of ionmobility. ${ }^{153,154}$

2.2.4 Ion-mobility mass spectrometry: separations in gas phase. MD approach has been applied using Ion-Mobility MS too. For example, Shvartsburg et al. isolated the proteolytic peptides by field asymmetry waveform ion mobility separation (FAIMS) analyzer using gases, $\mathrm{He} / \mathrm{N}_{2}$ or $\mathrm{H}_{2} / \mathrm{N}_{2} \cdot{ }^{155}$ Additionally, a few studies report about the application of MD approach involving native as well as denaturing ion-mobility MS, especially for characterization of therapeutic biosimilar antibodies and also for analysis of proteoforms, in particular of histones. ${ }^{156,157}$

\subsection{Conventional MS and tandem MS (MS/MS)}

Mass spectrometers basically have three modules namely ion source or ionization source, mass analyzer and detector. Because of the emergence of soft-ionization methods such as ESI and MALDI, ${ }^{24,25}$ it became possible to successfully apply these two ionization modes in various fields, mainly for the purpose of intact molecular mass measurements. In fact, the rapid progress in the field of proteomics was primarily driven by applying these two ionization modes. MALDI generates predominantly singly protonated ions of intact peptide or protein molecules, whereas multiply protonated ionic species of proteins or peptides are detected/generated by means of ESI.

2.3.1 Electrospray ionization (ESI). ${ }^{25}$ The processes involved in ESI are: formation of charged droplets, disintegration of large sized droplets into small sized droplets and release of ions from the small sized droplets into the gas phase or vacuum. (1) Charged droplet formation: samples in liquid form are allowed to pass through a capillary and a high electric voltage (about 3-5 kV) is applied at the tip of that capillary. Simultaneously, the liquid sample is 'sprayed' by allowing a nebulizing gas (typically $\mathrm{N}_{2}$ ) to flow through a tube, which is kept in concentric arrangement with the capillary carrying the liquid sample. While creation of 'spray' leads to the formation of droplets of the liquid sample, simultaneous application of electric potential to capillary tip, into which the liquid sample flows, enables formation of 'charged droplets'. And therefore, this process is called as 'electrospray'. The process of electrospray emanating from the tip of the capillary usually adopts a shape of a cone, referred as 'Taylor cone', which consists of charged droplets. Depending on the polarity of the electric potential, it is possible to produce either positively charged or negatively charged ions. It is important to note that electrospray process is an atmospheric pressure ionization (API) method, since all these steps take place at atmospheric pressure.

(2) The charged droplets would then begin to disperse from the Taylor cone (atmospheric pressure) towards mass analyzer, which is housed in high vacuum region. Consequently, the charged droplets move under the influence of pressure as well as electric potential gradient. During the course of this movement, the sizes of the droplets begin to shrink, attributed to the processes of 'Coulomb explosion' and 'desolvation'. When the population of like-charged analyte ions contained within a drop exceeds a certain limit (Rayleigh limit), Coulomb explosion happens, because under that circumstance the electrostatic repulsive forces between the like-charged analyte ions exceed the surface tension of that drop, leading to division of those drops into smaller-sized droplets. Desolvation is accomplished by supplying heated dry nitrogen gas (about 200-300 ${ }^{\circ} \mathrm{C}$ ), opposite to the direction of the flow of the charged droplets, which facilitates evaporation of solvent molecules, e.g., water, methanol, leading to reduction in the size of the droplets. The processes of 'Coulomb explosion' and 'desolvation' continue to take place until the analyte ions are completely devoid of any solvation. Thus, the ions are released in the gas phase or vacuum and then directed to the mass analyzer.

2.3.2 Matrix assisted laser desorption/ionization (MALDI). Formation of ions by MALDI occurs with the help of laser radiation. Sample, either in liquid or in powder form can be analyzed by MALDI. The sample is mixed with a solution containing matrix compound, e.g., alpha-cyano-4-hydroxy cinnamic acid ( $\alpha$-CHCA or $\alpha$-C) or 2,5-dihydroxy benzoic acid (DHB). The matrix solution is prepared using combination of acetonitrile and water. Such solutions containing matrix and the sample are then loaded into the wells on a target plate (96 or 384 well plate), which is called spotting the samples and these liquid spots are 


\section{Separation Techniques for Proteins’ Analysis \& Proteomics}

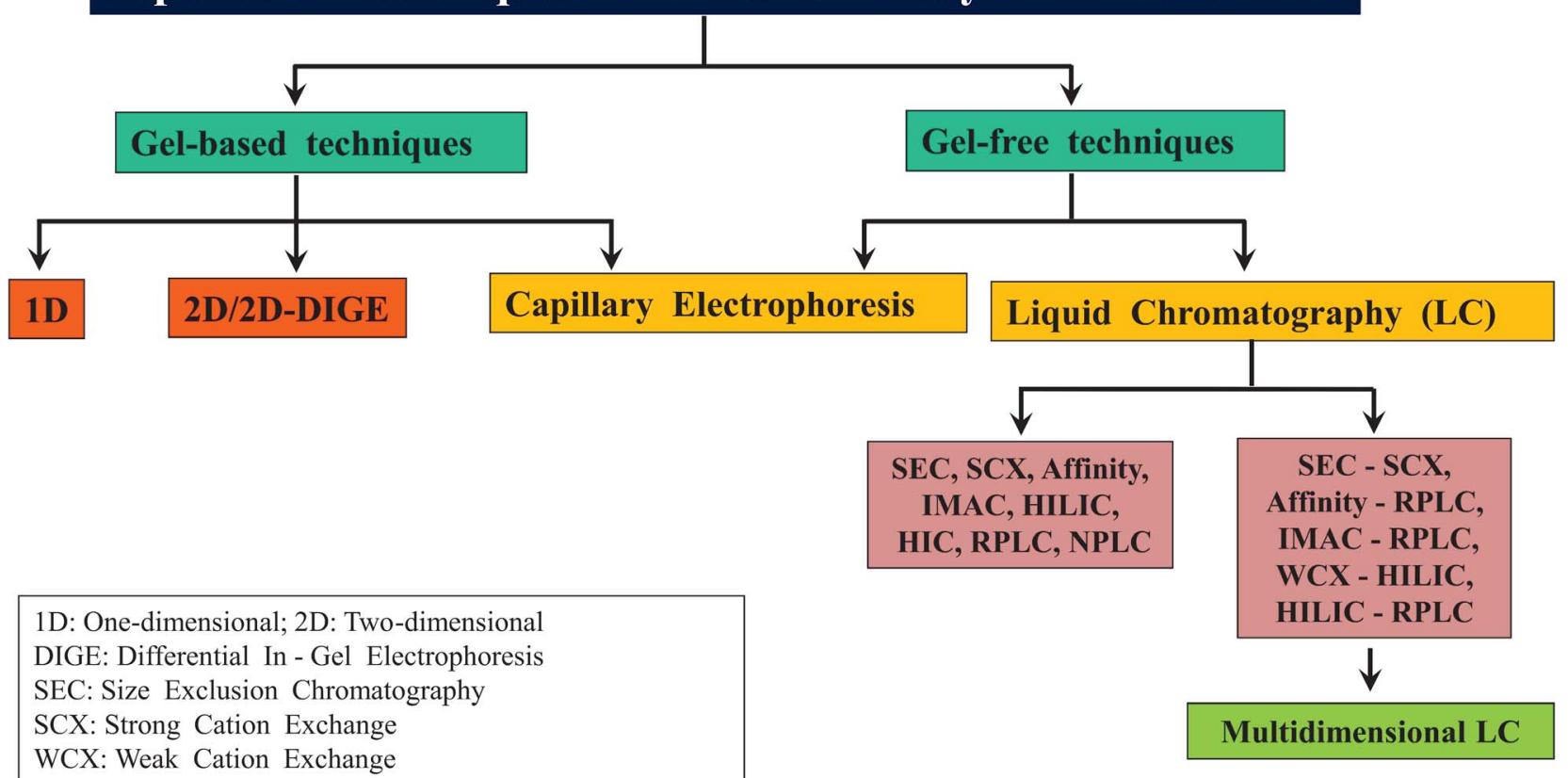

IMAC: Immobilized Metal ion Affinity Chromatography

HILIC: Hydrophilic Interaction Liquid Chromatography

HIC: Hydrophobic Interaction Chromatography

RPLC: Reverse Phase Liquid Chromatography

NPLC: Normal Phase Liquid Chromatography

Scheme 3 An overview of different types of separation techniques that have been widely followed for the analysis of proteins as well as for various kinds of proteomic analyses including MD approach based studies.

allowed to dry. These dried spots, when viewed with the help of a camera (under an appropriate scale of magnification), look either like a powdery deposit or have a crystalline appearance. Therefore, the sample spots are sometimes also referred as 'analyte-doped matrix crystals' ${ }^{158}$ Subsequently, the target plate is loaded onto the ionization chamber and the plate is introduced into the vacuum. Thereafter, the laser radiation is allowed to be incident on each of the dried sample spot, causing desorption (from the surface of the target plate) and ionization of the analyte as well as the matrix molecules. While the mechanism of MALDI is still a subject of research, an accepted concept is described herein: ${ }^{159,160}$ the wavelength of laser radiation is aptly suited or tuned in a manner that only the chromophore in the matrix molecule can absorb the radiation to a greater extent, but not by the surrounding analyte molecules under investigation. The absorption of the laser radiation causes electronic excitation of the matrix compound. The energy liberated, when the excited matrix molecule makes a transition to the ground state, is sufficient to cause desorption as well as ionization of the surrounding analyte molecules. Nitrogen $\left(\mathrm{N}_{2}\right)$ laser emitting at $337 \mathrm{~nm}$ or neodymium-yttrium aluminium garnet (Nd-YAG) laser emitting $355 \mathrm{~nm}$ (second harmonic) or $266 \mathrm{~nm}$ (third harmonic) are commonly used in MALDI mass spectrometers.

It is important to realize that MALDI is a pulsed ionization method, as it is accomplished by use of 'pulsed' lasers, typically of nanosecond or picosecond pulse width, whereas ions are generated continuously by ESI.

2.3.3 General features of ESI and MALDI mass spectra of peptides and proteins. MALDI predominantly produces singly charged or singly protonated ions of peptides/proteins, which is often denoted as $[\mathbf{M}+\mathbf{H}]^{+}$, where $\mathbf{M}$ is peptide or protein molecule and $\mathrm{H}^{+}$is proton bound to the molecule. Upon binding to the proton, the molecule becomes charged, which is called as 'molecular ion'. In contrast, detection of multiply protonated ions or multiply charged states is a hallmark of ESI mass spectra of peptides and proteins; multiple protonated states of peptide or protein molecular ions are denoted as $[\mathrm{M}+$ $n \mathrm{H}]^{n+}$, where ' $n$ ' can be $\geq 1$. The maximum limit for ' $n$ ', viz., the maximum number of bound protons on peptide or protein depends on the size or amino acid composition of the peptide or protein. Multiple protonation states are also detected due to MALDI of proteins, but very rarely. Thus, MALDI and ESI produce ions in the form of 'adducts', also called as 'adduct ions', wherein the charge on the protein/peptide ions are due to the protons bound on protein/peptide molecule. While both MALDI and ESI have found tremendous success for several kinds of BU proteomic studies, with regard to MD as well as TD approaches, ESI has been applied more extensively than MALDI. Since, MD approach based investigations have largely been accomplished by ESI of longer proteolytic peptides, the ESI charge states of precursor ions that are often involved in 
tandem MS (MS/MS) experiments are $4 \leq z \leq 10$. And therefore, the precursor charge states, $z=+1,+2$ and +3 are excluded from being subjected to MS/MS, which is in contrast to typical BU approach. The ESI charge states of multiply protonated peptide ions is determined from the differences in the $\mathrm{m} / \mathrm{z}$ values of the isotope peaks, for which high resolution mass analysis is essential. Fig. 5 shows the distribution of isotope peaks corresponding to four different ESI charge states, $z=+3, z=+4, z=$ +5 and $z=+6$ of the GluC peptide, [50-86] of bovine pancreatic RNase A, whose data were recorded using a hybrid quadrupole time-of-flight mass analyzer (see Fig. 2b). A constant mass difference of 0.333 observed between the $\mathrm{m} / \mathrm{z}$ values of successive isotope peaks is characteristic of charge state $z=+3$. The charge state, $z=+4$ can be known, when there is mass difference of 0.25 between the $m / z$ values of consecutive isotope peaks and the charge state $z=+5$ can be identified, if the $m / z$ values of the successive isotope peaks differ by 0.2 . It is well known that the main elements comprising peptides are carbon (C), hydrogen $(\mathrm{H})$, nitrogen $(\mathrm{N})$, oxygen $(\mathrm{O})$ and sulfur $(\mathrm{S})$. Among these, the natural abundance of ${ }^{13} \mathrm{C}$ isotope, which is $1.1 \%$, is the highest, as compared to the natural abundance of ${ }^{2} \mathrm{H},{ }^{14} \mathrm{~N}$ and ${ }^{17} \mathrm{O} .{ }^{3}$ Even though the natural abundance of ${ }^{34} \mathrm{~S}$ is $4.2 \%$ (approx.), the carbon atoms would outnumber the sulfur atoms by a large margin. And therefore, ${ }^{13} \mathrm{C}$ would be a major or significant contributor for the observation of isotope peaks in the mass spectrum of the peptides. Another important aspect is that the intensity distribution of isotope peaks would be dependent on the number of carbon $\left({ }^{12} \mathrm{C}\right)$ atoms constituting the peptide molecule, which in turn would impact the number of ${ }^{13} \mathrm{C}$ isotopes. ${ }^{161}$ In the mass spectrum of peptides of molecular masses greater than $\sim 1800 \mathrm{Da}$ or $2000 \mathrm{Da}$, the first peak in the isotope peak cluster corresponding to the +1 charge state would not be the most intense peak and this is true even for the charge states higher than +1 . This can be understood from Fig. 5, which shows the distribution of isotope peaks of four different charge states $(z=+3,+4,+5$ and +6$)$ of a GluC peptide (from bovine pancreatic RNase A), whose molecular mass is $\sim 4.2 \mathrm{kDa}$. Whereas for molecular masses less than $\sim 1700 \mathrm{Da}$ or $1800 \mathrm{Da}$, the first peak in the distribution of isotope peaks would have the highest intensity (see Fig. S1, supplementary information $\dagger$ ).

2.3.4 Mass analyzers. Mass analyzers perform the job of sorting the gas phase ions according to their mass-to-charge ratio $(\mathrm{m} / \mathrm{z})$. The mass analyzers of different types can be broadly categorized into two kinds, namely beam and trapping analyzers. The most widely used beam analyzers are quadrupole and time-of-flight (TOF). For MD approach, thus far, trapping analyzers have been more widely used such as ion trap and orbitrap ( $c f$. vide infra).

2.3.4.1 Quadrupole. Quadrupole is the one of the earliest and widely used mass analyzers consisting of four cylindrical rods, which are arranged in a parallel manner that would have
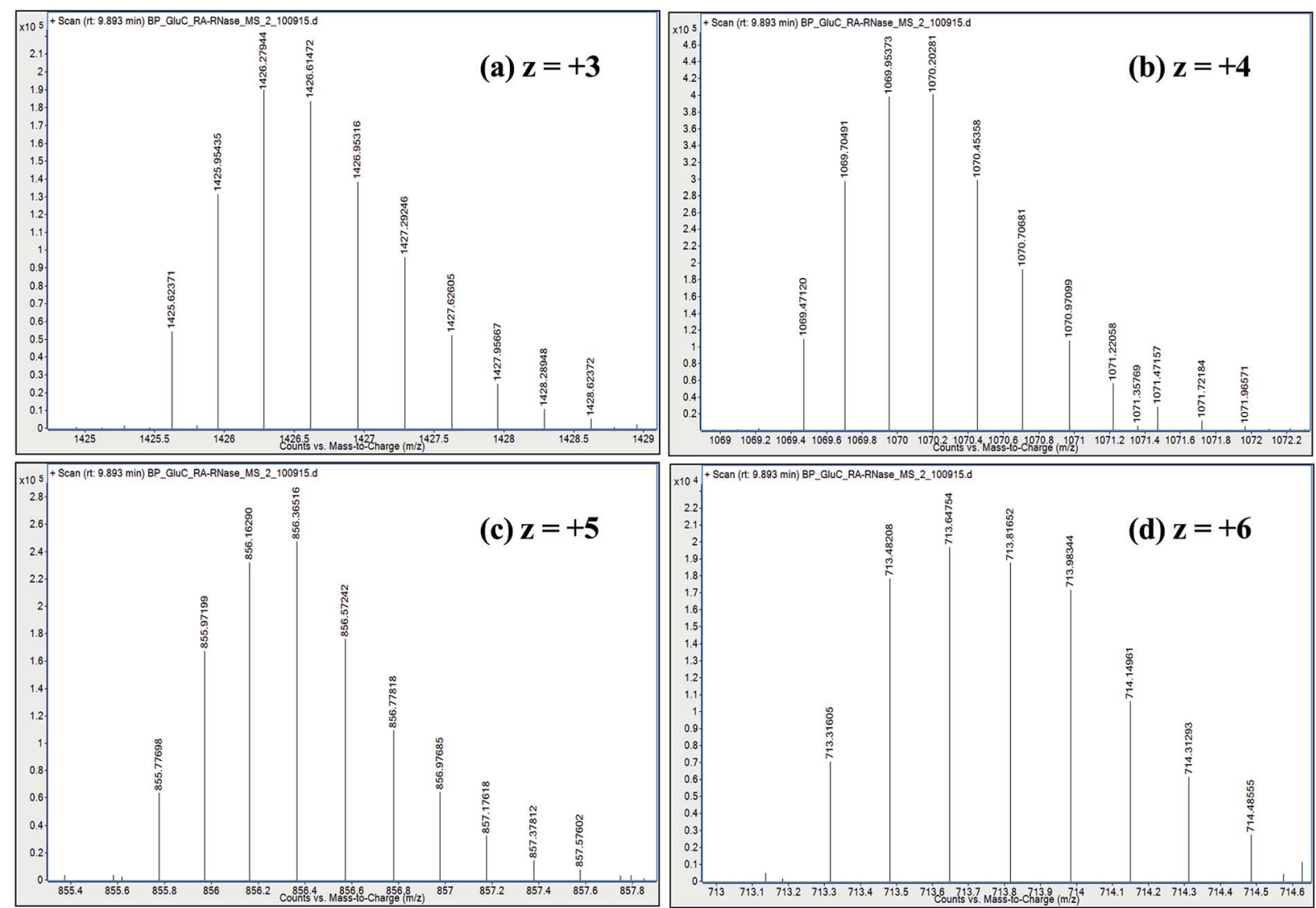

Fig. 5 Distribution of isotope peaks corresponding to charge states: $z=+3, z=+4, z=+5$ and $z=+6$, observed in ESI mass spectrum of a GluC proteolytic peptide (Residues No. [50-86], 37 a.a. residues long), zoomed-in from the spectrum shown in Fig. 2 b. 
hyperbolic cross-section. ${ }^{\mathbf{1 6 2}}$ A combination of direct current (DC) and radio frequency (RF) voltages are applied to opposing pair of rods. The ions are trapped and guided from one end to the other end of the quadrupole by suitably varying the RF and DC voltages. The stability of the ions' trajectories can be understood and manipulated through the Mathieu's stability diagram, from which it is possible to determine the optimum values of RF and DC voltages meant for a particular configuration of quadrupole. ${ }^{162}$ Thus, under certain conditions of RF and DC potentials, those ions that have 'stable' trajectories would be detected and their respective $\mathrm{m} / \mathrm{z}$ values would be measured. Those ions traversing with unstable trajectories would go undetected.

By applying apt RF and DC voltages, ions of a particular $m / z$ value can be trapped within the quadrupole and the ions of other $\mathrm{m} / \mathrm{z}$ values would not be let into the quadrupole. Therefore, quadrupole can also function as a 'mass filter', in addition to being used for conventional mass analysis or mass measurements. The virtue of the quadrupole as a 'mass filter' enables it to be applied for tandem mass spectrometry (MS/MS), whereby it is used for the purpose of precursor ion selection ( $c f$. vide infra).

Quadrupole mass analyzer mostly offers unit mass resolution. Most of the BUP studies have been carried out in quadrupole based mass spectrometers quite successfully. Thus far, only a few MD studies have been conducted in quadrupole containing spectrometers, where the quadrupole works as mass filter for precursor ion selection, while the fragment or product ions' analysis is done by high resolution mass analyzers, such as ion cyclotron resonance (ICR) and orbitrap, viz., Fourier Transform MS (FTMS). ${ }^{63,73,101,163}$

2.3.4.2 Ion trap. Ion trap is another most commonly used mass analyzer, which consists of three electrodes, where a ring electrode is placed between two end cap electrodes. ${ }^{\mathbf{1 6 2}} \mathrm{A}$ quadrupolar-like field can be produced within the ion trap by applying RF voltage to the central ring electrode only (and no potentials to the two end-cap electrodes), and this field can capture and store the ions (in millisecond timescale) within the trap. It is possible to formulate Mathieu's stability diagram for this three-electrode design of ion trap also, thereby optimum RF and DC voltages to achieve stable ion trajectories can be known. Therefore, an ion trap can function as both mass filter as well as conventional mass analyzer. ${ }^{\mathbf{1 6 2 , 1 6 4}}$ A fascinating aspect about the ion trap is that multi-dimensional tandem MS experiments, viz., $\mathrm{MS}_{2}, \mathrm{MS}_{3}, \mathrm{MS}_{4}$, etc. can be performed within this 'single' device, ${ }^{\mathbf{1 6 2 , 1 6 4 - 1 6 7}}$ which is not possible by a single quadrupole. In other words, tandem MS experiments in an ion trap are performed as a function of time (millisecond timescale). ${ }^{\mathbf{3 0}}$

While this configuration of three electrodes (Paul type) is called as 'three-dimensional (3D) ion trap', there have been attempts to build two-dimensional ion traps also based on the quadrupole (four electrode system), for example, linear ion trap (LIT) and linear trap quadrupole (LTQ). ${ }^{168-170}$ LIT or LTQ has certain advantages over the 3D ion trap, such as, better ion trapping efficiency, greater ion storage capacity and lesser space-charge effects. ${ }^{158,169}$ Further, multi-dimensional MS/MS experiments are possible to be effected in LTQ instruments also. ${ }^{169,171}$ Several MD approach based studies have been accomplished using LTQ for MS/MS experiments, which are then analyzed in mass analyzers used in FTMS: ICR ${ }^{172}$ as well as orbitrap. ${ }^{68,70,83,88,89,139}$ Among these MD studies, Fenselau's group reported about the utility of LTQ coupled to orbitrap for collision induced dissociation (CID) $\mathrm{MS} / \mathrm{MS},{ }^{\mathbf{8 8 , 8 9}}$ whereas it may be interesting to note that Jennifer Brodbelt and co-workers implemented ultraviolet photodissociation (UVPD) method in a dual linear ion trap for MS/MS experiments, by adopting a MD proteomic workflow. ${ }^{139}$ In addition, there are several MD based investigations that report on the use of electron transfer dissociation (ETD) MS/MS carried out in LTQOrbitrap. ${ }^{\text {70,71,78,81-83,99,173 }}$

2.3.4.3 Time-of-flight (TOF). In TOF, mass analysis is based on the time taken by the ions to reach the detector. The ions are pushed or accelerated into an empty hollow tube of known length, which is maintained at a high vacuum. The acceleration of ions is achieved by applying a very high voltage, e.g., about 15-20 kilovolts $(\mathrm{kV})$ and the usual length of the TOF tube would be about 1 metre. There are two different ways of operating a TOF analyzer: (1) linear mode and (2) reflectron mode. ${ }^{\mathbf{3 0 , 1 5 8}}$

In the linear mode of operation, ions traverse in the field-free region. All the ions in the analyte receive same electrical energy due to the acceleration potential and hence, those ions of lighter mass would travel at a higher velocity than the ions of heavier mass; which can be understood from the following equations:

$$
z V_{\mathrm{accl}}=\frac{1}{2} m \times v^{2}
$$

$z$ : charge of the ion; $V_{\text {accl }}$ : acceleration potential; $m$ : mass of the ion; $v$ : velocity of the ion

$$
z V_{\text {accl }}=\frac{1}{2} m_{1} \times v_{1}^{2} \text { and } z V_{\text {accl }}=\frac{1}{2} m_{2} \times v_{2}^{2}
$$

If $m_{1}<m_{2}$ and $z$ of $m_{1}=z$ of $m_{2}$, then $v_{1}>v_{2}$, because $V_{\text {accl }}$ is same (or fixed) for all the ions.

Since length of the tube is known $(L)$ and times of flight of every ion are measured experimentally, the $\mathrm{m} / \mathrm{z}$ value of every ion can be determined from the following equation:

$$
m / z=2 \times V_{\text {accl }} \times(L / t)^{2}
$$

But, operating TOF in linear mode may not offer good resolution, since the entire population of the ions of 'same $\mathrm{m} / \mathrm{z}$ value' may not reach the detector at the same time, leading to peak broadening. Consequently, masses may not be determined accurately. This problem can be overcome by following reflectron mode, where the ions are not allowed to move in field-free region. In reflector TOF, suitable electric potentials are applied to a set of electrodes that are appropriately positioned within the hollow tube and this helps to alter the trajectories of the ions of the same $\mathrm{m} / \mathrm{z}$ value; whereby the path of the slowly moving ions is adjusted to a shorter distance and the path of the faster moving ions is altered to take up a longer distance. Thus, by following reflectron mode, the 'entire population' of the 'ions 
of same $m / z$ value' could be 'focused' appropriately to reach the detector at the 'same time', thereby enabling accurate mass determination. Another method to improve mass resolution is 'delayed extraction', where the accelerating potential would be momentarily not applied for a very short duration, viz., 100 nanosecond or 500 nanosecond, just after the application of laser pulse (for desorption/ionization), which helps in better or enhanced focusing of the 'whole population' of the 'ions of same $m / z$ value' to reach the detector at the 'same time'. ${ }^{30,158}$

Not many MD investigations report the involvement of TOF based mass spectrometer, excepting a few, which have been carried out on antibodies to verify their sequences and to probe their extent of heterogeneity. ${ }^{\mathbf{1 0 4 , 1 0 5 , 1 3 3}}$

2.3.4.4 Fourier transform mass spectrometry (FTMS). Applying 'Fourier Transform (FT)' mathematical operation for mass spectrometric data processing leads to tremendous improvement in resolution, accuracy and sensitivity. ${ }^{158}$ The two mass analyzers: ICR and orbitrap, incorporate FT for data processing and consequently, these two analyzers are capable of offering high resolution, better mass accuracy and enhanced sensitivity. ${ }^{41}$ In both ICR and orbitrap, a broad range of frequencies due to ionic motions are measured and by applying FT to these measured frequencies, $m / z$ values of the ions are determined. Since MD approach involves characterization of the longer or medium-sized peptides (or polypeptides), high resolution mass analyzers are preferred and FTMS can be a technique of choice ( $c f$. vide infra).

2.3.4.5 Fourier transform-ion cyclotron resonance (FT-ICR). Ion cyclotron resonance (ICR) is the first mass spectrometric technique to which FT was applied and therefore, it is customary to refer this as FT-ICR-MS. ${ }^{174,175}$ In FT-ICR, ions are analyzed by applying both magnetic field and RF (alternating current: AC) voltage. The measurement of $\mathrm{m} / \mathrm{z}$ values of ions is based on their rotational frequencies in the presence of magnetic field, i.e., cyclotron frequencies. Each ion would have its own characteristic cyclotron frequency depending on its $\mathrm{m} / \mathrm{z}$ value (see eqn (4)). In other words, ions of higher $\mathrm{m} / \mathrm{z}$ values would traverse the circular path with lower cyclotron frequencies and vice versa.

$$
m / z=B / 2 \pi f
$$

$B$ : magnetic field intensity; $f$ : cyclotron frequency.

It is important to note that the determination of $m / z$ value is dependent only on the cyclotron frequency (angular velocity) and independent of the linear velocity of the ion.

When the frequency of RF or AC voltage (electromagnetic wave; which would be applied orthogonal to the direction of magnetic field), suitably matches with the cyclotron frequency of the ions, a condition of 'resonance excitation' is achieved. Such resonantly excited ions would then move in a circular path of a larger radius. Thus, by resonant excitation, the circular trajectories corresponding to ions of every $\mathrm{m} / \mathrm{z}$ value are brought closer to the detection plates and the signals are detected in the form of 'image currents'. These signals encompass a broad range of various cyclotron frequencies and hence, such a dataset would need to be deconvoluted by applying FT. Subsequently, the mass spectrum is plotted utilizing the cyclotron frequency values.

There are certain technical difficulties for online coupling of LC to FT-ICR-MS. ${ }^{176}$ Although, a few studies on the application of online LC-FT-ICR-MS are reported, there are not many investigations on its utility to proteomics. Nevertheless, FT-ICRMS has been well applied for TD investigations of proteins, where the samples have been introduced into the ICR by means of direct infusion (viz., offline nanoESI). ${ }^{177,178}$

2.3.4.6 Orbitrap. ${ }^{179}$ Orbitrap is another high resolution mass analyzer that utilizes FT for data processing. It consists of two outer barrel-like electrodes, which are co-axial with an inner spindle shaped electrode. ${ }^{\mathbf{4 0 , 1 8 0}}$ A special aspect about orbitrap is that it utilizes only electrostatic fields to trap ions for $\mathrm{m} / \mathrm{z}$ measurements. The ions not only orbit around the central spindle shaped electrode, but also oscillate in the axial direction. The frequencies of such axial oscillatory motions are recorded as image currents and these frequencies are then deconvoluted by applying FT, in a manner similar to FT-ICR. The frequency of the oscillation depends on the $\mathrm{m} / \mathrm{z}$ value of the ion and it is proportional to $(\mathrm{m} / \mathrm{z})^{-1 / 2}$.

Orbitrap was first commercialized by coupling it with LTQ (Thermo) and subsequently, different ionization modes such as ESI and MALDI have been combined with orbitrap for high resolution mass analysis, ${ }^{\mathbf{4 1}}$ thereby orbitrap found numerous applications in proteomics. ${ }^{\mathbf{1 8 1 - 1 8 3}}$ And there are a good number of MD proteomic approach based studies reporting the utility of orbitrap, since MD investigations demand high mass resolution (cf. vide infra).

2.3.5 Hybrid instruments. Hybrid mass spectrometers are instruments, which are designed by combining two or three analyzers to achieve better performance and a most important objective to design and build such instruments is, to carry out diverse kinds of tandem MS experiments by incorporating different ion dissociation/activation methods. With the evolvement of hybrid mass spectrometers, greater degree of success has been accomplished in several fields of investigations, including proteomics. Some examples of hybrid mass spectrometers are triple or tandem quadrupole, quadrupoleTOF (Q-TOF or Q/TOF), TOF-TOF (or TOF/TOF), LTQorbitrap, LTQ-FT-ICR-MS and quadrupole-FT-ICR-MS. Thus far, most of MD approach based proteomic studies have utilized LTQ-orbitrap. ${ }^{65,69-71,78,81-83,90,92,99,102,138,184}$ Certain MDP investigations have been performed using Orbitrap-Fusion instrument. ${ }^{64,67,68,77,79,85,91,139}$ Additionally, a few MD studies have been carried out using the hybrid LTQ-FT-ICR-MS also. $^{75,84,185,186}$

\subsection{Tandem mass spectrometry (MS/MS)}

MS/MS occupies a very important position not only in proteomics, but in several other studies that involve structure elucidation process of different types of molecules. In fact, MS/MS is now indispensable for any kind of proteomic studies. The three key steps in any MS/MS experiment are: (1) selection or isolation of precursor ion, (2) activation or fragmentation of the isolated 
precursor ion, leading to the formation of fragment ions or product ions and (3) detection and plotting mass spectrum of product ions, which is called as MS/MS spectrum. The first step, which is the isolation of precursor ion is mostly accomplished by quadrupole, which is capable of functioning as a mass filter; ion traps are also used for precursor ion isolation. Various methods have been developed to carry out the second step, viz., for effecting fragmentation of molecular ions (i.e. precursor ion), among which collision induced dissociation (CID) method has found tremendous applications..$^{31,32,187}$ CID can be carried out in a quadrupole or a hexapole or an ion trap (linear as well as three-dimensional) or in an ICR cell.

The process of CID involves kinetic excitation of the selected precursor molecular ions that are allowed to collide with neutral inert gas, referred as 'collision gas', such as helium (He), nitrogen $\left(\mathrm{N}_{2}\right)$ and argon (Ar). Zero grade air is also used for CID, but in selected instruments only. As a result of inelastic collisions with the neutral inert gas (atoms or molecules), the precursor ions begin to dissociate, which may become observable beyond a certain threshold value of the kinetic energy. In other words, when the amount of energy that is applied for kinetic excitation exceeds the internal energy of the precursor ion, the precursor ion starts to fragment. Thus, by suitably altering the kinetic energy that is deposited on the precursor ion for its excitation, which can also be referred as 'collision energy', it would be possible to effect complete dissociation of the entire structure of the precursor ion, giving rise to fragment ions or product ions. The degree of dissociation of the isolated precursor ion is also dependent on the property of its molecular structure, meaning certain chemical bonds of the precursor molecular ion would readily dissociate, whereas certain bonds would be refractory towards dissociation, at a particular value of collision energy. In other words, a specific value of collision energy would cause vibrational excitation of only a few selected chemical bonds in the precursor molecular ion, while some other chemical bonds would be vibrationally excited at a different or higher collision energy values. Thus, when the energy of the collision (that takes place between the neutral gas atoms/molecules and the precursor ion) exceeds the energy of the chemical bond(s) (viz., bond energy) in the precursor molecular ion, fragment ions or product ions are produced. Dissociation of different chemical bonds results in the generation of fragment ions of different sizes, i.e., different $m / z$ values. Consequently, the $\mathrm{m} / \mathrm{z}$ values of the product ion peaks in CID MS/MS spectrum are useful to elucidate or to ascertain the molecular structure. Not only collision energy, the extent of fragmentation can also be varied or optimized by adjusting the collision gas pressure, whereby the number of collisional events occurring between the neutral gas atoms/molecules and the precursor ions can be controlled. But, in some instruments, the option of changing the collision gas pressure may not be available, as the manufacturers preset or fix the pressure of the collision gas at a particular value and would permit the endusers for optimization of collision energy only. Another vital factor that severely impacts the extent of the precursor ion's fragmentation is, the charge state or protonation state, viz., the number of protons (or charges) appended on the precursor ion and this is true in many cases, when CID is carried out with ESI. In this regard, precursor ion of higher charge state would tend to undergo better fragmentation than the lower charge state of the precursor ion.

Further, MS/MS data can be acquired by two different modes: (1) data dependent acquisition (DDA) ${ }^{71,75,82}$ and (2) data independent acquisition (DIA). ${ }^{79}$ DDA relies on the ionic intensities or abundances of the precursor ions for MS/MS data acquisitions, whereby a few 'topmost intense' precursor ions are only selected for activation or fragmentation. In contrast, when all the ions, irrespective of their relative abundances are subjected to fragmentation, it is called as data independent acquisition, which means MS/MS data are acquired independent of the intensity or abundance of the precursor ions. So, in DIA process, all those ions that successfully reach the mass analyzer from the source would be precursor ions, whereas by DDA mode, MS/MS fragmentation process is allowed to take place solely on a selected number of ions and the criterion to choose a narrow range of precursor ions for MS/MS is based on their ionic intensities.

2.4.1 CID of peptide and protein molecular ions. In the case of peptide molecular ions, it has been widely found that the CID method predominantly causes cleavage of the backbone amide or peptide bond, yielding b- and y-type ions (see Scheme $4) ;^{\text {188-190 }}$ this has been observed quite well under several different instrumental conditions and with various types of peptide structures. ${ }^{187,191}$ In other words, CID MS/MS can be accomplished under both MALDI and ESI conditions, meaning that CID can be performed on singly as well as multiply charged precursor ions, involving different kinds of analyzers such as quadrupole, ion trap, time-of-flight and ICR cell. Consequently, it became possible to extend the application of CID for 'omics' kind of investigations (viz., for high-throughput applications), for which algorithms to build various database search engines were developed on the basis of the calculation of $m / z$ values of $\mathbf{b}$ and y-type ions from proteolytic peptide sequences derived from proteins, for e.g., Mascot, SEQUEST, OMSSA, etc. ${ }^{32}$ Thus, CID MS/MS method proved to be a strong foundation for facilitating high-throughput peptide based proteins' identification, thereby enabled to establish the so-called 'bottom-up or shotgun proteomics' field. ${ }^{\mathbf{3 2 , 4 9 , 1 4 2 , 1 8 7}}$ Eventually, by suitable experimental design, CID was successfully put to use even for quantification studies, the famous instance being 'isobaric tags for relative and absolute quantitation (iTRAQ)', which is done through BU approach. ${ }^{192-194}$ While it would not be possible to distinguish the iTRAQ labeled proteolytic peptides by conventional MS, it is the intensity values of the reporter ions released from iTRAQ labelled proteolytic peptides due to CID MS/MS, aids in the quantification process. Thus, iTRAQ is a MS/MS based quantitation method primarily involving CID and has been applied in many cases with reasonable degree of success, including for clinical research mainly to understand mechanisms of diseases such as cancers, neurodegenerative disorders e.g., Alzheimer's and Parkinson's disease. ${ }^{195-197}$

2.4.2 Radical mediated (electron based) dissociation of peptide and protein molecular ions. CID has been experimented for TD studies of proteins also, ${ }^{\mathbf{5 4 , 1 8 7}}$ but it has not been 
<smiles>[R]CNC(=O)C([R2])NC(=O)C([R])N</smiles>

Collision Induced Dissociation (CID) $b / y$ ions<smiles>[R3]C(C#[O+])NC(=O)C([R2])NC(=O)C([R])N</smiles>

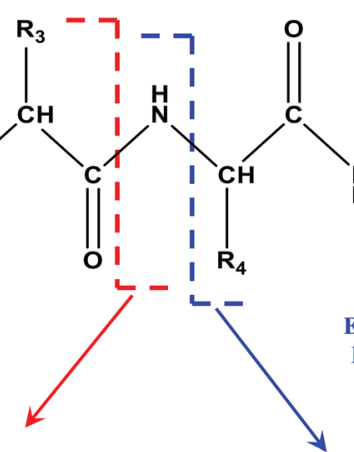<smiles>[R6]C(NC(=O)C([R5])NC)C(=O)O</smiles>

Electron Transfer Dissociation (ETD)/ Electron Capture Dissociation (ECD) $c / z$ ions<smiles>[R]C(N)C(=O)NC([R2])C(=O)NC([R3])C(=N)O</smiles><smiles>[R]C([NH3+])C(=O)NC([R5])C(=O)NC([R6])C(=O)O</smiles><smiles>[R]CC(=O)NC([R3])C(=O)N[C@@H]([R6])C(=O)O</smiles>

Scheme 4 Representative fragmentation pattern of a hexapeptide due to CID and ECD/ETD MS/MS. Molecular structure of different types of product/fragment ions resulting from CID and ECD/ETD MS/MS. In the case of MALDI, the charge state $(n+)$ on the peptide is $n=1$ and for ESI, $n$ $\geq 1$. In the case of ESI, higher values of $n$ are possible, depending on the length and nature of amino acid residues constituting the peptide/ protein. ECD and ETD MS/MS are not possible with MALDI, when $n=1$.

very fruitful, as compared to its success level for bottom-up/ shotgun proteomic investigations. As a result, there were attempts to develop innovative methods for fragmenting protein or peptide molecular ions in gas phase, under different instrumental conditions. Among various kinds of efforts, the advent of 'electron capture dissociation (ECD)' proved to be a crucial turning point, as it could be applied to decipher the primary structure, viz., sequence of intact protein. ${ }^{98}$ Thus, ECD could be applicable for TD characterization of proteins. ${ }^{199}$

In fact, ECD was observed serendipitously for the first time by Zubarev and Kelleher in McLafferty's research lab. ${ }^{33}$ An interesting aspect is that ECD of multiply protonated proteins or peptides would predominantly yield c- and z-type ions, viz., $\mathrm{c}^{\prime}$ and $\mathrm{z}^{\bullet}$ ions (see Scheme 4), which arise from radical mediated cleavage process of the backbone $\mathrm{N}-\mathrm{C}^{\alpha}$ bonds. ${ }^{33}$ Hence, the information obtained from ECD is complementary to that of CID. Despite its suitability for TD analysis of proteins, ECD could be performed in ICR mass spectrometer only. ${ }^{35}$ As a consequence, research attempts began in order to accomplish ECD like process in ion trap or quadrupole, which are not suitable analyzers to trap or store electrons. Eventually, such attempts paved way for the creation of a new MS/MS method called 'electron transfer dissociation (ETD)', which is actually an ion-ion reaction that is allowed to take place between an anion or radical anion (anthracene or fluoranthene) and the protonated protein/peptide precursor, within a quadrupole or two-dimensional or three-dimensional ion trap. ${ }^{35,200-202}$ Under such reaction conditions, the anion or radical anion is the source of electron, which upon transferring to the protonated peptide/protein precursor results in the formation of 'unstable' radical cationic species of peptide/protein precursor that undergo dissociation. Intriguingly, the process of ETD too yields c- and z-type of ions, again attributed to the radical mediated cleavage process of backbone $\mathrm{N}-\mathrm{C}^{\alpha}$ bonds of peptides/proteins (see Scheme 4).$^{35}$ It is important to realize that ECD and ETD can be carried out on multiply charged precursors only, viz., minimum prerequisite to carry out ECD or ETD is doubly protonated precursors: $[\mathrm{M}+n \mathrm{H}]^{n+}, n \geq 2$. Since, ETD could be accomplished in ion traps itself there was a rapid progress in applying ETD MS/MS for proteomics. Prior to applying for proteomics, the efficacy of ETD was evaluated in certain BU approach based model cases and it was observed that significantly greater number of tryptic or LysC or LysN peptides were identified by ETD MS/MS than CID MS/MS, whereby a larger proportion of these identifications were from the precursor charge state, $+3 \leq z \leq+5 .{ }^{203,204}$ Moreover, unlike CID MS/MS, the primary structure (viz. sequence) of peptides would not drastically influence the extent of fragmentation by ETD (BU approach) and hence, a better sequence coverage was obtainable from ETD of peptides than CID MS/MS, in BU 
approach based studies. ${ }^{35,203,205}$ Another virtue of ETD MS/MS was that it could be utilized to identify PTMs and consequently, the application of ETD particularly for phosphoproteomics proved to be beneficial. ${ }^{35,206-213}$ Additionally, ETD has been of use to elucidate glycosylated modified sites on proteins and peptides. ${ }^{\mathbf{2 1 4 - 2 1 6}}$ Because MD approach principally focuses on the longer proteolytic peptides, ETD (or ECD) based MS/MS were the most sought method(s) of choice, which not only aided in yielding better sequence coverage, but also useful for PTM identifications (see Table 4).

Another important aspect about ETD is the application of supplemental collisional activation concurrent with ETD, which was referred as ETcaD. ${ }^{217}$ ETcaD method was developed to specifically fragment the intact or undissociated 'electron transferred (ET)' product (radical) species produced from the doubly protonated $[\mathrm{M}+2 \mathrm{H}]^{2+}$ tryptic peptide precursor ions. Although, ETcaD enabled in enhancing the sequence coverage better than that was observed from ETD alone or CID, it also triggered the process of hydrogen atom (radical), viz., $\mathrm{H}^{\bullet}$ migration, which was observed preponderantly with the $[\mathrm{M}+$ $2 \mathrm{H}]^{2+}$ tryptic peptide precursors, during the course of ETcaD. Such a kind of $\mathrm{H}^{\bullet}$ migration resulted in the formation of oddelectron $c^{\bullet}(c-1)$ and even-electron $z^{\prime}(z+1)$ fragment ions, which were often detected besides the usually observed evenelectron $\mathrm{c}^{\prime}$ and odd-electron $\mathrm{z}^{\bullet}$ ions in the ETD MS/MS spectrum of $[\mathrm{M}+2 \mathrm{H}]^{2+}$ tryptic peptide precursors. ${ }^{217}$ However, the extent of $\mathrm{H}^{\bullet}$ migration was observed to be less pronounced, when ETcaD was carried out over the triply and other higher charge states of the proteolytic peptide ions. ${ }^{\mathbf{2 0 4 , 2 1 8}}$ Consequently, most of the ETD MS/MS experiments are performed by applying supplemental collisional activation on an appropriate charge state of the precursor ion. It is important to note that such a ETcaD process, when carried out in Paul-type (3-dimensional) ion trap (Bruker Daltonics), it is called as 'Smart Decomposition', ${ }^{218,219}$ whereas when the supplemental activation is applied by means of higher energy collision dissociation (HCD; Thermo Scientific), then it is referred as EThcD. ${ }^{\mathbf{2 1 0 , 2 1 6}}$ Over a period of time, instruments became available that had the option to vary even the collision energy corresponding to the supplemental activation, which is applied during the process of ETD; for instance, Yang et al. had applied $20 \%$ of supplemental activation energy for EThcD, whereas Cristobal et al. used $40 \%$ supplemental activation energy for their EThcD experiments (also see Table 4). ${ }^{64,85,91}$

In the case of ECD also, supplemental activation has been applied through different procedures such as increasing temperature of the ICR cell, ${ }^{220}$ by infrared (IR) irradiation ${ }^{221}$ or by in-beam collision activation with a background gas $\left(\mathrm{N}_{2}\right){ }^{222}$ These activation methods were devised in order to aid in disrupting the probable non-covalent interactions that may not allow the release of the backbone dissociated c-type and z-type ions. ${ }^{220,222}$ Such activation processes have helped in improving the yield of c-type and z-type of ions, thereby facilitating enhancement of the sequence coverage, ${ }^{221,222}$ but additionally, even-electron $\mathrm{z}^{\prime}(\mathrm{z}+1)$ and odd-electron $\mathrm{c}^{\bullet}(\mathrm{c}-1)$ fragment ions too are observed under the activated conditions, indicative of hydrogen atom or $\mathrm{H}^{\bullet}$ migration..$^{220,221}$ In fact, hydrogen atom
$\left(\mathrm{H}^{\bullet}\right)$ transfer has been a commonly occurring process giving rise to even-electron $z^{\prime}(z+1)$ and odd-electron $c^{\bullet}(c-1)$ fragment ions, even under normal conditions of ECD without application of any kind of activation, as evidenced from the ECD MS/MS data of 15000 tryptic peptides, acquired from their respective $[\mathrm{M}+2 \mathrm{H}]^{2+}$ precursors. ${ }^{223}$ Tsybin et al., have reported decreased ratio of population of $\left(\mathrm{c}^{\bullet} / \mathrm{c}^{\prime}\right)$ and increased ratio of abundance of $\left(\mathrm{z}^{\bullet} / \mathrm{z}^{\prime}\right)$, by applying IR radiation (vibrational excitation) prior to the ECD process. ${ }^{224}$

Overall, the above described details pertaining to ECD and ETD illustrate the significance of charge state of the precursor ion, in impacting the extent of fragmentation by ECD or ETD, so as to obtain better sequence coverage unambiguously. Table 4 summarizes various methods of chromatography and MS/MS (viz., online LC-MS/MS) that have been carried out on different instruments for MD investigations on different biological samples. Extensive applications of ETD and ECD MS/MS for MD approach based studies on a variety of biological systems are evident from Table 4.

2.4.3 Photodissociation of peptide and protein molecular ions. ${ }^{32}$ Light, i.e., application of electromagnetic radiation also has been exploited quite well for effecting dissociation of peptide and protein ions. Ultraviolet (UV) as well as infrared (IR) radiations have been utilized for this purpose, involving application of different types of lasers. For example, carbon-dioxide $\left(\mathrm{CO}_{2}\right)$ laser (wavelength $\left.(\lambda): 10.6 \mu \mathrm{m}\right)$ has been used for IR radiation, ${ }^{175}$ whereas for applying UV radiation, excimer lasers, e.g. , $\mathrm{F}_{2}$ excimer ( $\left.\lambda: 157 \mathrm{~nm}\right)$ or XeF excimer $(\lambda: 351 \mathrm{~nm})$ or Nd:YAG laser ( $\lambda: 266 \mathrm{~nm}$ or $355 \mathrm{~nm}$ ) have been employed. Because IR is less energetic than UV, several photons of IR are required, when compared to $\mathrm{UV}$, in order to cause dissociation. Therefore, the MS/MS method achieved by use of IR radiation, is called as infrared multiphoton dissociation (IRMPD), ${ }^{175}$ which has been implemented in FT-ICR, TOF as well as ion trap based mass spectrometers. ${ }^{25}$ IRMPD of peptide ions result in the formation of $b$ - and $y$-type ions, analogous to the output obtained from CID of peptide ions, ${ }^{225}$ whereas ultraviolet photodissociation (UVPD) leads to all possible backbone fragmentation of peptide ions, giving rise to a, b, c, x, y and $\mathrm{z}$ type ions. ${ }^{32}$ UVPD by $193 \mathrm{~nm}$ wavelength has been fruitful and more applicable than the other wavelengths in the UV range. Another remarkable feature of UVPD is that better sequence information was possible to be obtained from UVPD of the 'negatively charged' peptide precursors. ${ }^{225}$ Very recently, there have been a few reports describing about the application of UVPD for MD based workflow, which provide encouraging hints for a brighter and wider applications of UVPD for MD proteomics. ${ }^{\mathbf{1 3 9 , 2 2 6}}$

\subsection{Data analysis \& database search engines: computational methods}

2.5.1 Bottom-up proteomics. Any kind of Omics related research would involve acquisitions of huge number of data files, since such investigations are typically high-throughput in nature involving numerous and diverse samples. Therefore, computational strategies are essential for the purpose of 
Table 4 Application of different types of chromatography and high resolution mass analyzers (FTMS) for MD approach or MD based proteomics

\begin{tabular}{|c|c|c|c|c|c|}
\hline \multirow[b]{2}{*}{ S. no } & \multirow[b]{2}{*}{ Chromatography $^{a}$ (for online LC-MS/MS) } & \multicolumn{2}{|c|}{$\begin{array}{l}\text { LTQ-Orbitrap: } \\
\text { MS/MS methods }\end{array}$} & \multirow[b]{2}{*}{ Samples } & \multirow[b]{2}{*}{ References } \\
\hline & & CID or HCD & ETD & & \\
\hline 1 & RPLC (C8) & CID & - & Ubiquitin & 65 \\
\hline 2 & $\operatorname{RPLC}^{a}(\mathrm{C} 8) \&$ WCX-HILIC & - & ETD & HeLa S3 cells ${ }^{d}$ & 92 \\
\hline 3 & RPLC (C18) & CID & - & MCF 7 breast cells & 88 \\
\hline 6 & RPLC (Phenyl) & - & - & Monoclonal antibody & 102 \\
\hline 7 & $\operatorname{RPLC}^{a}(\mathrm{C} 18) \&$ WCX-HILIC & - & ETD & Mouse embryonic stem cells (ESC) ${ }^{d}$ & 184 \\
\hline 8 & RPLC (C4) & - & ETD & Monoclonal antibodies & 70 \\
\hline 9 & RPLC (C18)-WCX-HILIC ${ }^{b}$ & - & ETD & Mouse $\operatorname{ESC}^{d}$ & 76 \\
\hline 10 & $\operatorname{RPLC}^{a}(\mathrm{C} 18) \&$ WCX-HILIC & - & ETD & Histones $^{d}$ & 81 \\
\hline 11 & $\mathrm{SEC}^{a} \& \operatorname{RPLC}(\mathrm{C} 4)$ & - & - & Mustard allergen & 138 \\
\hline 16 & RPLC (C5) & - & ETD & Monoclonal antibodies & 99 \\
\hline 17 & RPLC (C8) & $\mathrm{CID} / \mathrm{HCD}$ & ETD & Monoclonal antibodies & 71 \\
\hline 18 & RPLC (C8) & HCD & - & Model proteins (e.g. enolase, RNase A, lysozyme, etc.) & 90 \\
\hline
\end{tabular}

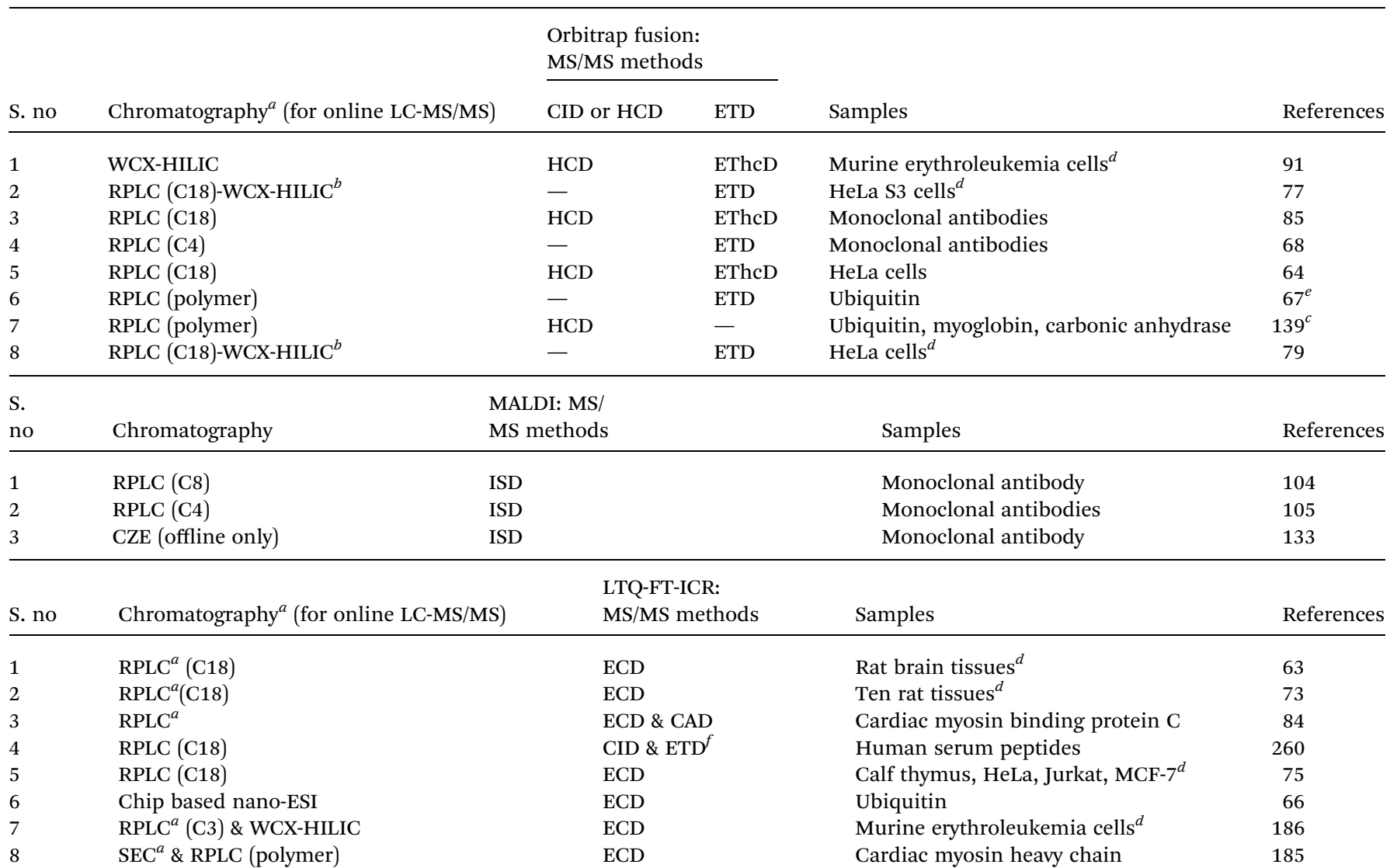

${ }^{a}$ Offline chromatographic methods used for fraction collection prior to LC-MS. ${ }^{b}$ RPLC (C18) used as smaller trap column prior to WCX-HILIC.

${ }^{c}$ UVPD. ${ }^{d}$ Studies on histones. ${ }^{e}$ Supplemented by collision induced decay (CID) using a collision energy of $10 \% .{ }^{f}$ Q-FTICR.

handling, processing and analyzing vast sets of data. With respect to proteomics, several computational tools have been developed to process and analyze mass spectrometric data, especially MS/MS data, for the purpose of identification of proteins. The two key aspects that facilitate analysis of proteomic datasets are 'databases', primarily 'sequence databases' and 'database search engines'. ${ }^{227,228}$ The algorithm for database search engine is devised based on the design or structural 
framework of the database and accordingly, various computational methods are followed. Most of the database search engines have been designed and built primarily for BU proteomics and particularly for analyzing LC-MS/MS data. Many search engines are capable of analyzing MALDI-MS/MS data as well. Although most of the search engines meant for BU proteomics have been designed to interrogate the two widely known databases: Uniprot $\mathrm{KB}$ and NCBI, considerable efforts have been devoted to construct databases suited for certain specific purposes or applications, viz., customized databases, for example, plasma proteome database, ${ }^{229,230}$ plant proteome database (http://ppdb.tc.cornell.edu/), etc. Mascot, ${ }^{231}$ Sequest, ${ }^{232}$ PEAKS, ${ }^{233}$ OMSSA, ${ }^{234}$ PRIDE, ${ }^{235}$ X!Tandem ${ }^{236}$ (see Scheme 5) are some popular database search algorithms, among which, Mascot and Sequest have found extensive applications for protein identifications through BU approach. Some of these search engines are also freely available, which are opensourced, for instance, PRIDE, OMSSA, OpenMS, ${ }^{237}$ TransProteomic Pipeline. ${ }^{238}$

Additionally, certain special computational software packages have been developed for the purpose of 'quantification' of peptides in BU proteomics, such as, MaxQuant, ${ }^{239,240}$ Skyline, ${ }^{\mathbf{2 4 1 , 2 4 2}}$ Census, ${ }^{243}$ etc. While several of these software programs meant for quantification are commercial that are license-protected, a good number of open-sourced software programs are also freely available. ${ }^{244}$

Peptide-based protein identification by BU approach can also been performed by means of matching with the MS/MS spectral library that have been catalogued from the experimental data. ${ }^{245}$ This approach can be more reliable for identifying peptides and proteins than the typical search method based on sequence databases, since the intensities of peptide fragment ions (i.e., b-ions and y-ions, obtained by CID MS/MS) in the MS/MS spectrum are also taken into account during the process of matching with the MS/MS spectrum library. ${ }^{\mathbf{2 4 6 , 2 4 7}}$
2.5.2 Top-down proteomics. Significant advances have also been made for the development of database search engines and softwares to analyze TD mass spectrometric data acquired on intact proteins. Two major processes that form the basis for the analysis of TD mass spectral data are 'deconvolution' and 'deisotoping', since most of the TD studies involve ESI of intact proteins. ESI of intact protein produces multiply charged species and through the process of deconvolution, the $\mathrm{m} / \mathrm{z}$ values corresponding to such multiply charged species are transformed to its respective neutral monoisotopic mass (or singly charged monoisotopic $\mathrm{m} / \mathrm{z}$ value) of the precursor. On the other hand, the process of deisotoping is important and essential, when two or more co-eluting intact proteins (viz., mixture of proteins) having very closely differing molecular masses are analyzed by ESI. Under this circumstance, the isotope peaks corresponding to multiply charged species of one protein would overlap with isotope peaks of another. Such overlaps of isotope peaks are separated by deisotoping process and thereby the intact molecular mass of the individual protein precursor within the co-eluting population is determined. It needs to be realized that the deconvolution and deisotoping methods must also be applied to the MS/MS spectra of proteins, which would contain multiply charged fragment ions, for e.g., $\left[\mathrm{b}_{65}\right]^{8+},\left[\mathrm{y}_{43}\right]^{6+},\left[\mathrm{c}_{79}\right]^{10+},\left[\mathrm{z}_{83}\right]^{14+}$ etc., since multiply protonated species of intact proteins are selected as precursors that are subjected to MS/MS methods.

When TD proteomic experiments are carried out by involving offline direct infusion mode of sample introduction, mixture of proteins would be simultaneously introduced into FT-ICR mass spectrometer, which would result in spectra containing isotope peaks of many proteins overlapping with one another. Hence, both deisotoping as well as deconvolution processes are required to analyze such convoluted data. In order to decrease the complexity of the mixture and introduce only simple mixtures (that would contain three or four proteins) into FT-ICR mass spectrometer, pre-fractionation or chromatographic steps

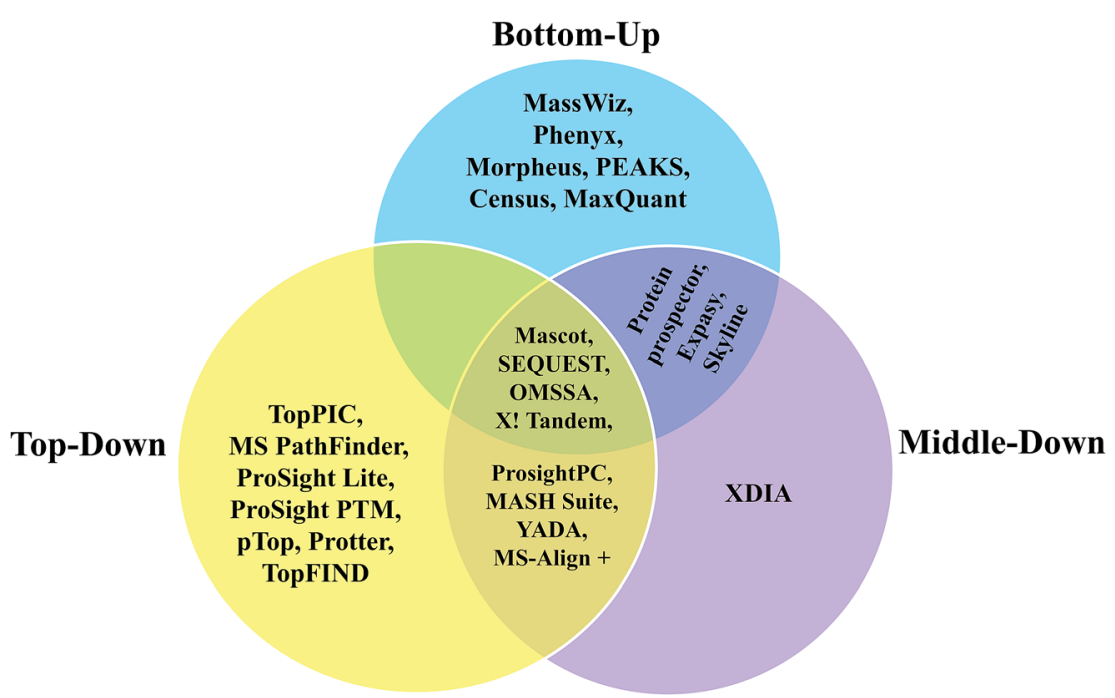

Scheme 5 Venn diagram representation of various computational tools used for each of the three different proteomic approaches. The tools shown within the category of TD approach are available at https://www.topdownproteomics.org/resources/software/. 
are necessary prior to performing offline direct infusion ${ }^{\mathbf{6 1}}$ or by LC-MS mode, so that deisotoping can be performed on the data acquired from a simple mixture in a relatively easier manner. For example, anion exchange chromatography has been applied preceding the online reverse phase LC-FT-ICR-MS for the TD proteomic analysis of Shewanella oneidensis MR-1 and Saccharomyces cerevisiae..$^{\mathbf{5 8 , 2 4 8}}$ In the case of Shewanella oneidensis MR1, THRASH algorithm ${ }^{249}$ was used to process and analyze the TD mass spectral data, whereas ProSightPC and ProSight PTM ${ }^{250}$ were utilized for analyzing the TD data acquired on yeast. The deconvolution and deisotoping processes are incorporated within the THRASH algorithm and ProSight PTM. Another key aspect about TD approach is identification of PTMs, which are given importance in database search engines and in the relevant software. $^{251}$ Not only PTMs, but also proteoforms (isoforms) can be detected by TD approach and suitable software tools have been developed to analyze TD mass spectral data for the purpose of identifying proteoforms. ${ }^{251-253}$ LC-MS based TD proteomics has been performed with the orbitrap as well ${ }^{62,254,255}$ and different computational strategies mentioned above have been adapted to analyze the TD mass spectral or proteomic data arising from orbitrap too. In a recently published study, a new standalone software called VisioProt-MS was reported, which provides a 2D LC-MS map representation by taking-up LC-MS data of TD studies. ${ }^{256}$ Further, VisioProt-MS can take-up data from different types of instrument configurations, e.g., FT-ICR, orbitrap, Q-TOF and therefore, aids in better comparison of the TD LC-MS data.

2.5.3 Middle-down proteomics. Not only TD proteomic data, but for the analysis of MD proteomic data also, deconvolution of MS/MS spectra is an important fundamental step, since much of the MS/MS data in MD proteomic investigations are based on ESI, rather than MALDI. As already discussed previously (vide supra, Section 2.3.3), detection of multiply protonated or charged ions is characteristic of ESI. Therefore, in MDP studies, MS/MS data are predominantly acquired over multiply protonated viz., $[\mathrm{M}+n \mathrm{H}]^{n+}$ proteolytic peptides, where 3 or $4 \leq n \leq 9$ or 10 . As a result, such MS/MS spectra consists of peaks due to multiply charged peptide fragment ions, for e.g., $\left[\mathrm{b}_{35}\right]^{4+},\left[\mathrm{y}_{17}\right]^{3+},\left[\mathrm{c}_{21}\right]^{3+},\left[\mathrm{z}_{38}\right]^{4+}$ etc. Thus, 'deconvolution' of MS/MS spectra is inevitable, prior to begin the interpretation of those spectra towards elucidation of sequence. The major process in deconvolution of MS/MS spectrum is to determine the $m / z$ value of singly charged fragment ion corresponding to the detected or observed $\mathrm{m} / \mathrm{z}$ value of the multiply charged fragment ion, for e.g., if $\left[\mathrm{b}_{35}\right]^{4+}=412.2014$, then $\left[\mathrm{b}_{35}\right]^{+}=1645.7821$. The charge state of the precursor ion as well as of the fragment ions can be determined from the respective isotope peak $\mathrm{m} / \mathrm{z}$ values, for which high-resolution mass analyzer is essential; in other words, MS/MS spectral data acquisitions must be accomplished in a high-resolution mass analyzer. In a manner similar to the TD approach, all of the MDP related studies have indeed been accomplished using high-resolution mass analyzers, where most of those have involved the use of FTMS (either ICR-MS or orbitrap) (see Section 2.3.4).

Since, most of the MD proteomic investigations have been performed over histones, efforts have been focused to create software tool to analyze data recorded on histones, namely 'isoScale' and 'Histone Coder' that are available in the site https://middle-down.github.io. ${ }^{76-80,82,173}$ Skyline software also has been utilized for quantifying histones, which were characterized by MD approach. ${ }^{\mathbf{1 8 6}}$ Other software, such as ProsightPC and MASH-Suite, which were primarily developed for analysis of TD proteomic data, have also been applied well for the purpose of analyzing MD proteomic data. ${ }^{66,67,70,88,89,99,172,185}$ Algorithms to process the raw data of MDP for the purpose of deconvolution are, Xtract, THRASH ${ }^{249}$ and MS-Deconv. ${ }^{75,91,257}$ Among these, Xtract and THRASH algorithms have been used mostly to analyze FT-MS data of longer proteolytic

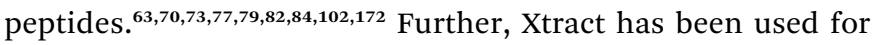
the deconvolution of mass spectra obtained from N-terminal tails of histones, which were extracted from HeLa cells and Caenorhabditis elegans embryos for the detection of PTMs. ${ }^{79,173}$ Based on Xtract algorithm, an application software, called cRAWler 2.0 (Thermo Fisher Scientific, San Jose, CA) was useful to process LC-MS/MS data (Thermo Scientific raw data files). ${ }^{172}$ cRAWler has also been used using THRASH algorithm for the purpose of deconvolution. ${ }^{88}$ YADA is another software tool developed for deisotoping and decharging (deconvolution), which was applied on ProLuCID and DTASelect to analyze large-scale MDP data. ${ }^{258}$ XDIA is a computational strategy meant to exclusively analyze ETD MS/MS spectra for MDP, where it helps in enhancing the sequence coverage and increase the number of identified peptides; this was demonstrated by conducting experiments on complex sample, such as crude yeast cell lysate digested using LysC. ${ }^{259}$ Furthermore, BioTools of Bruker Daltonics has been useful to process and analyze data acquired on middle-down-sized peptides from human serum samples, which involved ESI-CID and ETD MS/ MS, carried out using FT-ICR-MS. ${ }^{260}$ With regard to the application of MALDI-MS for MDP, a few studies have reported the utility of MALDI-in source decay (ISD) method to analyze middle-down sized peptides obtained from biosimilar monoclonal antibodies (mAbs) and in those studies, BioTools was used to process and analyze the data. ${ }^{\mathbf{1 0 4 , 1 0 5}}$ Various kinds of software applied for BU, TD and MD approaches for analysis of proteins and proteome, have been summarized in the form of a Venn diagram in Scheme 5.

It should to be realized that the deconvolution or decharging and deisotoping are not required for the analysis of ESI-MS/MS spectra acquired in BU proteomic studies. This is because quite often, the charge state $\left([\mathrm{M}+n \mathrm{H}]^{n+}\right)$ of the proteolytic peptide precursor ions encountered in BU approach, does not exceed 3 or 4 , i.e., 1 or $2 \leq n \leq 3$ or 4 . In fact, majority of the ESI-MS/MS spectral data in $\mathrm{BU}$ proteomic studies are from $[\mathrm{M}+2 \mathrm{H}]^{2+}$ (doubly protonated) or $[\mathrm{M}+3 \mathrm{H}]^{3+}$ (triply protonated) of the proteolytic (typically tryptic) peptide precursors. ${ }^{203}$ Consequently, in majority of the cases, singly charged fragment ions are observed and rarely doubly and triply charged fragment ions are detected in BU studies. Moreover, there is no need for deconvolution for the analysis of MALDI-MS/MS data, be it BU or MD approach (MALDI-ISD studies in the case of MD approach), since MALDI-MS/MS experiments are always/mostly carried out on singly charged precursors only. 


\section{Applications of MD approach}

Since, MD approach is relatively a new strategy, which was introduced about 5-10 years ago from now, thus far, there have not been many studies reporting about its application. A major motivation to put forth the concept of MD approach came from the investigations conducted on histones and consequently, MD strategy has been successfully applied predominantly on histones related studies, particularly for identification of PTMs on histones (see Table 4). This is because, PTMs on histones strongly influence epigenetic regulation of gene expression. ${ }^{\mathbf{2 6 1}, \mathbf{2 6 2}}$ Further, posttranslationally modified histones alter the structure of chromatin of eukaryotes, thereby modulate the chromatins' activities, such as gene transcription, DNA repair and DNA replication. ${ }^{263}$ Hence, studying variants of histones and their PTMs could be useful to understand the dynamics of variations occurring on chromatin; which in turn can be helpful to comprehend the causal factors of diseases. ${ }^{264,265}$ In this connection, MD strategy has been shown to be useful for better identification of novel isoforms of histones and their PTMs. ${ }^{73,76-79,83}$

\subsection{PTMs on histones}

With regard to identifying PTMs on histones, both MD and TD approaches have been followed, though there are relatively more studies reported on the application of MD workflow, in comparison to TD approach. For example, studies carried out on Caenorhabditis elegans have revealed different levels of methylated lysine (me-Lys), methylated arginine (me-Arg) and acetylated lysine (ac-Lys) in histone H3, whose relative abundances have been quantified at various developmental stages of this worm, through MD proteomic approach. ${ }^{78,173} \mathrm{~N}$-terminal proteolytic processing of histones has an important role in nucleosome dynamics, and such proteolytic clippings have been noted in a study, wherein differences in PTM patterns (acLys, me-Lys and me-Arg) were detected between intact and Nterminal tail clipped $\mathrm{H} 2 \mathrm{~B}$ and $\mathrm{H} 3$ histones in human hepatocytes by following $\mathrm{MD}$ in conjunction with TD approach. ${ }^{82}$ Additionally, MD approach also has been fruitful to successfully identify even 'phosphorylation' of histones (viz., H4) in HeLa S3 cells, whereby the phosphorylation status of serine was monitored along with the other PTMs, such as ac-Lys, me-Lys and me-Arg, at different stages of cell cycle. ${ }^{83}$ Additionally, in a very recently published study, phosphorylation of histones (H4) have been identified even in breast cancer cells (MDA-MB-231 and MCF-10A) at different cell cycle stages. ${ }^{266}$ Furthermore, tissuespecific variations in PTMs of histones $\mathrm{H} 3$ in a rat model was reported by Garcia et al., for which tissues from kidney, spleen, brain, bladder, lung, liver, heart, ovary, testes and pancreas were analyzed by MD proteomic approach. ${ }^{73}$ PTMs on histones have also been investigated and quantitated in mouse embryonic stem cells by MD based workflow, which involved the use of protease GluC and WCX-HILIC chromatography coupled online to ETD MS/MS. ${ }^{\mathbf{7 6 , 1 8 4}}$ Very recently, Schräder et al. have reported MD strategy by using neprosin, a novel propylendoprotease for getting the middle-range sized peptides to characterize the $\mathrm{H} 3$ and $\mathrm{H} 4$ histones of HeLa S3 cells. ${ }^{\mathbf{2 6 7}}$ It needs to be noted that BU approach may not be suitable to study histones, especially their PTMs. ${ }^{77,268}$ This is because N-terminal tails of histones are rich in lysine and arginine residues and therefore, very short length peptides would be produced upon carrying out trypsin digestion. Such short length peptides are not useful to identify the primary structures of the histones due to the ambiguities posed by the presence of paralogs and variants of histones. Also, these short length peptides are not suitable for identification of PTMs, in particular of co-occurring combinatorial PTMs.

\subsection{Therapeutic antibodies}

In addition to its comprehensive application for the study on histones, MD approach has been proven to be successful for characterization of therapeutic antibodies too, particularly, during the last few years (see Table 4). For example, MD based mass spectrometric approach was shown to be useful to evaluate the quality of two anti-CD20 monoclonal antibody (mAb) drug products, whose structural analyses were carried out by using IdeS enzyme and LC-ESI-MS. ${ }^{102}$ In an investigation performed on a single immunoglobulin (IgG) and mixture of IgGs, Tsybin and co-workers demonstrated that extended BU approach by employing Sap9 protease was helpful to obtain up to $99 \%$ and $100 \%$ sequence coverage of heavy chain (Hc) and light chain (Lc) of the respective IgG. ${ }^{71}$ However, in another study the same group applied MD strategy by using IdeS enzyme on a sample containing mixture of commercial IgGs, and showed that this workflow yielded better sequence coverage than the TD approach. ${ }^{70}$

It may be interesting to note that MD based approach has been applied along with hydrogen/deuterium exchange (HDX) for the structural characterization of a recombinant therapeutic antibody Herceptin (restricted pepsin digestion in conjunction with online ETD MS/MS) to probe the alterations to the threedimensional structure of the antibody that could happen due to deglycosylation. ${ }^{68}$ In fact, this is the first study reporting about the applicability of MD approach together with HDX method on the antibody, which may be extended for structural characterization of other therapeutic antibodies and other proteins as well.

In addition to MD approach, in recent times, 'middle-up' approach is gaining importance, particularly for characterization of therapeutic antibodies. Unlike MD strategy, middle-up approach does not involve the application of MS/MS at all. Nevertheless, similar to MD strategy, in middle-up approach also, limited proteolysis is carried out. Therefore, in the case of middle-up investigations on therapeutic antibodies, the IdeS enzyme is often employed and the resulting three large polypeptide fragments from the immunoglobulins are analyzed in their intact form by high-resolution MS. For instance, Sokolowska et al. adopted middle-up strategy to analyze the subunits of certain therapeutic antibodies, which were digested by IdeS enzyme and the resulting polypeptide fragments were characterized by Q-TOF mass spectrometer (Waters Xevo). ${ }^{269}$ Bruker maxis Q-TOF instrument was used for middle-up 
characterization of a therapeutic antibody, Cetuximab. ${ }^{270}$ In another study, middle-up approach in combination with BU approach was applied to characterize antibody drug conjugate (Brentuximab vedotin) by utilizing Triple TOF mass spectrometer (Sciex). ${ }^{271}$

In addition to a wealth of studies carried out by ESI-MS/MS based MD approach, there have been efforts to apply MALDI as well for characterization of certain important commercial antibodies, which were analyzed by MD approach involving 'InSource decay (ISD)' (Bruker); see Table $4 .^{\mathbf{1 0 4 , 1 0 5 , 1 3 3}}$

\subsection{Other applications of MD approach}

Other studies involving MD approach are characterization of ubiquitin, ${ }^{65-67}$ ribosomal proteins, ${ }^{88}$ mustard $2 \mathrm{~s}$ albumin, ${ }^{\mathbf{1 3 8}}$ leukocytes, ${ }^{163}$ nuclear proteins, ${ }^{172}$ serum peptides, ${ }^{260}$ and recombinant proteins; ${ }^{84}$ all these examples are included in Table 4. Among other biological effects of ubiquitin, a popularly known role is ubiquitin-mediated degradation of proteins in impacting the cell cycle events. ${ }^{272,273}$ Perturbation to such proteolytic process may lead to adverse effects such as uncontrolled proliferation, genomic instability and even cancer. ${ }^{272}$ Ubiquitin can covalently bind to the target protein in several modes, which involves modification of more than one site (i.e., $\varepsilon$-amino group of lysine) of the target proteins giving rise of different chain lengths, various kinds of linkages and configuration, for example, linear and branched.$^{67}$ Consequently, it has become important to investigate different chain linkages and topological configurations of ubiquitin modified proteins, for which MD proteomic strategy has been shown to be quite successful. ${ }^{65,67,274}$ Furthermore, the utility of MD approach along with intact protein MS to analyze microheterogeneity due to PTM features (e.g., glycosylation) in recombinant human erythropoietin and human plasma properdin was shown. ${ }^{\mathbf{8 5}}$ Additionally, MD approach also has been successfully applied for identification of many proteins, (i.e., typical proteomic analysis), e.g., several nuclear proteins from HeLa-S3 cells were identified by following LysC digestion ${ }^{\mathbf{1 7 2}}$ and in another study, acid-hydrolysis in combination with microwave treatment was performed on ribosomal proteins in human MCF7 cancer cells. $^{\mathbf{8 8}}$

\subsection{Combination of MD and TD approaches}

Furthermore, MD approach has been applied in tandem with TD strategy, which involves MS/MS experiments done on intact proteins as well as middle-down sized proteolytic peptides. ${ }^{275}$ For example, the extent of micro-heterogeneity in glycosylated proteins, which include biopharmaceutical products, e.g., monoclonal antibodies, recombinant erythropoietin, etc. was investigated by combining MD with TD approach. ${ }^{85,99,100,103,276}$ Similarly, by integrating MD and TD methods, it was possible to obtain full sequence coverage of a $142 \mathrm{kDa}$ cardiac myosin binding protein C (cMyBP-C), where MD was helpful to acquire details of the middle part of the sequence. ${ }^{84}$ Moreover, considerable number of investigations on histones by adopting both MD and TD workflows has been reported. ${ }^{63,81,82,268,277}$ Studies conducted on human leukocytes, mustard $2 \mathrm{~S}$ albumin allergen and monoclonal antibody $\mathrm{Fc} / 2$ are other examples, in which both MD and TD approaches have been adopted. ${ }^{\mathbf{1 3 3 , 1 3 8 , 1 6 3}}$ In the case of studies on mustard albumin allergen, combination of MD with TD workflow aided in identification of some isoforms of Sin a 1, which included a few novel isoforms too. ${ }^{138}$ In a very recently published study, Tsybin and co-workers have reported about multiplexed TD/MD MS workflow, which combines both TD and MD approaches, particularly for characterization of monoclonal antibodies. ${ }^{278}$

\section{Summary \& conclusion}

It is thus apparent from the previous sections that majority of MD based investigations have been performed on histones, a key reason being that the intact histone $\mathrm{N}$-terminal tail $(\sim 50-$ 60 a.a. residues) has most PTMs. ${ }^{80} \mathrm{MD}$ approach has also been shown to be very beneficial for the characterization of biopharmaceutically relevant antibodies and therapeutic proteins, since identifying PTMs is very important in these

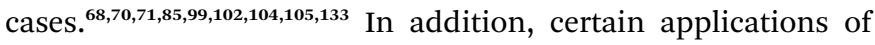
MD approach to determine the topological configuration of ubiquitylated proteins have been reported. ${ }^{65-67}$ Thus, it seems that excepting the studies conducted on histones, biopharmaceutical products and ubiquitinated proteins, MD approach has not been completely explored or not appropriately applied for research in other domains or fields yet, despite the availability of the knowhow and the necessary technological facilities to implement the MD workflow, in the current era. For instance, MD strategy can be useful for 'elucidation of the primary structure' of novel proteins or newly discovered enzymes that are of significance in translational research and/ or of relevance to biotechnological research or industries. In other words, MD approach can be promising for the purpose of 'de novo protein sequencing', which can be pursued either on fully purified or even on partially purified chromatographic samples.

Further, MD approach can be performed without the need for FTMS, meaning, MD approach based experiments can be done using Q-TOF (e.g. Sciex or Bruker or Waters or Agilent) or ion trap-TOF (e.g. Shimadzu), wherein the requirement for high resolution can be satisfactorily achieved with the help of TOF mass analyzer. Additionally, MD strategy can be extended for high-throughput work, viz., MD proteomics. Because of the development of new proteases such as OmpT, Sap9 and the already known enzymes, e.g., AspN and GluC, it is indeed feasible to carry out MD proteomics for microbial or plant investigations and this can be achieved in a manner similar to the workflow of BU approach, whereby MD proteomics may yield better results than BU proteomics. However, it is somewhat surprising to note that only a few studies report about applying MD approach for proteomics..$^{\mathbf{8 8} 89,172}$

Another domain, where MD strategy can be efficacious is 'proteogenomics', which is also emerging. ${ }^{279}$ The results obtained by MD approach can be integrated with the transcriptome and genomic data, not only to identify unannotated missing proteins and/or to confirm annotated coding regions in 


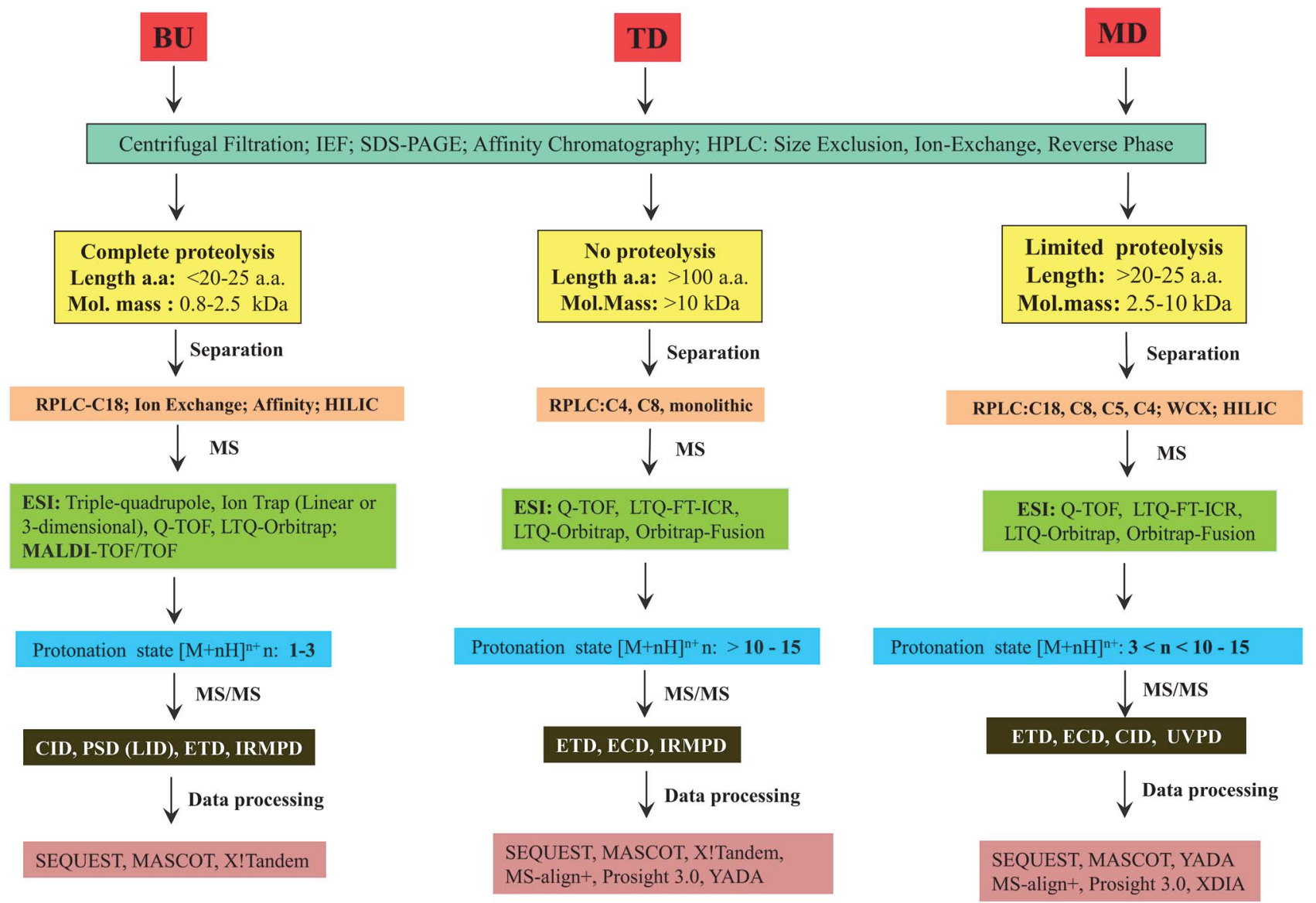

Scheme 6 Flow chart depicting various details and methods followed for each of the three approaches shown in Scheme 2, for analysis of proteins or proteomes.

the genome, but also to correct either the erroneously annotated gene sequences or to correct the proteome sequence databases. ${ }^{280-282}$ In this connection, there is a huge scope for MD proteomic approach to contribute immensely for the development of this upcoming field, since investigations thus far involving proteogenomics have mostly followed the BU proteomic approach only. ${ }^{281,283,284}$

Additionally, it needs to be noted that there has been no accurate definition for MD approach, which could clearly demarcate the boundary between BU and MD approaches. For instance, Tsybin and co-workers defined or proposed another approach called 'Extended Bottom-Up', which may be regarded as an offshoot of MD approach. ${ }^{72,96}$ According to their definition, studies on proteolytic peptides of molecular masses in the range 3-7 kDa would be considered as 'Extended Bottom-Up approach', whereas investigations on $7-12 \mathrm{kDa}$ proteolytic peptides were categorized under 'MD approach'. ${ }^{72}$ In this regard, Tsybin's research group applied a novel protease, Sap9 (secreted aspartic protease 9) to evaluate its utility for 'extended BUP ${ }^{96}$ and they have also demonstrated the usefulness of this approach to characterize monoclonal antibodies by utilizing Sap9. ${ }^{71}$ But, according to our view, if a particular study on proteins is carried out with the help of 'a protease', whose usage results in the formation of (longer) proteolytic peptides of molecular masses $>2.5 \mathrm{kDa}$ or $>3 \mathrm{kDa}$, then such an investigation can be called as a 'middle-down' based study of proteins or proteome. In other words, those studies that follow restricted or limited proteolysis using any protease that specifically produces peptides of molecular masses $>2.5 \mathrm{kDa}$ or $>3 \mathrm{kDa}$ can be regarded as an investigation adopting MD approach, e.g., Forbes et al. and Jung et al., have indeed adopted MD approach in their respective studies (as per our definition proposed herein), though they have not explicitly claimed or mentioned specifically about the approach. ${ }^{87,184}$

Overall, from our (re)view on the published studies reporting the utility of MD strategy that we have presented herein, it is clear that MD approach indeed has an immense potential in future to successfully implement the objectives in both low- as well as high-throughput works, i.e., for 'sequencing' purified protein(s) (one-by-one) as well as for 'proteomics'. Indeed, 100\% sequence coverage by MD approach is achievable, when it is applied on a highly purified and homogeneous protein sample, which can be (realistically) obtained by adept application of suitable chromatographic methods. And therefore, in the present scenario, MD based mass spectrometry does not seem to be surreal, though for proteomic scale, it may now be cumbersome. ${ }^{284}$ Perhaps, the current trend could undergo transformation in future paving way for brighter prospects for 
MD proteomics. Altogether, MD approach could be a better choice for identification and characterization of the protein or proteome, where it could serve to 'bridge the gaps ${ }^{\mathbf{2 8 5}}$ observed in BU and TD studies and hence, it can become indispensable for fulfilling the objectives in various biological, biomedical, biochemical and biotechnological domains of research. The flow chart depicting various details and methods followed at different stages corresponding to each of the three approaches (BU, MD and TD) are illustrated in scheme 6.

Before concluding, we wish to highlight salient features of two published reports that describe the efforts put forward for de novo sequencing. For de novo sequencing of a 72-residue polypeptide, both BU and TD approaches had to be executed involving application of MALDI-FT-ICR, nano-LC-ESI-Q-TOF and nano-ESI-FT-ICR, through which various types of MS/MS experiments, e.g., CID, ECD and IRMPD were conducted. ${ }^{286}$ This example shows that multiple sophisticated mass spectrometric techniques were sought after to elucidate the sequence of a polypeptide of molecular mass less than $10 \mathrm{kDa}$. In another study, sequence of a protein of molecular mass greater than 10 $\mathrm{kDa}$ (i.e., $13.6 \mathrm{kDa}$ ) deduced de novo by TD MALDI-ISD, was confirmed by BU approach by use of LC-ESI-MS/MS. ${ }^{287}$ These two examples indicate that a single approach cannot be fullproof and may not answer the problem completely. Depending on the question that is being addressed, it may be imperative to integrate two or more methods for designing a strategy. But, in doing so, the pros and cons of those methods and the designed strategy also must be borne in mind. Accordingly, the results need to be interpreted. Based on the nature of the results obtained by implementing a particular strategy, it may be essential to redesign the strategy and the efficacy of the newly redesigned strategy may have to be evaluated. On a final note, the choice of approach or strategy must be based on the case or the problem or the question that is undertaken for investigation. $^{288}$

\section{Conflicts of interest}

There are no conflicts to declare.

\section{Acknowledgements}

P. Boomathi Pandeswari thanks Council of Scientific and Industrial Research (CSIR), Govt. of India, for Senior Research Fellowship. V. Sabareesh wishes to acknowledge the completed Project No. SB/YS/LS-370/2013, 'Start-Up Research Grant (Young Scientists)', which was funded by Science and Engineering Research Board (SERB), Govt. of India.

\section{References}

1 P. Edman, Arch. Biochem. Biophys., 1949, 22, 475-480.

2 P. Edman and G. Begg, Eur. J. Biochem., 1967, 1, 80-91.

3 R. J. Simpson, Proteins and Proteomics. A Laboratory Manual, Cold Spring Harbor Laboratory Press, Cold Spring Harbor, New York, 2003, I.K. International Pvt. Ltd., New Delhi, India.
4 K. D. Speicher, N. C. Gorman and D. W. Speicher, Curr. Protoc. Protein Sci., 2009, 57, 11.10.1-11.10.31.

5 Y. Nishiyama, T. Fukamizo, K. Yoneda and T. Araki, Protein J., 2017, 36(2), 98-107.

6 A. Goffeau, B. G. Barrell, H. Bussey, R. W. Davis, B. Dujon, H. Feldmann, F. Galibert, J. D. Hoheisel, C. Jacq, M. Johnston, et al., Science, 1996, 274(5287), 563-567.

7 F. R. Blattner, G. Plunkett III, C. A. Bloch, N. T. Perna, V. Burland, M. Riley, J. Collado-Vides, J. D. Glasner, C. K. Rode, G. F. Mayhew, J. Gregor, N. W. Davis, H. A. Kirkpatrick, M. A. Goeden, D. J. Rose, B. Mau and Y. Shao, Science, 1997, 277, 1453-1462.

8 S. T. Cole, R. Brosch, J. Parkhill, T. Garnier, C. Churcher, D. Harris, S. V. Gordon, K. Eiglmeier, S. Gas, C. E. Barry 3rd, et al., Nature, 1998, 393(6685), 537-544.

9 E. S. Lander, L. M. Linton, B. Birren, C. Nusbaum, M. C. Zody, J. Baldwin, K. Devon, K. Dewar, M. Doyle, W. FitzHugh, et al., Nature, 2001, 409(6822), 860-921.

10 J. C. Venter, M. D. Adams, E. W. Myers, P. W. Li, R. J. Mural, G. G. Sutton, H. O. Smith, M. Yandell, C. A. Evans, R. A. Holt, et al., Science, 2001, 291(5507), 1304-1351.

11 M. S. Kim, S. M. Pinto, D. Getnet, R. S. Nirujogi, S. S. Manda, R. Chaerkady, A. K. Madugundu, D. S. Kelkar, R. Isserlin, S. Jain, et al., Nature, 2014, 509, 575-581.

12 G. S. Omenn, L. Lane, E. K. Lundberg, R. C. Beavis, C. M. Overall and E. W. Deutsch, J. Proteome Res., 2016, 15(11), 3951-3960.

13 T. Maier, M. Güell and L. Serrano, FEBS Lett., 2009, 583, 3966-3973.

14 S. Haider and R. Pal, Curr. Genomics, 2013, 14, 91-110.

15 Y. Bai, S. Wang, H. Zhong, Q. Yang, F. Zhang, Z. Zhuang, J. Yuan, X. Nie and S. Wang, Sci. Rep., 2015, 5, 14582, DOI: $10.1038 /$ srep14582.

16 H. D. Li, R. Menon, G. S. Omenn and Y. Guan, Trends Genet., 2014, 30, 340-347.

17 C. L. Barrett, C. DeBoever, K. Jepsen, C. C. Saenz, D. A. Carson and K. A. Frazer, Proc. Natl. Acad. Sci. U. S. A., 2015, E3050-E3057.

18 C. T. Walsh, S. Garneau-Tsodikova and G. J. Gatto Jr., Angew. Chem., Int. Ed., 2005, 44(45), 7342-7372.

19 T. Bartke, J. Borgel and P. A. DiMaggio, Briefings Funct. Genomics, 2013, 12, 205-218.

20 C. Choudhary, B. T. Weinert, Y. Nishida, E. Verdin and M. Mann, Nat. Rev. Mol. Cell Biol., 2014, 15(8), 536-550.

21 S. Doll and A. L. Burlingame, ACS Chem. Biol., 2015, 10(1), 63-71.

22 R. Aebersold and M. Mann, Nature, 2016, 537, 347-355.

23 J. E. Van Eyk, F. J. Corrales, R. Aebersold, F. Cerciello, E. W. Deutsch, P. Roncada, J.-C. Sanchez, T. Yamamoto, P. Yang, H. Zhang and G. S. Omenn, J. Proteome Res., 2016, 15(11), 3979-3987.

24 K. Tanaka, Angew. Chem., Int. Ed., 2003, 42, 3861-3870.

25 J. B. Fenn, Angew. Chem., Int. Ed., 2003, 42, 3871-3894.

26 M. Barber, R. S. Bordoli, R. D. Sedgwick and A. N. Tyler, J. Chem. Soc., Chem. Commun., 1981a, 325-327.

27 M. Barber, R. S. Bordoli, R. D. Sedgwick and A. N. Tyler, Nature, 1981b, 293, 270-275. 
28 J. W. Crabb, L. G. Armes, S. A. Carr, C. M. Johnson, G. D. Roberts, R. S. Bordoli and W. L. McKeehan, Biochemistry, 1986, 25, 4988-4993.

29 R. S. Johnson and K. Biemann, Biochemistry, 1987, 26, 12091214.

30 M. Kinter and N. E. Sherman, Protein sequencing and identification using tandem mass spectrometry, John Wiley \& Sons, New York, 2000.

31 L. Sleno and D. A. Volmer, J. Mass Spectrom., 2004, 39, 10911112.

32 J. S. Brodbelt, Anal. Chem., 2016, 88, 30-51.

33 R. A. Zubarev, N. L. Kelleher and F. W. McLafferty, J. Am. Chem. Soc., 1998, 120, 3265-3266.

34 R. A. Zubarev, D. M. Horn, E. K. Fridriksson, N. L. Kelleher, N. A. Kruger, M. A. Lewis, B. K. Carpenter and F. W. McLafferty, Anal. Chem., 2000, 72, 563-573.

35 J. E. P. Syka, J. J. Coon, M. J. Schroeder, J. Shabanowitz and D. F. Hunt, Proc. Natl. Acad. Sci. U. S. A., 2004, 101, 95289533.

36 M. C. Crowe and J. S. Brodbelt, J. Am. Soc. Mass Spectrom., 2004, 15, 1581-1592.

37 R. Bakhtiar and Z. Guan, Biotechnol. Lett., 2006, 28, 10471059.

38 J. A. Madsen and J. S. Brodbelt, J. Am. Soc. Mass Spectrom., 2009, 20, 349-358.

39 M. S. Kim and A. Pandey, Proteomics, 2012, 12, 530-542.

40 Q. Hu, R. J. Noll, H. Li, A. Makarov, M. Hardman and R. G. Cooks, J. Mass Spectrom., 2005, 40, 430-443.

41 R. A. Zubarev and A. Makarov, Anal. Chem., 2013, 85, 52885296.

42 S. Eliuk and A. Makarov, Annu. Rev. Anal. Chem., 2015, 8, 6180.

43 P. G. Righetti, A. Castagna, P. Antonioli and E. Boschetti, Electrophoresis, 2005, 26, 297-319.

44 S. L. Wu, A. F. R. Huhmer, Z. Hao and B. L. Karger, J. Proteome Res., 2007, 6, 4230-4244.

45 M. P. Washburn, D. Wolters and J. R. Yates III, Nat. Biotechnol., 2001, 19(3), 242-247.

46 J. Peng and S. P. Gygi, J. Mass Spectrom., 2001, 36, 10831091.

47 J. R. Yates, C. I. Ruse and A. Nakorchevsky, Annu. Rev. Biomed. Eng., 2009, 11, 49-79.

48 X. Zhang, A. Fang, C. P. Riley, M. Wang, F. E. Regnier and C. Buck, Anal. Chim. Acta, 2010, 664(2), 101-113.

49 R. Aebersold and M. Mann, Nature, 2003, 422, 198-207.

50 E. Vandermarliere, M. Mueller and L. Martens, Mass Spectrom. Rev., 2013, 32(6), 453-465.

51 L. C. Gillet, A. Leitner and R. Aebersold, Annu. Rev. Anal. Chem., 2016, 9, 449-472.

52 F. Xie, R. D. Smith and Y. Shen, J. Chromatogr. A, 2012, 1261, 78-90.

53 N. Siuti and N. L. Kelleher, Nat. Methods, 2007, 4, 817-821. 54 B. A. Garcia, J. Am. Soc. Mass Spectrom., 2010, 21, 193-202.

55 H. Zhou, Z. Ning, A. E. Starr, M. Abu-Farha and D. Figeys, Anal. Chem., 2012, 84, 720-734.
56 Y. Ge, B. G. Lawhorn, M. ElNaggar, E. Strauss, J. H. Park, T. P. Begley and F. W. McLafferty, J. Am. Chem. Soc., 2002, 124(4), 672-678.

57 S. M. Patrie, J. P. Charlebois, D. Whipple, N. L. Kelleher, C. L. Hendrickson, J. P. Quinn, A. G. Marshall and B. Mukhopadhyay, J. Am. Soc. Mass Spectrom., 2004, 15, 1099-1108.

58 B. A. Parks, L. Jiang, P. M. Thomas, C. D. Wenger, M. J. Roth, M. T. Boyne II, P. V. Burke, K. E. Kwast and N. L. Kelleher, Anal. Chem., 2007, 79(21), 7984-7991.

59 H. Zhang, W. Cui, J. Wen, R. E. Blankenship and M. L. Gross, J. Am. Soc. Mass Spectrom., 2010, 21(12), 1966-1968.

60 W. Cui, H. W. Rohrs and M. L. Gross, Analyst, 2011, 136, 3854-3864.

61 A. D. Catherman, O. S. Skinner and N. L. Kelleher, Biochem. Biophys. Res. Commun., 2014, 445(4), 683-693.

62 T. K. Toby, L. Fornelli and N. L. Kelleher, Annu. Rev. Anal. Chem., 2016, 9(1), 499-519.

63 B. A. Garcia, N. Siuti, C. E. Thomas, C. A. Mizzen and N. L. Kelleher, Int. J. Mass Spectrom., 2007, 259, 184-196.

64 A. Cristobal, F. Marino, H. Post, H. W. P. van den Toorn, S. Mohammed and A. J. R. Heck, Anal. Chem., 2017, 89, 3318-3325.

65 P. Xu and J. Peng, Anal. Chem., 2008, 80, 3438-3444.

66 E. M. Valkevich, N. A. Sanchez, Y. Ge and E. R. Strieter, Biochemistry, 2014, 53, 4979-4989.

67 S. O. Crowe, A. S. J. B. Rana, K. K. Deol, Y. Ge and E. R. Strieter, Anal. Chem., 2017, 89, 4428-4434.

68 J. Pan, S. Zhang, A. Chou and C. H. Borchers, Chem. Sci., 2016, 7, 1480-1486.

69 Y. J. Tan, W. H. Wang, Y. Zheng, J. Dong, G. Stefano, F. Brandizzi, R. M. Gatavito, G. E. Reid and M. L. Brueining, Anal. Chem., 2012, 84(19), 8357-8363.

70 L. Fornelli, D. Ayoub, K. Aizikov, A. Beck and Y. O. Tsybin, Anal. Chem., 2014, 86, 3005-3012.

71 K. Srzentic, L. Fornelli, U. A. Laskay, M. Monod, A. Beck, D. Ayoub and Y. O. Tsybin, Anal. Chem., 2014, 86, 99459953.

72 U. A. Laskay, A. A. Lobas, K. Srzentic, M. V. Gorhkov and Y. O. Tsybin, J. Proteome Res., 2013, 12, 5558-5569.

73 B. A. Garcia, C. E. Thomas, N. L. Kelleher and C. A. Mizzen, J. Proteome Res., 2008, 7(10), 4225-4236.

74 P. Voigt, G. LeRoy, W. J. Drury III, B. M. Zee, J. Son, D. Beck, N. L. Young, B. A. Garcia and D. Reinberg, Cell, 2012, 151(1), 181-193.

75 A. Kalli, M. J. Sweredoski and S. Hess, Anal. Chem., 2013, 85, 3501-3507.

76 S. Sidoli, V. Schwammle, C. Ruminowicz, T. A. Hansen, X. Wu, K. Helin and O. N. Jensen, Proteomics, 2014, 14, 2200-2211.

77 S. Sidoli, S. Lin, K. R. Karch and B. A. Garcia, Anal. Chem., 2015, 87, 3129-3133.

78 S. Sidoli, J. Vandamme, A. E. Salcini and O. N. Jensen, Proteomics, 2016, 16(3), 459-464. 
79 S. Sidoli, C. Lu, M. Coradin, X. Wang, K. R. Karch, C. Ruminowicz and B. A. Garcia, Epigenet. Chromatin, 2017, 10, 34.

80 S. Sidoli and B. A. Garcia, Expert Rev. Proteomics, 2017, 14(7), 617-626.

81 R. C. Molden and B. A. Garcia, Curr. Protoc. Protein Sci., 2014, 77, 1-28.

82 A. Tvardovskiy, K. Wrzesinski, S. Sidoli, S. J. Fey, A. Rogowska-Wrzesinska and O. N. Jensen, Mol. Cell. Proteomics, 2015, 14, 3142-3153.

83 K. Yamamoto, Y. Chikaoka, G. Hayashi, R. Sakamoto, R. Yamamoto, A. Sugiyam, T. Kodama, A. Okamoto and T. Kawamura, Mass Spectrom., 2015, 4(1), A0039.

84 Y. Ge, I. N. Rybakova, Q. Xu and R. L. Moss, Proc. Natl. Acad. Sci. U. S. A., 2009, 106(31), 12658-12663.

85 Y. Yang, F. Liu, V. Franc, L. A. Halim, H. Schellekens and A. J. R. Heck, Nat. Commun., 2016, 7, 13397.

86 K. Khatri, Y. Pu, J. A. Klein, J. Wei, C. E. Costello, C. Lin and J. Zaia, J. Am. Soc. Mass Spectrom., 2018, 29(6), 1075-1085.

87 A. J. Forbes, M. T. Mazur, H. M. Patel, C. T. Wals and N. L. Kelleher, Proteomics, 2001, 1, 927-933.

88 J. Cannon, K. Lohnes, C. Wyne, Y. Wang, N. Edwards and C. Fenselau, J. Proteome Res., 2010, 9(8), 3886-3890.

89 J. R. Cannon, N. J. Edwards and C. Fenselau, J. Mass Spectrom., 2013, 48(3), 340-343.

90 K. Srzentic, K. O. Zhurov, A. A. Lobas, G. Nikitin, L. Fornelli, M. V. Gorshkov and Y. O. Tsybin, J. Proteome Res., 2018, 17(6), 2005-2016.

91 M. J. Sweredoski, A. Moradian, M. Raedle, C. Franco and S. Hess, Anal. Chem., 2015, 87, 8360-8366.

92 N. L. Young, P. A. DiMaggio, M. D. Plazas-Mayorca, R. C. Baliban, C. A. Floudas and B. A. Garcia, Mol. Cell. Proteomics, 2009, 8, 2266-2284.

93 S. Trevisiol, D. Ayoub, A. Lesur, L. Ancheva, S. Gallien and B. Domon, Proteomics, 2016, 16(5), 715-728.

94 C. Wu, J. C. Tran, L. Zamdborg, K. R. Durbin, M. Li, D. R. Ahlf, B. P. Early, P. M. Thomas, J. V. Sweedler and N. L. Kelleher, Nat. Methods, 2012, 9(8), 822-824.

95 U. A. Laskay, K. Srzentic, L. Fornelli, O. Upir, A. N. Kozhinov, M. Monod and Y. O. Tsybin, Chimia, 2013, 67, 244-249.

96 U. A. Laskay, K. Srzentic, M. Monod and Y. O. Tsybin, J. Proteomics, 2014, 110, 20-31.

97 M. H. Ryan, D. Petrone, J. F. Nemeth, E. Barnathan, L. Bjorck and R. E. Jordan, Mol. Immunol., 2008, 45, 18371846.

98 K. Okuno, M. Yabuta, K. Kawanishi, K. Ohsuye, T. Ooi and S. Kinoshita, Biosci., Biotechnol., Biochem., 2002, 66, 127134.

99 B. Q. Tran, C. Barton, J. Feng, A. Sandjong, S. H. Yoon, S. Aswasti, T. Liang, M. M. Khan, D. P. A. Kilgour, D. R. Goodlett and Y. A. Goo, Data Brief, 2016, 6, 68-76.

100 L. He, L. C. Anderson, D. R. Barnidge, D. L. Murray, C. L. Hendrickson and A. G. Marshall, J. Am. Soc. Mass Spectrom., 2017, 28(5), 827-838.
101 A. M. Belov, L. Zang, R. Sebastiano, M. R. Santos, D. R. Bush, B. L. Karger and A. R. Ivanov, Electrophoresis, 2018, 39(16), 2069-2082.

102 B. Wang, A. C. Gucinski, D. A. Keire, L. F. Buhse and M. T. Boyne II, Analyst, 2013, 138, 3058-3065.

103 L. Fornelli, K. Srzentić, R. Huguet, C. Mullen, S. Sharma, V. Zabrouskov, R. T. Fellers, K. R. Durbin, P. D. Compton and N. L. Kelleher, Anal. Chem., 2018, 90(14), 8421-8429.

104 D. Ayoub, W. Jabs, A. Resemann, W. Evers, C. Evans, C. Baessmamm, E. Wagner-Rousset, D. Suckau and A. Beck, $m A b s, 2013$, 5(5), 699-710.

105 A. Resemann, W. Jabs, A. Wiechmann, E. Wagner, O. Colas, W. Evers, E. Belau, L. Vorwerg, C. Evans, A. Beck and D. Suckau, $m A b s, 2016,8(2), 318-330$.

106 K. Mizuno, T. Nakamura, T. Ohshima, S. Tanaka and H. Matsuo, Biochem. Biophys. Res. Commun., 1989, 159(1), 305-311.

107 Y. Shi, R. Xiang, C. Horvath and J. A. Wilkins, J. Chromatogr. A, 2004, 1053, 27-36.

108 B. R. Fonslow and J. R. Yates III, J. Sep. Sci., 2009, 32(8), 1175-1188.

109 C. Desiderio, D. V. Rossetti, F. Iavarone, I. Messana and M. Casagnola, J. Pharm. Biomed. Anal., 2010, 53(5), 11611169.

110 G. Lin, C. Gao, Q. Zheng, Z. Lei, H. Geng, Z. Lin, H. Yang and Z. Cai, Chem. Commun., 2017, 53(26), 3649-3652.

111 L. Monteoliva and J. P. Albar, Briefings Funct. Genomics Proteomics, 2004, 3(3), 220-239.

112 G. Baggerman, E. Vierstraete, A. De Loof and L. Schoofs, Comb. Chem. High Throughput Screening, 2005, 8, 669-677.

113 J. P. Lambert, M. Ethier, J. C. Smith and D. Figeys, Anal. Chem., 2005, 77, 3771-3788.

114 M. Unlü, M. E. Morgan and J. S. Minden, Electrophoresis, 1997, 18(11), 2071-2077.

115 G. Zhou, H. Li, D. DeCamp, S. Chen, H. Shu, Y. Gong, M. Flaig, J. W. Gillespie, N. Hu, P. R. Taylor, M. R. Emmert-Buck, L. A. Liotta, E. F. Petricoin III and Y. Zhao, Mol. Cell. Proteomics, 2002, 1, 117-124.

116 R. Westermeier and B. Scheibe, Methods Mol. Biol., 2008, 424, 73-85.

117 J. S. Minden, S. R. Dowd, H. E. Meyer and K. Stühler, Electrophoresis, 2009, (Suppl 1), S156-S161.

118 A. Venkatesan, K. Palaniyandi, D. Sharma, D. Bisht and S. Narayanan, Can. J. Microbiol., 2018, 64(4), 243-251.

119 S. Ananthi, C. N. P. Lakshmi, P. Atmika, K. Anbarasu and S. Mahalingam, Sci. Rep., 2018, 8(1), 1567, DOI: 10.1038/ s41598-018-19937-3.

120 L. Sun, G. Zhu, X. Yan, Z. Zhang, R. Wojcik, M. M. Champion and N. J. Dovichi, Proteomics, 2016, 16, 188-196.

121 J. W. Cooper, Y. Wang and C. S. Lee, Electrophoresis, 2004, 25, 3913-3926.

122 D. C. Simpson and R. D. Smith, Electrophoresis, 2005, 26, 1291-1305.

123 Z. Zhu, J. J. Lu and S. Liu, Anal. Chim. Acta, 2012, 709, 21-31.

124 V. Brocke, G. Nicholson and E. Bayer, Electrophoresis, 2001, 22, 1251-1266. 
125 T. Manabe, Electrophoresis, 1999, 20, 3116-3121.

126 H. Mischak, J. J. Coon, J. Novak, E. M. Weissinger, J. Schanstra and A. F. Dominiczak, Mass Spectrom. Rev., 2009, 28(5), 703-724.

127 Y. Li, M. M. Champion, L. Sun, P. A. Champion, R. Wojcik and N. J. Dovichi, Anal. Chem., 2012, 84(3), 1617-1622.

128 G. Zhu, L. Sun, X. Yan and N. J. Dovichi, Anal. Chem., 2013, 85, 2569-2573.

129 K. Faserl, B. Sarg, L. Kremser and H. Lindner, Anal. Chem., 2011, 83(19), 7297-7305.

130 Y. Li, P. D. Compton, J. C. Tran, I. Ntai and N. L. Kelleher, Proteomics, 2014, 14(10), 1158-1164.

131 R. Wojcik, G. Zhu, Z. Zhang, X. Yan, Y. Zhao, L. Sun, M. M. Champion and N. J. Dovichi, Bioanalysis, 2016, 8(2), 89-92.

132 Y. Zhao, N. M. Riley, L. Sun, A. S. Hebert, X. Yan, M. S. Westphall, M. J. P. Rush, G. Zhu, M. M. Champion, F. M. Medie, P. A. D. Champion, J. J. Coon and N. J. Dovichi, Anal. Chem., 2015, 87, 5422-5429.

133 M. Biacchi, N. Said, A. Beck, E. Leize-Wagner and Y. N. Francois, J. Chromatogr. A, 2017, 1498, 120-127.

134 C. M. Whitehouse, R. N. Dreyer, M. Yamashita and J. B. Fenn, Anal. Chem., 1985, 57(3), 675-679.

135 Y. Shen and R. D. Smith, Electrophoresis, 2002, 23, 31063124.

136 G. Mitulovic and K. Mechtler, Briefings Funct. Genomics Proteomics, 2006, 5(4), 249-260.

137 Y. Y. Zhao and R. C. Lin, Chem.-Biol. Interact., 2014, 215, 716.

138 M. Hummel, T. Wigger and J. Brockmeyer, J. Proteome Res., 2015, 14, 1547-1556.

139 J. D. Sanders, S. M. Greer and J. S. Brodbelt, Anal. Chem., 2017, 89(21), 11772-11778.

140 X. Sun, J. F. Chiu and Q. Y. He, Expert Rev. Proteomics, 2005, 2(5), 649-657.

141 J. Fila and D. Honys, Amino Acids, 2012, 43, 1025-1047.

142 Y. Zhang, B. R. Fonslow, B. Shan, M. C. Baek and J. R. Yates III, Chem. Rev., 2013, 113, 2343-2394.

143 R. R. Prasanna, S. Sidhik, A. S. Kamalanathan, K. Bhagavatula and M. A. Vijayalakshmi, J. Chromatogr. B: Anal. Technol. Biomed. Life Sci., 2014, 955-956, 42-49.

144 K. Karkra, K. K. R. Tetala and M. A. Vijayalakshmi, J. Chromatogr. B: Anal. Technol. Biomed. Life Sci., 2017, 1052, 1-9.

145 X. Wei and L. Li, Briefings Funct. Genomics Proteomics, 2008, 8(2), 104-113.

146 S. Pan, R. Chen, R. Aebersold and T. A. Brentnall, Mol. Cell. Proteomics, 2011, 10, 1-14.

147 J. Nilsson, A. Halim, A. Grahn and G. Larson, Glycoconjugate J., 2013, 30, 119-136.

148 Q. Zhang, N. Tang, J. W. C. Brock, H. M. Mottaz, J. M. Ames, J. W. Baynes, R. D. Smith and T. O. Metz, J. Proteome Res., 2007, 6(6), 2323-2330.

149 C. Zhou, X. Chen, Z. Du, G. Li, X. Xia and Z. Cai, J. Chromatogr. A, 2017, 1498, 90-98.

150 H. J. Issaq, Electrophoresis, 2001, 22, 3629-3638.
151 H. Liu, D. Lin and J. R. Yates III, BioTechniques, 2002, 32, 898-911.

152 Y. Zheng, X. Huang and N. L. Kelleher, Curr. Opin. Chem. Biol., 2016, 33, 142-150.

153 J. A. McLean, B. T. Ruotolo, K. J. Gillig and D. H. Russell, Int. J. Mass Spectrom., 2005, 240, 301-315.

154 D. Helm, J. P. C. Vissers, C. J. Hughes, H. Hahnet, B. Ruprecht, F. Pachl, A. Grzyb, K. Richardson, J. Wildgoose, S. K. Maier, H. Marx, M. Wilhelm, I. Becher, S. Lemeer, M. Bantscheff, J. I. Langridge and B. Kuster, Mol. Cell. Proteomics, 2014, 13(12), 3709-3715.

155 A. A. Shvartsburg, Y. Zheng, R. D. Smith and N. L. Kelleher, Anal. Chem., 2012, 84, 4271-4276.

156 A. Beck, F. Debaene, H. Diemer, E. Wagner-Rousset, O. Colas, A. Van Dorsselaer and S. Cianférani, J. Mass Spectrom., 2015, 50(2), 285-297.

157 A. Garabedian, M. A. Baird, J. Porter, K. Jeanne Dit Fouque, P. V. Shliaha, O. N. Jensen, T. D. Williams, F. FernandezLima and A. A. Shvartsburg, Anal. Chem., 2018, 90(4), 2918-2925.

158 E. de Hoffmann and V. Stroobant, Mass spectrometry Principles and Applications, John Wiley \& Sons Ltd, Chichester, West Sussex, England, 3rd edn, 2007.

159 M. Karas, D. Bachmann and F. Hillenkamp, Anal. Chem., 1985, 57, 2935-2939.

160 M. Karas, D. Bachmann, U. Bahr and F. Hillenkamp, Int. J. Mass Spectrom. Ion Processes, 1987, 78, 53-68.

161 J. Yergey, D. Heller, G. Hansen, R. J. Cotter and C. Fenselau, Anal. Chem., 1983, 55(2), 353-356.

162 W. Paul, Angew. Chem. Int. Ed., 1990, 29, 739-748.

163 M. J. Roth, B. A. Parks, J. T. Ferguson, M. T. Boyne II and N. L. Kelleher, Anal. Chem., 2008, 80, 2857-2866.

164 R. E. March, J. Mass Spectrom., 1997, 32, 351-369.

165 K. R. Jonscher and J. R. Yates III, Anal. Biochem., 1997, 244, 1-15.

166 M. Mohamed-Benkada, M. Montagu, J. F. Biard, F. Mondeguer, P. Verite, M. Dalgalarrondo, J. Bissett and Y. F. Pouchus, Rapid Commun. Mass Spectrom., 2006, 20(8), 1176-1180.

167 V. Sabareesh, Mass spectrometric sequencing of acyclic and cyclic peptides, $\mathrm{PhD}$ thesis, Indian Institute of Science, Bengaluru, Karnataka, India, 2007.

168 J. W. Hager, Rapid Commun. Mass Spectrom., 2002, 16(6), 512-526.

169 J. C. Schwartz, M. W. Senko and J. E. P. Syka, J. Am. Soc. Mass Spectrom., 2002, 13, 659-669.

170 J. W. Hager and J. C. Yves Le Blanc, Rapid Commun. Mass Spectrom., 2003, 17(10), 1056-1064.

171 B. Macek, L. F. Waanders, J. V. Olsen and M. Mann, Mol. Cell. Proteomics, 2006, 5(5), 949-958.

172 M. T. Boyne II, B. A. Garcia, M. Li, L. Zamdborg, C. D. Wenger, S. Babai and N. L. Kelleher, J. Proteome Res., 2009, 8(1), 374-379.

173 J. Vandamme, S. Sidoli, L. Mariani, C. Friis, J. Christensen, K. Helin, O. N. Jensen and A. E. Salcini, Nucleic Acids Res., 2015, 43(20), 9694-9710. 
174 M. B. Comisarow and A. G. Marshall, Chem. Phys. Lett., 1974, 25(2), 282-283.

175 A. G. Marshall, C. L. Hendrickson and G. S. Jackson, Mass Spectrom. Rev., 1998, 17, 1-35.

176 W. Schrader and H. W. Klein, Anal. Bioanal. Chem., 2004, 379, 1013-1024.

177 F. Meng, B. J. Cargile, S. M. Patrie, J. R. Johnson, S. M. McLoughlin and N. L. Kelleher, Anal. Chem., 2002, 74, 2923-2929.

178 V. Zabrouskov, L. Giacomelli, K. J. van Wijk and F. W. McLafferty, Mol. Cell. Proteomics, 2003, 2, 1253-1260.

179 A. Makarov, Anal. Chem., 2000, 72, 1156-1162.

180 R. H. Perry, R. G. Cooks and R. J. Noll, Mass Spectrom. Rev., 2008, 27(6), 661-699.

181 K. J. Webb, T. Xu, S. K. Park and J. R. Yates III, J. Proteome Res., 2013, 12, 2177-2184.

182 F. Meier, P. E. Geyer, S. Virreira Winter, J. Cox and M. Mann, Nat. Methods, 2018, 15(6), 440-448.

183 R. Danda, K. Ganapathy, G. Sathe, A. K. Madugundu, U. M. Krishnan, V. Khetan, P. Rishi, H. Gowda, A. Pandey, K. Subramanian, T. S. K. Prasad and S. V. Elchuri, Proteomics: Clin. Appl., 2018, e1700101, DOI: 10.1002/prca.201700101.

184 H. R. Jung, S. Sidoli, S. Haldbo, R. R. Sprenger, V. Schwämmle, D. Pasini, K. Helin and O. N. Jensen, Anal. Chem., 2013, 85(17), 8232-8239.

185 Y. Jin, L. Wei, W. Cai, Z. Lin, Z. Wu, Y. Peng, T. Kohmoto, R. L. Moss and Y. Ge, Anal. Chem., 2017, 89, 4922-4930.

186 A. Moradian, C. Franco, M. J. Sweredoski and S. Hess, J. Anal. Sci. Technol., 2015, 6, 21.

187 A. W. Jones and H. J. Cooper, Analyst, 2011, 136, 3419-3429.

188 K. Biemann, Methods Enzymol., 1990, 193, 886-887.

189 V. H. Wysocki, G. Tsaprailis, L. L. Smith and L. A. Breci, J. Mass Spectrom., 2000, 35, 1399-1406.

190 B. Paizs and S. Suhai, Mass Spectrom. Rev., 2005, 24, 508548.

191 K. F. Medzirahradszky, Methods Enzymol., 2005, 402, 209244.

192 P. L. Ross, Y. N. Huang, J. N. Marchese, B. Williamson, K. Parker, S. Hattan, N. Khainovski, S. Pillai, S. Dey, S. Daniels, S. Purkayastha, P. Juhasz, S. Martin, M. Bartlet-Jones, F. He, A. Jacobson and D. J. Pappin, Mol. Cell. Proteomics, 2004, 3, 1154-1169.

193 S. Wiese, K. A. Reidegeld, H. E. Meyer and B. Warscheid, Proteomics, 2007, 7(3), 340-350.

194 M. Bantscheff, M. Schirle, G. Sweetman, J. Rick and B. Kuster, Anal. Bioanal. Chem., 2007, 389, 1017-1103.

195 E. Sachon, S. Mohammed, N. Bache and O. N. Jensen, Rapid Commun. Mass Spectrom., 2006, 20(7), 1127-1134.

196 B. McDonagh, P. Martínez-Acedo, J. Vázquez, C. A. Padilla, D. Sheehan and J. A. Bárcena, Int. J. Proteomics, 2012, 2012, 514847, DOI: 10.1155/2012/514847.

197 H. R. Fuller and G. E. Morris, Quantitative proteomics using iTRAQ labeling and mass spectrometry, Integrative Proteomics, ed. H.-C. Leung, InTech, London, United Kingdom, 2012, pp. 347-362.
198 F. W. McLafferty, D. M. Horn, K. Breuker, Y. Ge, M. A. Lewis, B. Cerda, R. A. Zubarev and B. K. Carpenter, J. Am. Soc. Mass Spectrom., 2001, 12, 245-249.

199 A. Pamreddy and N. R. Panyala, J. Appl. Bioanal., 2016, 2(2), 52-75.

200 Y. Xia, P. A. Chrisman, D. E. Erickson, J. Liu, X. Liang, F. A. Londry, M. J. Yang and S. A. McLuckey, Anal. Chem., 2006, 78(12), 4146-4154.

201 G. C. McAlister, D. Phanstiel, D. M. Good, W. T. Berggren and J. J. Coon, Anal. Chem., 2007, 79(10), 3525-3534.

202 R. Hartmer, D. A. Kaplan, C. R. Gebhardt, T. Ledertheil and A. Brekenfeld, Int. J. Mass Spectrom., 2008, 276, 82-90.

203 D. M. Good, M. Wirtala, G. C. McAlister and J. J. Coon, Mol. Cell. Proteomics, 2007, 6(11), 1942-1951.

204 R. J. Chalkley, K. F. Medzihradszky, A. J. Lynn, P. R. Baker and A. L. Burlingame, Anal. Chem., 2010, 82(2), 579-584.

205 H. Molina, R. Matthiesen, K. Kandasamy and A. Pandey, Anal. Chem., 2008, 80, 4825-4835.

206 L. M. Mikesh, B. Ueberheide, A. Chi, J. J. Coon, J. E Syka, J. Shabanowitz and D. F. Hunt, Biochim. Biophys. Acta, 2006, 1764(12), 1811-1822.

207 H. Molina, D. M. Horn, N. Tang, S. Mathivanan and A. Pandey, Proc. Natl. Acad. Sci. U. S. A., 2007, 104(7), 2199-2204.

208 D. L. Swaney, C. D. Wenger, J. A. Thomson and J. J. Coon, Proc. Natl. Acad. Sci. U. S. A., 2009, 106(4), 995-1000.

209 Y. Zhou, J. Dong and R. W. Vachet, Curr. Pharm. Biotechnol., 2011, 12(10), 1558-1567.

210 C. K. Frese, H. Zhou, T. Taus, A. F. Altelaar, K. Mechtler, A. J. Heck and S. Mohammed, J. Proteome Res., 2013, 12(3), 1520-1525.

211 A. Schmidt, D. B. Trentini, S. Spiess, J. Fuhrmann, G. Ammerer, K. Mechtler and T. Clausen, Mol. Cell. Proteomics, 2014, 13, 537-550.

212 E. L. de Graaf, P. Giansanti, A. F. M. Altelaar and A. J. R. Heck, Mol. Cell. Proteomics, 2014, 13, 2426-2434.

213 L. von Stechow, C. Francavilla and J. V. Olsen, Expert Rev. Proteomics, 2015, 12(5), 469-487.

214 I. Perdivara, R. Petrovich, B. Alliquant, L. J. Deterding, K. B. Tomer and M. Przybylski, J. Proteome Res., 2009, 8(2), 631-642.

215 Y. Mechref, Curr. Protoc. Protein Sci., 2012, 12.11.112.11.11.

216 Q. Yu, B. Wang, Z. Chen, G. Urabe, M. S. Glover, X. Shi, L. W. Guo, K. C. Kent and L. Li, J. Am. Soc. Mass Spectrom., 2017, 28(9), 1751-1764.

217 D. L. Swaney, G. C. McAlister, M. Wirtala, J. C. Schwartz, J. E. Syka and J. J. Coon, Anal. Chem., 2007, 79(2), 477-485.

218 V. Sabareesh, P. Sarkar, A. A. Sardesai and D. Chatterji, Analyst, 2010, 135, 2723-2729.

219 K. Gupta, M. Kumar, K. Chandrashekara, K. S. Krishnan and P. Balaram, J. Proteome Res., 2012, 11(2), 515-522.

220 V. A. Mikhailov and H. J. Cooper, J. Am. Soc. Mass Spectrom., 2009, 20(5), 763-771.

221 C. Lin, J. J. Cournoyer and P. B. O'Connor, J. Am. Soc. Mass Spectrom., 2008, 19(6), 780-789. 
222 D. M. Horn, Y. Ge and F. W. McLafferty, Anal. Chem., 2000, 72, 4778-4784.

223 M. M. Savitski, F. Kjeldsen, M. L. Nielsen and R. A. Zubarev, J. Am. Soc. Mass Spectrom., 2007, 18, 113-120.

224 Y. Tsybin, H. He, M. R. Emmett, C. L. Hendrickson and A. G. Marshall, Anal. Chem., 2007, 79(20), 7596-7602.

225 J. S. Brodbelt, Chem. Soc. Rev., 2014, 43(8), 2757-2783.

226 V. C. Cotham, A. P. Horton, J. Lee, G. Georgiou and J. S. Brodbelt, Anal. Chem., 2017, 89, 6498-6504.

227 T. Chen, J. Zhao, J. Ma and Y. Zhu, Genomics, Proteomics Bioinf., 2015, 13, 36-39.

228 K. Verheggen, H. Ræder, F. S. Berven, L. Martens, H. Barsnes and M. Vaudel, Mass Spectrom. Rev., 2017, 115, DOI: $10.1002 /$ mas.21543.

229 V. Nanjappa, J. K. Thomas, A. Marimuthu, B. Muthusamy, A. Radhakrishnan, R. Sharma, A. Ahmad Khan, L. Balakrishnan, N. A. Sahasrabuddhe, S. Kumar, B. N. Jhaveri, K. V. Sheth, R. Kumar Khatana, P. G. Shaw, S. M. Srikanth, P. P. Mathur, S. Shankar, D. Nagaraja, R. Christopher, S. Mathivanan, R. Raju, R. Sirdeshmukh, A. Chatterjee, R. J. Simpson, H. C. Harsha, A. Pandey and T. S. Prasad, Nucleic Acids Res., 2014, 42, D959-D965.

230 B. Muthusamy, G. Hanumanthu, S. Suresh, B. Rekha, D. Srinivas, L. Karthick, B. M. Vrushabendra, S. Sharma, G. Mishra, P. Chatterjee, et al., Proteomics, 2005, 5, 35313536.

231 D. N. Perkins, D. J. Pappin, D. M. Creasy and J. S. Cottrell, Electrophoresis, 1999, 20(18), 3551-3567.

232 J. K. Eng, A. L. McCormack and J. R. Yates III, J. Am. Soc. Mass Spectrom., 1994, 5, 976-989.

233 B. Ma, K. Zhang, C. Hendrie, C. Liang, M. Li, A. DohertyKirby and G. Lajoie, Rapid Commun. Mass Spectrom., 2003, 17(20), 2337-2342.

234 L. Y. Geer, S. P. Markey, J. A. Kowalak, L. Wagner, M. Xu, D. M. Maynard, X. Yang, W. Shi and S. H. Bryant, J. Proteome Res., 2004, 3, 958-964.

235 L. Martens, H. Hermjakob, P. Jones, M. Adamski, C. Taylor, D. States, K. Gevaert, J. Vandekerckhove and R. Apweiler, Proteomics, 2005, 5(13), 3537-3545.

236 R. Craig and R. Beavis, Bioinformatics, 2004, 20, 1466-1467. 237 A. Bertsch, C. Gröpl, K. Reinert and O. Kohlbacher, Methods Mol. Biol., 2011, 696, 353-367.

238 E. W. Deutsch, L. Mendoza, D. Shteynberg, T. Farrah, H. Lam, N. Tasman, Z. Sun, E. Nilsson, B. Pratt, B. Prazen, J. K. Eng, D. B. Martin, A. Nesvizhskii and R. Aebersold, Proteomics, 2010, 10(6), 1150-1159.

239 J. Cox and M. Mann, Nat. Biotechnol., 2008, 26(12), 13671372.

240 S. Tyanova, T. Temu and J. Cox, Nat. Protoc., 2016, 11, 23012319.

241 B. MacLean, D. M. Tomazela, N. Shulman, M. Chambers, G. L. Finney, B. Frewen, R. Kern, D. L. Tabb, D. C. Liebler and M. J. MacCoss, Bioinformatics, 2010, 26(7), 966-968.

242 L. K. Pino, B. C. Searle, J. G. Bollinger, B. Nunn, B. MacLean and M. J. MacCoss, Mass Spectrom. Rev., 2017, DOI: 10.1002/mas.21540.
243 S. K. Park, J. D. Venable, T. Xu and J. R. Yates III, Nat. Methods, 2008, 5(4), 319-322.

244 F. F. Gonzalez-Galarza, C. Lawless, S. J. Hubbard, J. Fan, C. Bessant, H. Hermjakob and A. R. Jones, OMICS, 2012, 16(9), 431-442.

245 R. Craig, J. C. Cortens, D. Fenyo and R. C. Beavis, J. Proteome Res., 2006, 5(8), 1843-1849.

246 B. E. Frewen, G. E. Merrihew, C. C. Wu, W. S. Noble and M. J. MacCoss, Anal. Chem., 2006, 78, 5678-5684.

247 S. Dasari, M. C. Chambers, M. A. Martinez, K. L. Carpenter, A.-J. L. Ham, L. J. Vega-Montoto and D. L. Tabb, J. Proteome Res., 2012, 11(3), 1686-1695.

248 S. Sharma, D. C. Simpson, N. Tolic, N. Jaitly, A. M. Mayampurath, R. D. Smith and L. Pasa-Tolic, J. Proteome Res., 2007, 6, 602-610.

249 D. M. Horn, R. A. Zubarev and F. W. McLafferty, J. Am. Soc. Mass Spectrom., 2000, 11, 320-332.

250 G. K. Taylor, Y.-B. Kim, A. J. Forbes, F. Meng, R. McCarthy and N. L. Kelleher, Anal. Chem., 2003, 75(16), 4081-4086.

251 R. T. Fellers, J. B. Greer, B. P. Early, X. Yu, R. D. LeDuc, N. L. Kelleher and P. M. Thomas, Proteomics, 2015, 15(7), 1235-1238.

252 Q. Kou, L. Xun and X. Liu, Bioinformatics, 2016, 32(22), 3495-3497.

253 W. Cai, H. Guner, Z. R. Gregorich, A. J. Chen, S. Ayaz-Guner, Y. Peng, S. G. Valeja, X. Liu and Y. Ge, Mol. Cell. Proteomics, 2016, 15(2), 703-714.

254 C. Wynne, N. J. Edwards and C. Fenselau, Proteomics, 2010, 10, 3631-3643.

255 K. Scheffler, Methods Mol. Biol., 2014, 1156, 465-487.

256 M. Locard-Paulet, J. Parra, R. Albigot, E. Mouton-Barbosa, L. Bardi, O. Burlet-Schiltz and J. Marcoux, Bioinformatics, 2018, DOI: 10.1093/bioinformatics/bty680.

257 X. Liu, Y. Inbar, P. C. Dorrestein, C. Wynne, N. Edwards, P. Souda, J. P. Whitelegge, V. Bafnat and P. Pevzner, Mol. Cell. Proteomics, 2010, 9, 2772-2782.

258 P. C. Carvalho, T. Xu, X. Han, D. Cociorva, V. C. Barbosa and J. R. Yates III, Bioinformatics, 2009, 25(20), 2734-2736.

259 P. C. Carvalho, X. Han, T. Xu, D. Cociorva, M. da Gloria Carvalho, V. C. Barbosa and J. R. Yates III, Bioinformatics, 2010, 26(6), 847-848.

260 S. Nicolardi, H. Dalebout, M. R. Bladergroen, W. E. Mesker, R. A. E. M. Tollenaar, A. M. Deelder and Y. E. M. van der Burgt, Int. J. Proteomics, 2012, 2012, 804036.

261 E. Bártová, J. Krejčí, A. Harničarová, G. Galiová and S. Kozubek, J. Histochem. Cytochem., 2008, 56(8), 711-721.

262 P. Chi, C. D. Allis and G. G. Wang, Nat. Rev. Cancer, 2010, 10(7), 457-469.

263 E. S. Chrun, F. Modolo and F. I. Daniel, Pathol., Res. Pract., 2017, 213, 1329-1339.

264 A. Portela and M. Esteller, Nat. Biotechnol., 2010, 28(10), 1057-1068.

265 E. L. Greer and Y. Shi, Nat. Rev. Genet., 2012, 13(5), 343-357.

266 T. Jiang, M. E. Hoover, M. V. Holt, M. A. Freitas, A. G. Marshall and N. L. Young, Proteomics, 2018, 18(11), e1700442. 
267 C. U. Schräder, D. S. Ziemianowicz, K. Merx and D. C. Schriemer, Anal. Chem., 2018, 90(5), 3083-3090.

268 A. Moradian, A. Kalli, M. J. Sweredoski and S. Hess, Proteomics, 2014, 14, 489-497.

269 I. Sokolowska, J. Mo, J. Dong, M. J. Lewis and P. Hu, mAbs, 2017, 9(3), 498-505.

270 M. Biacchi, R. Gahoual, N. Said, A. Beck, E. Leize-Wagner and Y.-N. François, Anal. Chem., 2015, 87(12), 6240-6250.

271 N. Said, R. Gahouala, L. Kuhn, A. Beck, Y.-N. Françoisa and E. Leize-Wagner, Anal. Chim. Acta, 2016, 918, 50-59.

272 K. Nakayama and K. Nakayama, Nat. Rev. Cancer, 2006, 6(5), 369-381.

273 D. M. Koepp, Methods Mol. Biol., 2014, 1170, 61-73.

274 J. Peng, BMB Rep., 2008, 41(3), 177-183.

275 C. D. Wenger, M. T. Boyne, J. T. Ferguson, D. E. Robinson and N. L. Kelleher, Anal. Chem., 2008, 80, 8055-8063.

276 Y. Jin, Z. Lin, Q. Xu, C. Fu, Z. Zhang, Q. Zhang, W. A. Pritts and Y. Ge, mAbs, 2018, DOI: 10.1080/ 19420862.2018.1525253.

277 Z. Tian, N. Tolic, R. Zhao, R. J. Moore, S. M. Hengel, E. W. Robinson, D. L. Stenoien, S. Wu, R. D. Smith and L. Pasa-Tolic, Genome Biol., 2012, 13, R86.

278 K. Srzentić, K. O. Nagornov, L. Fornelli, A. A. Lobas, D. Ayoub, A. N. Kozhinov, N. Gasilova, L. Menin, A. Beck, M. V. Gorshkov, K. Aizikov and Y. O. Tsybin, Anal. Chem., 2018, 90(21), 12527-12535.

279 A. Nesvizhskii, Nat. Methods, 2014, 11(11), 1114-1125.
280 D. S. Kelkar, D. Kumar, P. Kumar, L. Balakrishnan, B. Muthusamy, A. K. Yadav, P. Shrivastava, A. Marimuthu, S. Anand, H. Sundaram, R. Kingsbury, H. C. Harsha, B. Nair, T. S. Prasad, D. S. Chauhan, K. Katoch, V. M. Katoch, P. Kumar, R. Chaerkady, S. Ramachandran, D. Dash and A. Pandey, Mol. Cell. Proteomics, 2011, 10(12), M111.011627.

281 S. E. Lee, J. Song, K. Bösl, A. C. Müller, D. Vitko, K. L. Bennett, G. Superti-Furga, A. Pandey, R. K. Kandasamy and M. S. Kim, Proteomics, 2018, 18(8), e1700386.

282 G. M. Sheynkman, M. R. Shortreed, A. J. Cesnik and L. M. Smith, Annu. Rev. Anal. Chem., 2016, 9(1), 521-545.

283 N. E. Castellana, S. H. Payne, Z. Shen, M. Stanke, V. Bafna and S. P. Briggs, Proc. Natl. Acad. Sci. U. S. A., 2008, 105(52), 21034-21038.

284 B. Meyer, D. G. Papasotiriou and M. Karas, Amino Acids, 2011, 41, 291-310.

285 L. He, C. R. Weisbrod and A. G. Marshall, Int. J. Mass Spectrom., 2018, 427, 107-113.

286 M. Ma, R. Chen, Y. Ge, H. He, A. G. Marshall and L. Li, Anal. Chem., 2009, 81(1), 240-247.

287 A. Resemann, D. Wunderlich, U. Rothbauer, B. Warscheid, H. Leonhardt, J. Fuchser, K. Kuhlmann and D. Suckau, Anal. Chem., 2010, 82, 3283-3292.

288 J. J. Thelen and J. A. Miernyk, Biochem. J., 2012, 444(2), 169181. 